\title{
Epigenetics of Bladder Cancer: Where Biomarkers and Therapeutic Targets Meet
}

\author{
Victor G. Martinez 1,2, Ester Munera-Maravilla 1,2,3, Alejandra Bernardini 1,2,3, \\ Carolina Rubio ${ }^{1,2,3}$, Cristian Suarez-Cabrera ${ }^{1,2}$, Cristina Segovia ${ }^{1,2}$, Iris Lodewijk ${ }^{1,2}$, \\ Marta Dueñas 1,2,3, Mónica Martínez-Fernández ${ }^{4}$ and Jesus Maria Paramio 1,2,3*
}

\begin{abstract}
${ }^{1}$ Biomedical Research Institute I+12, University Hospital 12 de Octubre, Madrid, Spain, ${ }^{2}$ Molecular Oncology Unit, CIEMAT (Centro de Investigaciones Energéticas, Medioambientales y Tecnológicas), Madrid, Spain, ${ }^{3}$ Centro de Investigación Biomédica en Red de Cáncer (CIBERONC), Madrid, Spain, ${ }^{4}$ Genomes \& Disease Lab, CiMUS (Center for Research in Molecular Medicine and Chronic Diseases), Universidade de Santiago de Compostela, Santiago de Compostela, Spain
\end{abstract}

\section{OPEN ACCESS}

Edited by:

Yun Liu,

Fudan University, China

Reviewed by:

Stephanie Michelle Willerth,

University of Victoria, Canada

Daniel B. Lipka,

German Cancer Research Center

(DKFZ), Germany

Lucio Lara Santos,

Portuguese Institute of Oncology

Francisco Gentil, Portugal

*Correspondence:

Jesus Maria Paramio

jesusm.paramio@ciemat.es

Specialty section:

This article was submitted to

Epigenomics and Epigenetics,

a section of the journal

Frontiers in Genetics

Received: 19 June 2019 Accepted: 17 October 2019 Published: 18 November 2019

Citation:

Martinez VG, Munera-Maravilla E, Bernardini A, Rubio C,

Suarez-Cabrera C, Segovia C, Lodewijk I, Dueñas $M$,

Martínez-Fernández $M$ and

Paramio JM (2019) Epigenetics of Bladder Cancer: Where Biomarkers and Therapeutic Targets Meet.

Front. Genet. 10:1125.

doi: 10.3389/fgene.2019.01125
Bladder cancer (BC) is the most common neoplasia of the urothelial tract. Due to its high incidence, prevalence, recurrence and mortality, it remains an unsolved clinical and social problem. The treatment of $\mathrm{BC}$ is challenging and, although immunotherapies have revealed potential benefit in a percentage of patients, it remains mostly an incurable disease at its advanced state. Epigenetic alterations, including aberrant DNA methylation, altered chromatin remodeling and deregulated expression of non-coding RNAs are common events in $\mathrm{BC}$ and can be driver events in $\mathrm{BC}$ pathogenesis. Accordingly, these epigenetic alterations are now being used as potential biomarkers for these disorders and are being envisioned as potential therapeutic targets for the future management of BC. In this review, we summarize the recent findings in these emerging and exciting new aspects paving the way for future clinical treatment of this disease.

Keywords: Epigenetic, chromatin remodelling, bladder cancer, biomarkers, therapeutic target

\section{INTRODUCTION}

$\mathrm{BC}$ is a common urogenital cancer which represents a current clinical and social problem. At diagnosis, two thirds of patients present a non-muscle invasive bladder cancer (NMIBC), a relatively limited aggressive disease confined to the bladder and without signs of invasion of the underlying muscle layer. The remaining patients display muscle-invasive bladder cancer (MIBC) (Knowles and Hurst, 2015). This pathological classification also defines clinical management. NMIBC is treated by transurethral resection, which can be followed by intravesical instillation with Bacillus CalmetteGuérin (BCG) or mitomycin (Babjuk et al., 2017). However, a large proportion (60-75\%) of NMIBC patients relapse and, in some cases (15-25\%), the recurrent tumor shows signs of MIBC indicating tumor progression (van Rhijn et al., 2009). The current therapeutic options for MIBC include radical cystectomy and platin-based chemotherapy in adjuvant or neoadjuvant settings (Stenzl et al., 2011). However, in a high proportion of cases, the disease progresses showing metastatic spread, which is associated with extremely low survival rates (Stenzl et al., 2011; Pal et al., 2013; Witjes et al., 2014a). No major improvement in MIBC management occurred during the last decades, until recent years, in which immunotherapy has been shown to increase survival with responses in $20-30 \%$ of the patients presenting advanced and metastatic BC (Powles et al., 2014; Rosenberg et al., 2016; Balar et al., 2017; Bellmunt et al., 2017; Plimack et al., 2017). As in other cancers, 
immunotherapy in BC is mainly based on the use of antibodies that prevent PD-1/PD-L1 interaction, the so called immune checkpoint, leading to immune killing of tumor cells (Pardoll, 2012). The limited activity of immune checkpoint inhibitors in the clinics has led to the consideration of possible combinations of different immune and non-immune therapies (Gotwals et al., 2017). Moreover, in the case of BC patients, it is unclear which patients are more likely to benefit from this treatment (Powles et al., 2014; Rosenberg et al., 2016; Balar et al., 2017; Bellmunt et al., 2017; Plimack et al., 2017). Thus, there is a need not only for more effective therapies in patients with advanced BC, but also for new biomarkers that will help to define which patients may benefit from immunotherapy (Havel et al., 2019).

Epigenetics are heritable but reversible modifications that alter gene expression without changing primary DNA sequences. Epigenome functions are fundamental for the normal status of gene expression and their alterations affect basic cellular processes such as proliferation, differentiation and apoptosis, which may lead to important diseases including cancer (Liep et al., 2012; Baylin and Jones, 2016). Therefore, epigeneticbased cancer biomarkers are promising tools for detection, diagnosis, assessment of prognosis, and prediction of response to therapy (Esteller, 2008; Jerónimo and Henrique, 2014). An extraordinary number of alterations in epigenetic machinery have been observed in BC, affecting DNA methylation (Marques-Magalhaes et al., 2018), chromatin organization, histone modifications (Weinstein et al., 2014; Robertson et al., 2018) and non-coding RNAs expression (Pop-Bica et al., 2017; Taheri et al., 2018). This has produced a large body of evidence indicating that epigenetic machinery could represent a putative target for BC management, a source of valuable biomarkers for diagnostic, prognostic and response prediction, and also a novel research field with amazing new insights into the molecular mechanisms of cancer biology governing cell autonomous cancer processes as well as the intricate cross talk between cancer cells and their niche.

\section{CHROMATIN REMODELERS IN BC}

The epigenome is defined by changes that do not involve alterations in the DNA nucleotide sequence. These changes are broadly divided into DNA methylation and modifications of the histone tails that allow the opening or closing of the chromatin. The functions of the epigenome are fundamental for normal gene expression, and its alterations affect basic cellular processes (Tsai and Baylin, 2011;Liep et al., 2012). The aberrant epigenetic landscape is a hallmark of human cancer (Han et al., 2012; Mio et al., 2019; Zhao et al., 2019) and, in particular, characterizes $\mathrm{BC}$ as an epigenome disease, as studies of complete exome sequencing have shown that it presents frequent alterations in the genes that govern the organization of chromatin and histone modifications, either by mutation or by its expression/altered function (Gui et al., 2011; Weinstein et al., 2014).

Nevertheless, the mechanisms for epigenetic regulation of gene expression are not limited to chromatin modifiers or DNA methylation changes, as non-coding RNAs are also involved
(Fabbri and Calin, 2010; Gupta et al., 2010; Kogo et al., 2011) (Figure 1).

\section{DNA Methylation in BC}

Methylation of DNA is the process by which a methyl group is added by a covalent bound to the 5 ' position of a cytosine ring of the DNA molecule. The methylation event is a frequent epigenetic episode and usually occurs on a cytosine followed by a guanine (CpG dinucleotide). There are regions of the genome, termed $\mathrm{CpG}$ islands, which contain a higher density of the $\mathrm{CpG}$ dinucleotide than the rest of the genome (Li et al., 2016a). These CpG islands are located in sites that normally overlap with gene regulatory regions (Baylln et al., 1997). Thereupon, there are CpG islands at promoter $/ 5$ ' regions of $50 \%$ of all known genes and they are normally unmethylated (Reinert, 2012) which is associated with (potentially) active transcription (Jones and Liang, 2009). CpG islands are also found in gene bodies and their methylation status positively correlates with gene expression (Yang et al., 2014). DNA methylation is a key process in mammalian development, and its alterations are hallmarks of diseases, including cancer. Changes in normal DNA methylation status exist in approximately $50-90 \%$ of BCs, including DNA hypermethylation of promoter sites of $A 3 B P 1, N P T X 2, Z I C 4$, PAX5A, MGMT, IGSF4, GDF15, SOX11, HOXA9, MEIS1, VIM, STK11, MSH6, BRCA1, TBX2, TBX3, TERT, GATA2, DAPK1, CDH4, CCND2, GSTP1, CDKN2A, CDKN2B, WIF1, RASSF1A, among others (Porten, 2018). These genes are mainly tumor suppressors that belong to biological pathways such as DNA repair, cell cycle control, cell invasion and apoptosis (Reinert et al., 2011; Sánchez-Carbayo, 2012). DNA methylation of promoter regions typically negatively affects gene expression, which can promote the development (Costa et al., 2010; Chung et al., 2011) and progression of BC (Yates et al., 2007; Kandimalla et al., 2012; Casadevall et al., 2017), and can predict therapy outcomes (Agundez et al., 2011; Xylinas et al., 2016).

First studies of DNA methylation in BC focused on potential genes which methylated status might correlate with stage, grade and recurrence. More recently, the development of modern whole-genome DNA methylation assays has allowed to analyze in depth the BC methylome. Wolff et al. stablished that most DNA methylation changes happen in early BC and are conserved in carcinoma in situ, non-invasive as well as invasive tumors, and are located in CpG islands (Wolff et al., 2010). Furthermore, the degree and extent of hypermethylation correlates with grade and stage since low-grade tumors have less altered methylation loci compared to high-grade and invasive tumors (Catto et al., 2005; Yates et al., 2007; Wolff et al., 2010). DNA methylation also separates mutation status of FGFR3. NMIBC FGFR3 wild-type tumors, which have a poorer prognosis compared to FGFR3 mutant NMIBC (Van Rhijn et al., 2012), were more methylated than FGFR3-mutant tumors (Serizawa et al., 2011; Kandimalla et al., 2012). Besides, in low-grade non-invasive tumors, DNA hypomethylation was more frequent than in invasive tumors (Wolff et al., 2010). Hypermethylation of ZO2, MYOD and $\mathrm{CDH} 13$ was also detected in normal-appearing urothelium from bladder with cancer compared to urothelium from healthy 


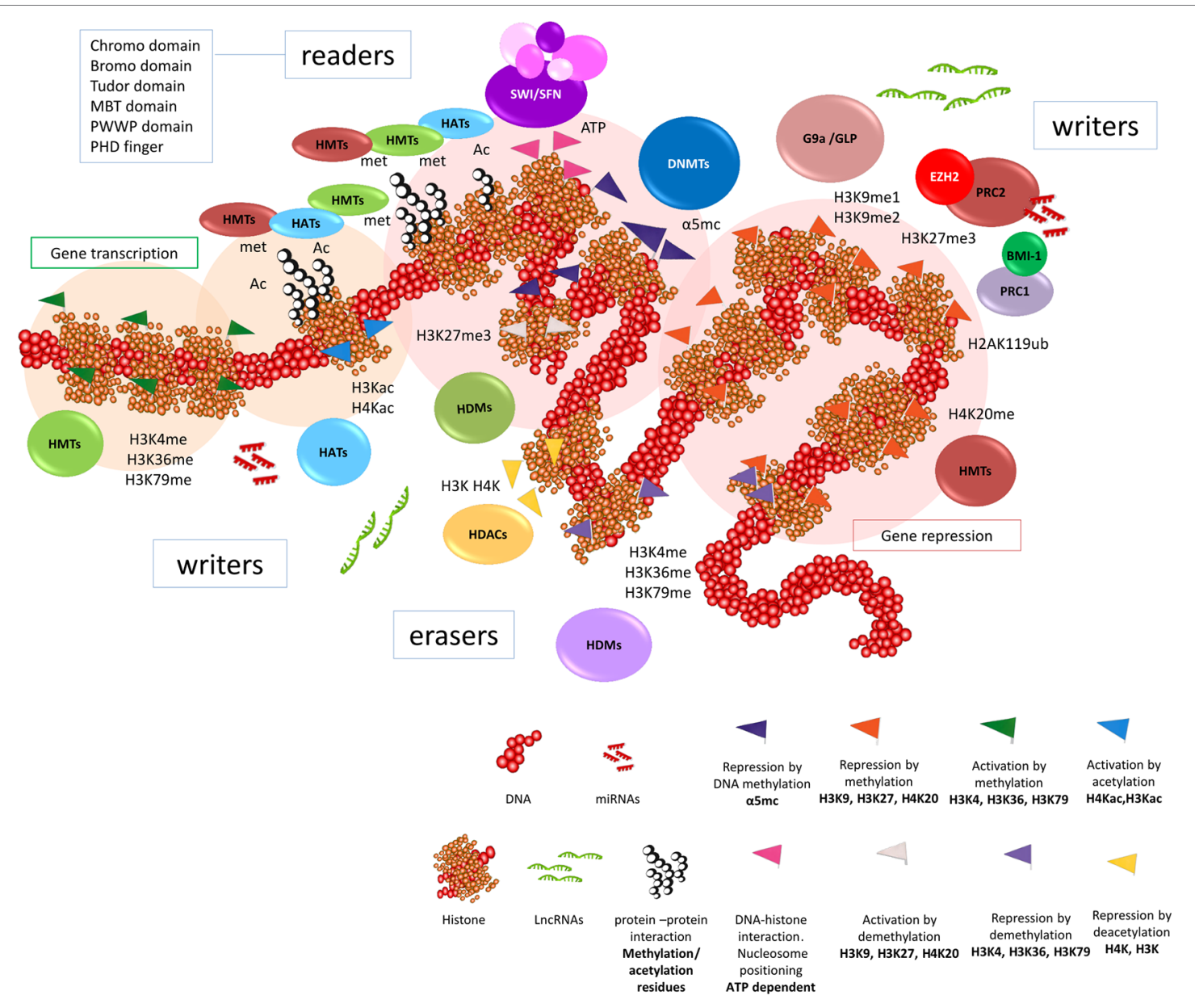

FIGURE 1 | Epigenetic regulation in cancer cells. General scheme of the dynamic interaction of DNA methylation, histone modifications, positioning of nucleosomes, among other factors, that participate in the mechanisms of the epigenome to regulate gene expression. Thus, the tumor cell acquires a particular identity. DNA methylation is present throughout the genome, however we can find aberrant DNA methylations or alterations in the DNMTs enzymes (methyltranferases of DNA nucleotides) in the tumor. The methylation mark H3K27 is the main brand that controls the gene repression in euchromatin. The remodeling enzymes called writers (HMT, histone methyltransferase, HAT, histone acetyltransferase), erasers (HDM, histone demethylase; HDAC, histone deacetylase) and readers (specialized interaction motif containing proteins that recognize post-translational modifications, mostly acetylation and methylation) of the main histone modifications work in a coordinated manner for the regulation of gene transcription. Depending on the genes they regulate, they are recruited to the same place to function together. Therefore, all these molecules are subject of study as possible therapeutic targets.

bladder, indicating an epigenetic 'field defect' and a possible contribution to a loss of epithelial integrity, likely generating a permissive environment for tumor recurrences (Wolff et al., 2010; Majewski et al., 2019).

Since several genes were identified as frequently hypermethylated in primary BC, diagnosis could be performed based on the methylated status of a gene set. For instance, methylation of IPF1, GALR1, TAL1, PENK and TJP2 was found to be higher in MIBC tumors than in NMIBC (Wolff et al., 2010). Sacristan et al. indicated that methylation of $R A R B, C D 44$, GSTP1, IGSF4, CHFR, PYCARD, TP53, STK11 and GATA5 distinguished low-grade versus high-grade tumors, whereas Olkhov-Mitsel et al. stablished that the inclusion of GP5 and ZSCAN12 in a methylation panel could feasibly distinguish highgrade and low-grade BC (Olkhov-Mitsel et al., 2017). Unluckily, the overlap between genes found in different studies is limited.
Since $20 \%$ of BC patients recur, finding epigenetic markers of progression would be useful to predict recurrence. A wide study reviewed 87 articles reporting the association of epigenetic markers with prognostic outcomes (Casadevall et al., 2017). However, the prognostic influence of epigenetic alterations in $\mathrm{BC}$ remains unclear. CACNA1G (García-Baquero et al., 2014) and TBX3 (Kandimalla et al., 2012) were associated with progression and SFRP5 correlated with recurrence (García-Baquero et al., 2014). CDNK2A is methylated in $64 \%$ of BCs, however, inconsistent results were found in prognosis (Casadevall et al., 2017). Based on TCGA data, methylation and expression levels of SOWAHC were found to be correlated with prognosis (Yang et al., 2019). HOX genes appear hypermethylated in almost all aggressive tumors (Reinert et al., 2011; Kandimalla et al., 2012), and HOXA9 promoter methylation correlated with higher recurrence, progression, and death by cancer in NMIBC and 
MIBC (Kitchen et al., 2015) and was associated with cisplatin resistance in BC cell lines (Xylinas et al., 2016). High-risk NMIBC manifest higher rates of progression to invasive tumors than lowand intermediate-risk bladder tumors, which in many cases do not recur or progress. Recently, some investigations proposed multiple CpG sites differentially methylated between high-risk recurrence/progression tumors and less aggressive low-risk no-recurrence tumors (Kitchen et al., 2018; Peng et al., 2018).

A three-gene methylation panel which differentiates between patients with metastatic and free of cancer lymph nodes might also be predictive of metastasis development, and enable the selection of patients that would benefit from lymph node resection and neoadjuvant chemotherapy (Stubendorff et al., 2019). In patients undergoing BCG treatment, methylation status of MSH6 and THBS1 may help to distinguish responders to therapy, and methylation of GATA5 associated with survival (Agundez et al., 2011), allowing the possible identification of patients requiring a more aggressive therapy. After chemotherapeutic treatment, the MDR1 gene was found to be overexpressed in BC compared with untreated tumors, and in tumors from patients that eventually recurred. This overexpression correlated negatively with methylation of $\mathrm{CpG}$ sites in the promoter region (Tada et al., 2000). An interesting study tested gene methylation in second recurrences in bladder of primary upper-tract urothelial carcinomas, and stablished that the methylation rate in certain genes tend to increase with the number of recurrences, which may be a predictive factor for recurrences after surgery (Guan et al., 2018). Nevertheless, the existence of inconsistent results and lack of validation studies hampers at present relevance of these findings (Casadevall et al., 2017; Porten, 2018).

Less data is reported about hypomethylation status in BC. In 1983, a pioneer study reported that hypomethylation could distinguish genes of cancer cells compared with their normal counterparts (Feinberg and Vogelstein, 1983). In normal cells, certain $\mathrm{CpG}$ rich satellite repeats are strongly methylated, such as LINE-1 (Schulz, 2006). Interestingly, these regions are strongly hypomethylated in all types of BC (Kreimer et al., 2013) and could translate in genomic instability (Wolff et al., 2010). Besides, as a tissue-fingerprint, the hypomethylation pattern of LINE-1 seems to be specific for each tumor type and tissue (Sharma et al., 2019). Furthermore, a different type of study analyzed global methylation in DNA from blood cells and found that leukocyte DNA hypomethylation is a risk factor for BC (Moore et al., 2008).

DNA methylation is catalyzed by three DNA methyltransferases (DNMT): DNMT1, DNMT3A and DNMT3B. DNMT1 is the keeper of the regular methylation status of the genome after cell replication (Goll and Bestor, 2005), whereas DNMT3a and DNMT3b are de novo methyltransferases (Okano et al., 1999). Mutations in chromatin regulatory genes are present in around $76 \%$ of BC (Robertson et al., 2018) and are more frequently found in BC than in any other solid tumor (Weinstein et al., 2014). However, the alterations regarding DNMTs in BC are mainly found to be an increase in their expression ( $\mathrm{Li}$ et al., 2016a). Several genes that are methylated in BC are repressed by polycomb complexes (Wolff et al., 2010; Kandimalla et al., 2012). These complexes composed of EZH2 recruit DNMTs required for
DNA methylation (Viré et al., 2006), which suggests an upstream regulation of methylation in $\mathrm{BC}$.

\section{Chromatin Remodeling and Histone Modification in BC}

Mutations in chromatin remodeling genes are very frequent in BC (Robertson et al., 2018), affecting $89 \%$ of histone remodelers and $64 \%$ of nucleosome positioning genes in MIBC (Weinstein et al., 2014; Robertson et al., 2018). The post-translational modifications of histones, such as acetylation, methylation, phosphorylation or ubiquination in specific residues of lysines, arginines and serines (Allis et al., 2007; Rothbart and Strahl, 2014), modulate the dynamic and reversible changes in chromatin structural changes. This "histone code" can be written, erased and read by different molecules modulating transcription (Gillette and Hill, 2015). Therefore, chromatin remodelers can be classified as writers (methyltransferases (HMTs) or acetylases (HATs)), erasers (demethylases (HDMs) and deacetylases (HDACs) ) and readers, which are further divided in proteins or effector complexes that interact with specific domains (Gillette and Hill, 2015; Hyun et al., 2017), and nucleosome remodeling multiprotein complexes that are able to alter DNA-histone contacts. The main marks of gene transcription are acetylation of histone 3 and histone $4(\mathrm{H} 3 \mathrm{Kac}, \mathrm{H} 4 \mathrm{Kac})$ and methylation of histone 3 on lysine 4, 36 and 79 (H3K4me, H3K36me, H3K79me), while methylation of histone 3 on lysine 9 and 27 and histone 4 on lysine 20 (H3K9me, H3K27me, H4K20me) represent important marks for gene repression (Bernstein et al., 2007) (Figure 1).

\section{Writers}

Histone methyltransferase EZH2 catalyzes H3K27me2 and $\mathrm{H} 3 \mathrm{~K} 27 \mathrm{me} 3$ marks to regulate the repression of gene expression (Deb et al., 2014), and compacts chromatin with other molecules like BMI-1 (Cao et al., 2005) (Figure 1). Its involvement in tumor development and progression is a common characteristic of several human tumors, including BC (Yamaguchi and Hung, 2014). It has been demonstrated that the existence of the oncogenic axis $\mathrm{Rb}-\mathrm{E} 2 \mathrm{~F}-\mathrm{EZH} 2$ predicts recurrence and progression in NMIBC (Santos et al., 2014) and promotes global changes in gene expression, including the aberrant expression of lncRNAs such as HOTAIR (Martínez-Fernández et al., 2015b), and the silencing of several microRNAs, such as mir-200 family (Martínez-Fernández et al., 2015a). Several studies have shown that EZH2 also interacts with other modifiers such as DNMTs, HDAC or G9a, that could explain some oncological properties of $\mathrm{EZH} 2$. The importance of these non-canonical functions of $\mathrm{EZH} 2$ in BC is still not well understood, although it could favor intratumoral heterogeneity (Gupta et al., 2011).

Histone methyltransferase G9a (EHMT2) is considered an oncogenic epigenetic factor (Lee et al., 2015), which can be involved in urothelial tumors (Shankar et al., 2013; Cho et al., 2015). This enzyme binds GLP (EHMT1) and catalyzes $\mathrm{H} 3 \mathrm{~K} 9 \mathrm{me} 2$ leading to gene silencing through physical interaction with cofactors (Bian et al., 2015; Maier et al., 2015; Simon et al., 2015; Hu et al., 2018) and/or non-coding RNAs (Nagano et al., 2008). Additionally, G9a may interact with EZH2 allowing the 
silencing of specific loci in a cooperative way (Mozzetta et al., 2014; Mozzetta et al., 2015) becoming a possible target for advanced metastatic BC (Segovia et al., 2019).

Methyltransferase KMT2D (MLL2), which catalyzes H3K4me1 and H3K4me2 (Lee et al., 2013), displays the highest mutation rate among all HMTs in BC (Weinstein et al., 2014) in close association with tumor development, recurrence ( $\mathrm{Wu}$ et al., 2016a) and resistance to therapy (Lu et al., 2017). KMT2C (MLL3) is also commonly mutated in high grade NMIBC (Weinstein et al., 2014; Hurst et al., 2017) and in luminal papillary and basal squamous MIBC subtypes (Robertson et al., 2018), and its silencing affects DNA damage response genes (Rampias et al., 2019). Additionally, somatic mutations of 13 HMT genes, including NSD1 and NSD3, are present in a high proportion of BC tumors (Ding et al., 2019). Moreover, the genes encoding acetyltransferases EP300 and CREBBP are among the genes most frequently inactivated by mutation in human BC (Gui et al., 2011; Duex et al., 2018b).

\section{Erasers}

The gene encoding histone demethylase KDM6A (UTX), located on the $\mathrm{X}$ chromosome, is one of the genes most frequently mutated in BC (Gui et al., 2011; Nickerson et al., 2014). This demethylase can specifically erase the marks written by EZH2 (Agger et al., 2007; Lee et al., 2007). Mutations in KDM6A are more common in NIMBC and in women (Hurst et al., 2017), and tend to be mutually exclusive with $M L L 2$ alterations (Kim et al., 2015a) suggesting a predominant silenced chromatin during bladder carcinogenesis (Casadevall et al., 2017). In some cases, it has been associated with $R B 1$ mutation in high grade urothelial tumors (Balbás-Martínez et al., 2013; Ross et al., 2014).

Acetylation of lysine residues in histone tails results in a more open state of the chromatin (Roger et al., 2011) and histone acetylation levels decrease during progression towards MIBC (Ellinger et al., 2016). Furthermore, the deregulated expression of various HDACs, like HDAC1, 2, 3 and 6, has been described in urothelial tumors in close association with malignancy (Chen et al., 2011; Li et al., 2016b; Niegisch et al., 2013; Poyet et al., 2014; Lee and Song, 2017).

\section{Readers}

The effects of epigenetic marks are mediated through effector complexes which "read" marks and facilitate the DNA-histone and protein-protein interactions. This provides recruitment platforms for other epigenetic regulators to specific DNA loci (Dawson and Kouzarides, 2012) (Figure 1). The methylation and acetylation writers usually have reader domains (predominantly bromodomain (BRD) and plant homeodomain (PHD) finger) that allow recognition of the histone methylation/acetylation status (Dawson and Kouzarides, 2012; Biswas and Rao, 2018).

Methyl CpG sites are recognized by proteins that contain conserved binding domains such as methyl CpG binding domain (MBD), SRA domain and zinc finger $(\mathrm{ZnF})$. These proteins work together with other factors to alter the transcriptional status of DNA (Biswas and Rao, 2018). The histone methylated residues are recognized by conserved binding domains such as PHD finger, Tudor domain, PWWP (Pro-Trp-Trp-Pro) domain, chromodomain, malignant brain tumor domain (MBT), ankyrin repeats (present in G9a and GLP1), ZnFs and WD40 domain, among others. Furthermore, BRDs, double PHD finger and Yeats domains bind specifically to acetylated residues of histones (Dhalluin et al., 1999; Fischle, 2003; Kouzarides, 2007; Taverna et al., 2007; Dawson and Kouzarides, 2012; Biswas and Rao, 2018). BRDs are present in the acetylation writers CBP and p300 along with several protein interaction motifs, both closely related proteins have been deeply investigated since they are able to acetylate the four histones (Dawson and Kouzarides, 2012). Additionally, BRDs of chromatin remodeling enzymes BRM (SMARCA2) and BRG1 (SMARCA4) recognize multiple acetylation sites at $\mathrm{H} 3$ and $\mathrm{H} 4$. In $\mathrm{BC}$, the BRD4 histone acetylation reader is overexpressed and can upregulate C-MYC, which controls the expression of cell cycle progression genes, enhancing the recruitment of this factor to the EZH2 promoter and subsequently upregulating EZH2 expression, which has a significant relevance on tumor growth (Wu et al., 2016b). Consequently, EZH2 promotes growth of BC by chromatin modification (Wu et al., 2016b), especially in tumors with loss of KDM6A (Ler et al., 2017). Some susceptibilities to EZH2 inhibitors have been found in relation to mutations in components of SWI/SNF complexes such as ARID1B (12\%), SMARCA4 (15\%) SMARCA2 (16\%) (Helming et al., 2014; Bitler et al., 2015; Kim et al., 2015b). This is relevant in the context of $\mathrm{BC}$, since components of the SWI/SNF complexes are also frequently altered in BC patients (Knowles and Hurst, 2015; Robertson et al., 2018). Other remodelers such as the SWI/SNF nucleosomal complex component, ARID1A, often show inactivating mutations or deep eliminations in both MIBC (Weinstein et al., 2014; Robertson et al., 2018) and NIMBC (Hurst et al., 2017).

An additional complexity of chromatin remodeling lies in the fact that many chromatin regulators have more than one type of reader domain, and their binding to chromatin can be further influenced by histone modifications (Ruthenburg et al., 2007). The understanding of the dynamic plasticity of DNA and histone modifications will allow us to open new venues to the management and treatment of BC.

\section{Non-Coding RNAs in BC Etiology and Progression}

Non-coding RNAs (ncRNA) represent an important role in the epigenetic changes leading to $\mathrm{BC}$ development and progression. Additional to transfer RNA and ribosomal RNA molecules, which represent the most abundant ncRNAs $\left(3-10 \times 10^{7}\right.$ and $3-10 \times 10^{6}$ molecules per cell, respectively), several ncRNA classes can be distinguished, including long non-coding RNA (lncRNA), transcribed ultraconserved region (T-UCR), circular RNA (circRNA), small interfering RNA (siRNA), Y RNA (Y RNA), micro-RNA (miRNA; miR), piwi-interacting RNA (piRNA), small nucleolar RNAs and small nuclear ribonucleic acid (Palazzo and Lee, 2015; Anastasiadou et al., 2017; Gulìa et al., 2017)

NcRNA molecules are specific RNAs which are not translated into proteins, and represent essential regulatory roles in practically every aspect of cellular function. They have been 
suggested to exert an essential function in the maintenance of genomic stability, mainly through adjusting DNA expression and complex formation with other ncRNA molecules as well as proteins. Consequently, the description of ncRNA function in isolation is very complicated. Several ncRNAs (like miRNAs) are able to target the messenger RNAs (mRNAs) of multiple other genes, whereas the mRNA of one gene can also be targeted by numerous miRNAs. Furthermore, miRNAs can interact with other ncRNA molecules, like lncRNAs and circRNAs, in order to control their stability, while lncRNAs and circRNAs are able to regulate the abundance of miRNAs. Besides, ncRNAs can interact with individual proteins and protein complexes which might facilitate specific protein targeting or the assembly of protein complexes by providing a scaffold (Anastasiadou et al., 2017; Gulia et al., 2017).

LncRNAs and miRNAs represent the two main classes of ncRNA involved in BC epigenetic etiology as well as progression, and will be discussed in detail below. Additionally, some other ncRNA molecules associated to this pathology will be briefly described.

\section{Long Non-Coding RNAs}

LncRNAs consist of more than 200 nucleotides, and are involved in several essential biochemical processes (Wang and Chang, 2011). Clark et al. examined about 7,200 lncRNA molecules and described a wide variation in stability, ranging from half-lives of less than $30 \mathrm{~min}$ for unstable molecules to half-lives of more than $48 \mathrm{~h}$ for extremely stable lncRNAs, with a median lncRNA halflife of $3.5 \mathrm{~h}$ (Clark et al., 2012). Besides, these lncRNA molecules have been found to be significantly less abundant than, for example, total mRNA $\left(3-50 \times 10^{3}\right.$ versus $3-10 \times 10^{5}$ molecules per cell, respectively) (Palazzo and Lee, 2015). Many lncRNAs were found to be differentially expressed in a wide range of tumor tissues compared to corresponding healthy control tissues, suggesting an important role in carcinogenesis (MartensUzunova et al., 2014; Bhan et al., 2017). In BC, deregulation of lncRNAs has been found to contribute to carcinogenesis in several ways including sustained proliferative signaling and induction of invasion as well as metastasis (Bhan et al., 2017).

LncRNA expression in BC has been extensively reviewed (Gulia et al., 2017; Taheri et al., 2018). Based on their expression patterns and functions in $\mathrm{BC}$ tissue compared to healthy control tissue, lncRNA molecules can be classified in two groups, either showing increased (oncogenic lncRNAs) or decreased (tumor suppressor lncRNAs) expression in tumor tissue. For example, oncogenic lncRNA-UCA1 has been reported to induce epithelialmesenchymal transition (EMT) and promote BC cell migration and invasion through the miR-145-ZEB1/2-FSCN1 pathway, as well as by targeting miR-582-5p or modulation of the miR-143/ HMGBG1 signaling pathway (Xue et al., 2016; Luo et al., 2017; Wu et al., 2019a). Overexpression of UCA1 has been associated with high risk of poor outcome in $\mathrm{BC}$. Accordingly, the use of UCA1 as potential biomarker is subject of ongoing research (Wang et al., 2006; Cui et al., 2017). LncRNA-H19 has been found to be abundantly expressed in BC leading to increased miR-675 expression, thus inhibiting TP53 activation (Ariel et al., 2000; Liu et al., 2016). LncRNA-H19 has further been described to promote metastasis and EMT through E-cadherin inhibition as well as by targeting miR-29b-3p (Lv et al., 2017; Zhu et al., 2018). Other well-described oncogenic lncRNAs involved in BC include MALAT1, HOTAIR, TUG1, ANRIL and PVT1, whereas well-known lncRNAs-MEG3 and GAS5 represent tumor suppressor lncRNA molecules (Sun et al., 2015; Gulia et al., 2017; Guo et al., 2018; Liu et al., 2017b; Xie et al., 2017a; Yang et al., 2017; Yu et al., 2019; Jiao et al., 2018; Liu et al., 2018a; Wang et al., 2018b; Huang et al., 2019a; Tian et al., 2019). Even though many other oncogenic and tumor suppressor lncRNAs have recently been identified in $\mathrm{BC}$, they need further investigation to validate their relevance in this disease. Additionally, the use of specific lncRNA as biomarkers or therapeutic targets is subject of ongoing research and will be further discussed below.

\section{Micro-RNAs}

As abovementioned, lncRNAs extensively interact with miRNA in the regulation of oncogenic pathways. MiRNAs consist of 21-24 nucleotides and play important roles in the regulation of gene expression (Sohel, 2016). Mature miRNAs have shown high stability reflecting half-lives of approximately 8 hours in the cell, which is reflected in a relatively high abundance of miRNA molecules (1-3×105 molecules per cell) (Palazzo and Lee, 2015).

Aberrantly expressed miRNAs have been found in BC tissues causing an altered expression of target genes, resulting in $\mathrm{BC}$ development and progression (Zhu et al., 2011). As for lncRNAs, miRNA expression in BC has been extensively reviewed (Enokida et al., 2016; Gulì et al., 2017). The aberrant expression of several miRNAs has been found to alter two main genetic pathways predisposing to BC. Some miRNAs target the FGFR3 pathway (including miR-99a, miR-100, miR-101, and miR-145), while other miRNA molecules modify the TP53 pathway (such as miR21 and miR-373) (Homami and Ghazi, 2016). Like lncRNAs, miRNA molecules can be divided in oncogenic miRNAs or tumor suppressor miRNAs. For example, the decreased expression of miR-34a in BC has an anti-metastatic function through the CD44/EMT signaling pathway (Yu et al., 2014) and through targeting NOTCH1 and HNF4G also negatively modulates BC cell proliferation and invasion (Zhang et al., 2012; Sun et al., 2015). Accordingly, low expression of miR-34 has been found to be correlated with unfavorable prognosis (Xie et al., 2017b). Besides, downregulation of the tumor suppressor miR-200 family has been proposed to be associated with poor prognosis in $\mathrm{BC}$, and the use of this family as prognostic marker has been indicated (Wiklund et al., 2011; Martínez-Fernández et al., 2015a). The miR-200 family consists of five different members, namely miR200a, miR-200b, miR-200c, miR-429 and miR-141, and has been suggested to play an essential role in the inhibition of the EMT process by regulation of ZEB1 and ZEB2 transcription factors (Korpal et al., 2008; Park et al., 2008).

Many other tumor suppressor and oncogenic miRNAs have been extensively described or recently discovered as particular players in BC (Enokida et al., 2016; Gulìa et al., 2017). For example, low expression of miR-100, miR-101 and miR-214, as well as high expression of miR-452, miR-21, miR-222, miR-182, miR-133b, miR-155, miR-145, and miR-152 has been correlated with unfavorable prognosis(Xie et al., 2017b). 
Given their deregulated expression, the miRNAs have been widely studied as therapeutic target and biomarkers in different pathologies, including several types of cancers (Romero-Cordoba et al., 2014; Shah and Calin, 2014; Chan et al., 2015). Accordingly, the study of miRNAs in liquid biopsy offers great perspective for diagnostic and prognostic purposes. These objectives will be further discussed below.

\section{Other ncRNA}

CircRNA molecules represent a type of ncRNA that are covalently closed in a loop at the $3^{\prime}$ and $5^{\prime}$ ends. The lack of free $3^{\prime}$ or $5^{\prime}$ ends provides increased resistance of circRNAs to exoribonuclease-dependent RNA degradation, which results in a prolonged half-life of over $48 \mathrm{~h}$ (Jeck and Sharpless, 2014). Even though their cellular functions are still largely unknown, various circRNAs have shown relevance in multiple cancer types (Zhang et al., 2017; Kristensen et al., 2018). Although circRNA research in BC is still scarce, several circRNAs have been shown to be highly expressed in human BC. These endogenous circRNAs competitively target specific miRNAs, thereby suppressing miRNA activity by acting as a miRNA sponge. For example, circTCF25 has been demonstrated to promote cell proliferation and metastasis by acting as a RNA sponge for miR-103a-3p and miR-107, resulting in increased CDK6 levels (Zhong et al., 2016). Besides, circRNA-MYLK and circRNA-CTDP1 competitively bind miR-29a-3p leading to enhanced expression of its target genes DNMT3B, VEGFA, HAS3 and ITGB1, resulting in angiogenesis, EMT and metastasis (Huang et al., 2016; Zhong et al., 2017). Recently, additional circRNA molecules representing an oncogenic role in $\mathrm{BC}$ tumorigenesis and progression have been discovered, including circCEP128, circRNA-VANGL1, circPRMT5 and circRNA-cTFRC (Chen et al., 2018; Wu et al., 2018; Zeng et al., 2019; Su et al., 2019).

Contrarily to the oncogenic role of several circRNAs, some circRNAs act as tumor suppressors and have been shown to be downregulated in human BC. For example, circRNA-ITCH has been shown to suppress the aggressive biological behavior of $\mathrm{BC}$ through increased expression of p21 and PTEN by sponging miR17 and miR-224, whereas circRNA-BCRC-3 has been found to act as a sponge of miR-182-5p resulting in enhanced expression of p27 (Xie et al., 2018; Yang et al., 2018a). Other circRNA molecules which have recently been discovered to mediate antioncogenic functions include circRNA-BCRC4, circRNA-Cdr1as and circMTO1 (Li et al., 2017; Li et al., 2018a; Liu et al., 2018b).

Their extensive abundance, stability and tissue-specific expression make circRNAs attractive molecules for clinical research (Barrett and Salzman, 2016). Further research into their regulatory mechanisms on miRNA expression will help us to improve our knowledge regarding their function in carcinogenesis and may provide insights in the use of circRNA molecules as predictive and diagnostic biomarkers as well as novel therapeutic targets (Kulcheski et al., 2016; Han et al., 2017).

Y RNA molecules are small ncRNAs (21-24 nucleotides) necessary for DNA replication through interactions with chromatin and initiation proteins. Four Y RNAs have been identified and found to be highly evolutionary conserved, namely Y1, Y3, Y4 and Y5 (Christov et al., 2006). These ncRNAs are protected from degradation by its interaction with Ro, a ribonucleoprotein particle that provides stability to these molecules, and their abundance has been found to be relatively high (about $1 \times 10^{5}$ molecules per cell) (Christov et al., 2006; Chen et al., 2007). Even though a role for Y RNAs in BC has been indicated by various studies, contradicting observations have been published (Christov et al., 2008; Tolkach et al., 2017). Christov et al. described the significant overexpression of two $\mathrm{Y}$ RNAs, Y1 and Y3, whereas Tolkach et al. published the significant downregulation of all four Y RNAs in BC tissue compared to tissue of healthy controls. Accordingly, this emphasizes the need for further studies to clarify the possible role of Y RNA in BC etiology and progression.

PiRNA molecules are short single strands non-coding RNAs (26-31 nucleotides) mediating epigenetic and posttranscriptional gene silencing through interactions with PIWI proteins (Siomi et al., 2011). Their small size suggests particular resistance to degradation, which can result in the presence of relatively high levels of piRNA molecules (Palazzo and Lee, 2015; Pardini and Naccarati, 2017). Deregulated expression of some piRNAs has been found in different cancer types (Chalbatani et al., 2019). In BC, Martinez et al. described the association of high levels of piRNA FR004819 with poorer survival, whereas Taubert et al. defined a significant association between diminished PIWIL2 expression and poor prognosis (Martinez et al., 2015; Taubert et al., 2015). Additionally, piRABC has been observed to be downregulated in BC tissue and has been identified as an important piRNA in the development and progression of this pathology. Besides, it has been proposed that piRABC may promote cell apoptosis in $\mathrm{BC}$ by upregulation of the TNFSF4 protein (Chu et al., 2015; Chalbatani et al., 2019).

\section{EPIGENETIC REGULATION OF THE BC MICROENVIRONMENT}

\section{Immune Cell Compartment}

Cancer initiation and tumor progression are often associated with the inhibition of anticancer immune response and dysregulation of inflammatory activity (Berraondo et al., 2016; Sukari et al., 2016). Different solid tumors are characterized by the presence of immune cells, such as $\mathrm{T}$ and B lymphocytes, natural killer $(\mathrm{NK})$ cells, macrophages, and antigen-presenting cells in the tissue microenvironment (TME). These immune cells exhibit different behaviors and morphologies as a result of aberrant differentiation (Olivieri et al., 2016), sometimes driven by epigenetically regulated lineage-specific changes influencing the expression of genes crucial for the identity of immune cells and promoting cellular responses to stimuli (Herold et al., 2012; Smith and Meissner, 2013; Luperchio et al., 2014) (Figure 2).

Recently, some studies have shown that post-translational modification of histones may regulate the behavior of cells involved in the immune response, including tumor associated macrophages (TAMs), regulatory $\mathrm{T}$ cells (Tregs), dendritic cells (DCs), NK cells, myeloid-derived suppressor cells (MDSCs), effector T cells (Teffs), and others (Liu et al., 2017a). Based on whole-genome bisulfite sequencing datasets from 


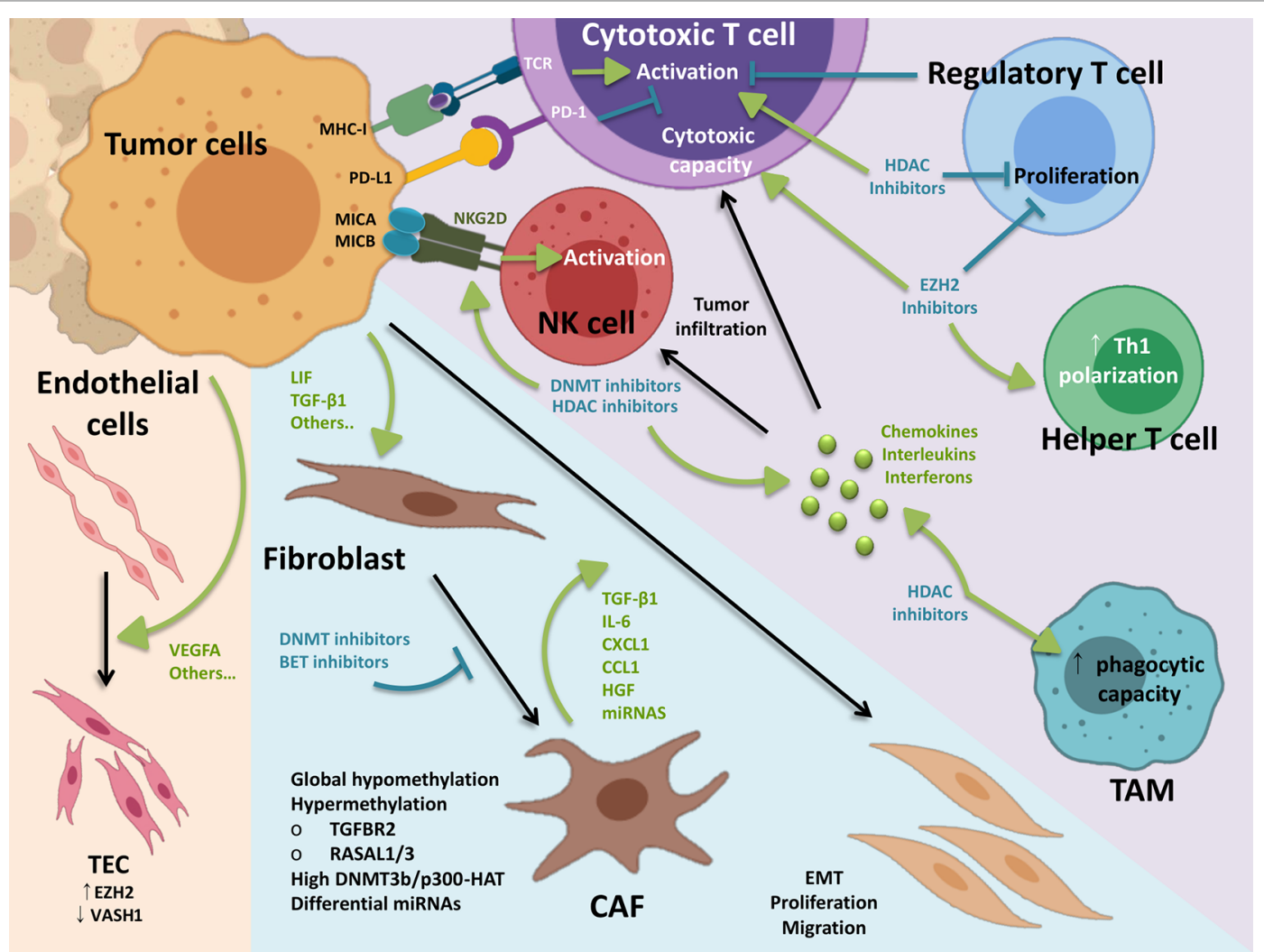

FIGURE 2 | Epigenetic landscape of the tumor microenvironment. Tumor cells can influence the stroma through different factors, being soluble factors the most characterized. Tumor-derived VEGFA induces EZH2 in TEC, which drives hypermethylation of anti-angiogenic Vash1. Also induced by tumor cells, CAF differentiation is associated with several epigenetic features and can be blocked by a number of chromatin remodelers inhibitors. In turn, CAFs promote tumor growth and metastasis via secretion of soluble factors and matrix remodeling. On the immune side, cytotoxic T cells and natural killer cells are the main effectors of the anti-cancer immune response. Balance between activating and inhibiting signals coming from tumor targeted cells determines cytotoxic activity of these cells. Other immune cells such as regulatory $T$ cells and macrophages are key in the anti-cancer immune response. Of note, myeloid and lymphoid lineages present inverse methylation patterns in cancer tissues, contributing to aberrant functionality. Inhibition of epigenetic writers can block regulatory $T$ cell differentiation and function, while promoting anti-tumor activity in effector cells. Reverting tumor-driven epigenetic modifications imprinted in the TME may condition the tumor stroma for effective elimination of malignant cells in combination with existing treatments such as immunotherapy. TEC, tumor endothelial cells; CAF, cancer-associated fibroblasts; EMT, epithelial-mesechymal transition; TAM, tumor-associated macrophage.

the BLUEPRINT Epigenome Project (http://www.blueprintepigenome.eu), Schuyler et al. identified inverse methylation patterns in the myeloid and lymphoid lineages in cancer tissues, where lymphoid-derived neoplasms lose CpG methylation patterns whereas myeloid malignancies significantly increase levels of DNA methylation (Schuyler et al., 2016). These observations have been reproduced by other authors showing that different methylation patterns contribute to the activation of myeloid and lymphoid cancer cells (Bröske et al., 2009; Bock et al., 2012).

The main component of the immune infiltrates present in solid tumors are TAMs, which have been frequently associated with worse prognosis. Compared to the binary M1/ M2 classification, TAMs include multiple populations sharing features of both M1 and M2 phenotypes that in many cases do not fit the M1/M2 classification. Nonetheless, it offers a useful working frame for the study of TAMs, in which the overall consensus is that M1 macrophages are anti-tumorigenic, while M2 macrophages can promote tumor growth. M2-macrophage marker genes are epigenetically regulated by reciprocal changes in histone $\mathrm{H} 3$ lysine-4 (H3K4) and histone $\mathrm{H} 3$ lysine-27 (H3K27) methylation. After IL-4 stimulation, a decrease of H3K27 dimethylation and trimethylation (H3K27me2/3) marks occur as well as the transcriptional activation of specific M2 marker genes. Additionally to methylation, during monocyte to macrophage differentiation, there is a massive reconfiguration of lysine acetylation patterns at gene regulatory elements with a positive correlation between transcriptionally permissive $\mathrm{H} 3$ histone acetylation and the activity of regulatory elements (Bistoni et al., 1986).

When analyzing the activation/polarization status of tumor infiltrating lymphocytes (TILs), TAMs and DCs, several studies have shown that the methylation status of immune genes in these cells influences the tumor immune response in the TME, and correlates with the density of TILs and tumor progression. For example, in naive $\mathrm{CD}^{+} \mathrm{T}$ cells the interferon- $\gamma($ IFN- $\gamma)$ gene promoter and upstream enhancer is methylated. However, in Th1 lymphocytes, where the expression of $I F N-\gamma$ is induced, 
the IFN- $\gamma$ gene promoter and enhancer are demethylated, suggesting an important role in Th1/Th2 differentiation (Janson et al., 2008). The histone methyl transferase EZH2 has also been shown to play an important role in shaping the function of $\mathrm{T}$ cells. Wang et al. demonstrated that accumulation of H3K4me3 in the promoter of FOXP 3 results in the generation of Tregs, and pharmacological or genetic suppression of the activity of EZH2 on tumor-infiltrating Tregs (TI-Tregs) results in the acquisition of pro-inflammatory functions (Wang et al., 2018a) (Figure 2). In addition, suppression of EZH2 modulates the TME and enhances the infiltration of $\mathrm{CD}^{+}$and $\mathrm{CD}^{+}$effector $\mathrm{T}$ cells, which can favor tumor eradication (Wang et al., 2018a). Besides H3K27 methylation, G9a-dependent H3K9me2 is an important regulator of inflammatory gene expression and has also been implicated in several aspects of T cell biology. Although genomewide studies mapping the binding of G9a (or the H3K9me2 mark) in immune cells has not been carried out, a descriptive genome-wide analysis of $\mathrm{H} 3 \mathrm{~K} 9 \mathrm{me} 2$ marks in resting human lymphocytes using ChIP-on-chip methods demonstrated that this epigenetic mark is enriched on genes that are associated with several specific pathways including T cell receptor signaling, IL-4 signaling, and GATA3 transcription (Zhang et al., 2018a).

In addition to $\mathrm{T}$ and $\mathrm{B}$ lymphocytes, NK cells are effector lymphocytes of the innate immune system that have been shown to control tumor growth (Vivier et al., 2008). Although studies investigating the role of epigenetic modulation on NK cell activation and cytotoxicity are still scarce, some reports indicate that histone acetylation is involved in the regulation of NK cell activation and effector functions (Schenk et al., 2016; Raulet et al., 2017). Particularly in cancer, HDAC inhibitors have been shown to modulate the expression of NK ligands on the surface of neuroblastoma, melanoma, osteosarcoma, colon and Merkel cell (Zhu et al., 2015; Kiany et al., 2017) (Figure 2). Besides, Hicks et al. shows that HDAC inhibitors, in addition to significantly enhancing the expression of multiple NK ligands and death receptors resulting in enhanced NK cell-mediated lysis, also increases tumor cell PD-L1 expression both in vitro and in carcinoma xenografts (Hicks et al., 2018). This data offers a rationale for combining HDAC inhibitors with inhibitors of the PD-1/PD-L1 axis, including for patients who are refractory or expected not to respond to these therapies alone due to absent or low PD-L1 tumor expression.

\section{Cancer-Associated Fibroblasts}

The tumor stroma is defined as the non-malignant cells and extracellular components that surround tumors, with a fundamental role in growth and progression. Fibroblasts in the tumor microenvironment differentiate into cancer-associated fibroblasts (CAFs), being one of the main components in the tumor stroma (Figure 2). CAFs play key roles in all cancerous stages, the vast majority of the studies demonstrating protumoral functions that include extracellular matrix remodeling, angiogenesis, immune suppression and drug resistance (Kalluri, 2016; Tao et al., 2017; Ziani et al., 2018).

The current knowledge on CAF biology in BC is scarce and mostly coming from in vitro experiments. Nonetheless, it has been shown that there is a positive correlation between the presence of active CAFs and expression of EMT markers and worse prognosis in BC patients (Schulte et al., 2012; Wu et al., 2017). In vitro, BC cells can induce differentiation of healthy fibroblast into CAFs via exosomes (Ringuette Goulet et al., 2018; De Palma et al., 2019; Goulet et al., 2019) and other not fully characterized secreted factors (Wang et al., 2007; Grimm et al., 2015; Shi et al., 2015; Yeh et al., 2015). As a result, differentiated CAFs induce motility and migration in cancer cells via induction of EMT through secretion of a number of soluble factors which include TGF- $\beta 1$ (Zhuang et al., 2015; Wu et al., 2017), IL-6 (Yeh et al., 2015; Goulet et al., 2019), and hepatocyte growth factor (HGF) (Wang et al., 2007; Grimm et al., 2015), and/or by direct chemokine attraction through CXCL1 (Shi et al., 2015) and CCL1 (Yeh et al., 2015).

Studies using global methylation analysis have shown that epigenetic modification plays a fundamental role in fibroblast activation and CAF differentiation ( $\mathrm{Hu}$ et al., 2005; Jiang et al., 2008; Bechtel et al., 2010; Lamprecht et al., 2018). Indeed, an overall hypomethylated status was found in human CAFs (Jiang et al., 2008; Eckert et al., 2019) (Figure 2), as well as in functionally related fibrotic fibroblasts (Komatsu et al., 2012). Nevertheless, certain key genes appear hypermethylated in CAFs such as Tgfbr2 (Banerjee et al., 2014), RASAL1 and others (Bechtel et al., 2010; Zeisberg and Zeisberg, 2013; Mishra et al., 2018). Seminal work by Cedric Gaggioli’s group demonstrated that tumor-derived LIF induces activation of DNMT3b and p300-HAT in CAFs, which sustain JAK1/STAT3 signaling, necessary to maintain a pro-invasive activity (Albrengues et al., 2015). More recently, the nicotinamide N-methyltransferase has been shown as fundamental for CAF's protumoral behavior in vitro and in vivo, directly affecting DNA and histone methylation (Eckert et al., 2019). CAF differentiation and activity in vivo can be blocked by treating with the DNMT inhibitor 5'-Aza-2'deoxycytidine (Albrengues et al., 2015; Eckert et al., 2019), acting specifically in pancreatic CAFs compared to normal fibroblasts (Yu et al., 2012). Relevant results when DNMT inhibitors are considered for therapy, which will be further discussed below.

Interestingly, the RasGTP RASAL3, negative regulator of the Ras signaling pathway, was also found hypermethylated in prostate cancer (PCa) CAFs (Mishra et al., 2018), increasing Ras signaling in these cells, which drives support of tumor growth and neuroendocrine differentiation. Noteworthy, switch in CAFs towards a Warburg metabolism has been implicated in tumor immune evasion in PCa (Comito et al., 2019), which adds further clinical relevance of epigenetic-mediated changes in CAFs metabolism. Indeed, an in vitro 3D-microfluidoc system has shown that CAFs provide metabolic support to proliferation and invasion of BC cells (Shi et al., 2015). The role of epigenetic modifications in this phenomenon and its relevance in vivo will require further investigation.

Besides DNA methylation, other epigenetic modifications have been observed in the tumor stroma (Li et al., 2015; Du and Che, 2017; Schoepp et al., 2017; Vafaee et al., 2017; Zhao et al., 2017; Kim et al., 2018). In a proof-of-concept study, Zong et al. showed that overexpression of the non-histone chromosomal high-mobility group protein family member Hmga2 in urogenital sinus mesenchymal cells drives tumorigenesis in a model for 
prostatic intraepithelial neoplasia (Zong et al., 2012). In models for pancreatic cancer and in situ skin squamous cell carcinomas, an inhibitor of the BRD and extraterminal domain (BET) family proteins decreases tumor growth affecting specifically CAF's secretome (Yamamoto et al., 2016; Kim et al., 2017). Since targeting histone acetylation has been proposed for combined therapy in BC (Yoon et al., 2011), it would be necessary to characterize the histone acetylation status of stromal cells in BC patients.

Many studies show that miRNAs play fundamental roles in CAF differentiation and function, a subject that has been extensively reviewed (Chou et al., 2013; Kohlhapp et al., 2015; Kuninty et al., 2016; Marks et al., 2016). MiRNAs can be expressed by CAFs or incorporated from other sources, mainly cancer cells via exosomes (Pang et al., 2015). The opposite is also possible, when CAFs modulate cancer cell behavior via transfer of miRNAs (Josson et al., 2015; Shah et al., 2015). In BC, a study compared miRNA expression between fibroblasts from healthy and tumoral human bladder, finding higher expression of miR16 and miR-320 (Enkelmann et al., 2011). Which functions are these miRNAs regulating in CAFs and whether they can be used as surrogate markers for stroma abundance would require further investigations.

\section{Tumor Endothelial Cells}

In solid cancers, increased de novo formation of blood vasculature, known as angiogenesis, is normally observed and provides adequate nourishment for the growing tumor (Figure 2). The link between vasculature density and worse prognosis in BC is well documented (Bochner et al., 1995). Indeed, targeting angiogenesis via disruption of vascular endothelial growth factor (VEGF) signaling is being considered for treating BC in combination with existing therapies (Petrylak et al., 2016; Sonpavde and Bellmunt, 2016).

Tumor endothelial cells (TECs) display a number of characteristics compared to normal endothelium (Hashizume et al., 2000; Hida et al., 2004). In BC, exacerbated proliferation and sprouting of TECs has been linked to staging and lower survival in patients (Roudnicky et al., 2013; Roudnicky et al., 2017). Invasive BC cell lines show increased adhesion to endothelial cells via MUC1 and CD43 binding to ICAM-1, which could be linked to metastatic potential (Laurent et al., 2014; Sundar Rajan et al., 2017). Besides, an in vitro study shows that TECs may promote $\mathrm{BC}$ cell growth through a paracrine loop involving secretion of epidermal growth factor by TECs in response to tumor-derived VEGFs (Huang et al., 2019b). Finally, TECs have been found in MIBC with aberrant expression of a non-anti-angiogenic thrombospondin-2 variant, also responsible for uncontrolled angiogenesis in these tumors (Roudnicky et al., 2018).

It is well known that epigenetic modifications play a role in endothelial cell (ECs) proliferation, differentiation and pathogenesis (Hulshoff et al., 2018; Nagai et al., 2018; Schlereth et al., 2018; Stone et al., 2018; Nicorescu et al., 2019). In fact, recent work by Wang $\mathrm{S}$. and colleagues shows that response to VEGFA, a master regulator of EC biology, strongly relies on epigenetic mechanisms (Wang et al., 2019). Although less explored, several studies have addressed the role of epigenetic modifications in TECs (Marks et al., 2016). Chromatin remodeling inhibitors reduce tumor growth and angiogenesis by acting on both tumor cells (Kim et al., 2001) and ECs (Deroanne et al., 2002; Hellebrekers et al., 2006). More specifically, high expression of EZH2 in ECs is associated with high-stage and grade, and decreased overall survival in epithelial ovarian cancers (Lu et al., 2010). The authors showed that tumor-derived VEGFs induce expression of EZH2 in ECs, which in turn drives hypermethylation of the anti-angiogenic gene, Vash1 (Lu et al., 2010) (Figure 2). Of note, EZH2 expression in ECs is also under control of the vascular endothelial cadherin, which appears reduced in ovarian TECs (Morini et al., 2018). As new anticancer therapies targeting both DNMTs and methylation readers evolve, it is necessary to evaluate their effect in TECs.

Importantly, CAF and TEC biology has a meeting point in what is known as endothelial-to-mesenchymal transition (EndMT) in cancer (Zeisberg et al., 2007). By ChIP-seq, Nagai N. and collaborators found that the transcription factor ERG/FLI1 associates with $\mathrm{H} 3 \mathrm{~K} 27 \mathrm{ac}$ marks at enhancer/promoter regions of various EC-specific genes, inducing expression of miR-126, which represses EndMT genes. Using available data, the authors also found that lower expression of ERG was significantly related to poor prognosis (Nagai et al., 2018).

\section{NEW THERAPIES IN EPIGENETICS}

Epigenetic changes have been suggested as essential for tumor development (Biswas and Rao, 2017). As discussed before, aberrant DNA methylation, histone modifications and chromatin states, as well as aberrant expression of ncRNAs can be used as potential targets by specific drugs and combined with existing therapies. Several molecules targeting epigenetic alterations have been developed and used in different cancers. In the following section, we describe the most recent cancer drugs targeting some epigenetic enzymes. Although in most cases their applications in $\mathrm{BC}$ are still in its very early days, we will focus on how they are currently studied in this context.

\section{Drugs Targeting Writers DNA Methyltransferase Inhibitors}

DNMTs inhibitors (DNTMi) are classified in two major subtypes: nucleoside and non-nucleoside inhibitors. Decitabine (5-aza-2'-deoxycytidine) and Azacytidine (5-azacytidine) are cytosine analogues and the best known nucleoside DNMTi. Decitabine and Azacytidine are currently approved by FDA for the treatment of specific forms of myelodysplastic syndromes, chronic myelomonocytic leukemia and acute myeloid leukemia (Lu et al., 2011; Giagounidis et al., 2014). Regarding BC, in vitro experiments have demonstrated that Decitabine enhances cisplatin susceptibility, suggesting that combination of both drugs could improve clinical responses (Shang et al., 2008; Wu et al., 2019b). Moreover, Decitabine has completed phase II trials for treatment of $\mathrm{BC}$ and phase I trials in combination with tetrahydrouridine (Shang et al., 2008; Bertino and Otterson, 2011). 
Second generation nucleoside DNMTi, such as Guadecitabine (SGI-110) or 4'-thio-2'- deoxycytidine, have been developed in order to reduce high toxicity without reducing the therapeutic dose needed. Clinical trials for 4'-thio-2'- deoxycytidine are currently recruiting patients for the treatment of advanced solid tumors (NCT03366116). On the other hand, SGI-110 is in clinical stage for various cancers such as acute myeloid leukemia and myeloidDdysplastic syndrome (NCT03603964), and for different solid tumors like advanced hepatocellular carcinomas (NCT01752933). Also, it has been tested in combination with other therapies such as Ipilimumab in metastatic melanoma (NCT02608437) or with carboplatin in ovarian cancer (NCT01696032), among others. As immune checkpoint inhibitors are currently used in BC, their combination with these second generation DNMTi could represent an attractive scenario to improve the therapeutic response or to expand the number of patients that benfit from immunotherapy. Some others like SGI-1027, a quinoline derivative, and Nanaomycin A, a quinone antibiotic, which are reported to inhibit all three DNMTs or only DNMT3a, respectively, are in preclinical stages for colorectal cancer (Datta et al., 2009; Kuck et al., 2010) (Figure 3 and Table 1).

Apart from these inhibitors, various non-nucleoside DNMTi have been developed and suggested to minimize the direct effect on DNA (Villar-garea et al., 2003). Non-nucleoside analogues, such as Procainamide and MG98, inhibit methylation by binding to the CpG regions of DNA and blocking the activity of DNMTs. MG98, for example, was tested against metastatic renal cell carcinoma but the clinical trial was stopped due to its toxicity (Winquist et al., 2006). However, it has also been evaluated in combination with interferon and results are promising at a specific dose (Amato et al., 2012). Moreover, MG98 was tested in $\mathrm{BC}$ patients but the researchers did not find response to the treatment (Plummer et al., 2009).

\section{Histone Lysine Methyltransferase Inhibitors}

As it was previously described in this review, HMTs such as G9a and $\mathrm{EZH} 2$ are considered oncogenic epigenetic factors in BC (Cho et al., 2015). One of the first histone lysine methyltransferase inhibitors (HKMTi), specific against G9a (EHMT2), was BIX-01294 (Kubicek et al., 2007), which has been shown to inhibit cell proliferation in BC cell lines and induce apoptosis in neuroblastoma cells (Cui et al., 2015). Since then, numerous and improved inhibitors related to G9a blocking have been developed. Various studies have been carried out in molecules like A-366, BRD4770 or UNC0638, in different types of cancer such as neuroblastoma, breast or leukemias (Vedadi et al., 2012; Yuan et al., 2012; Pappano et al., 2015).

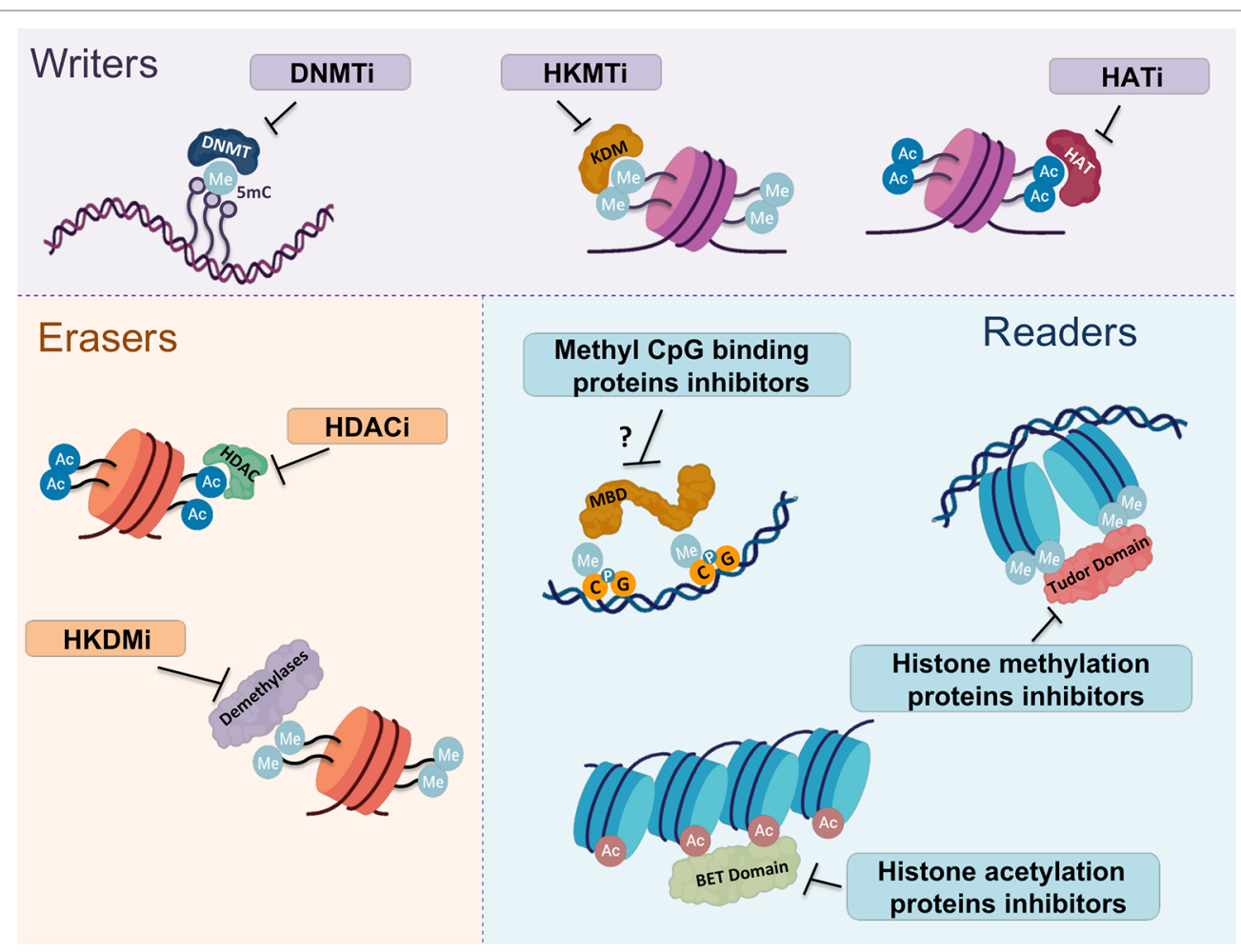

FIGURE 3 | Most representative epigenetic inhibitors targeting writers, readers and erasers. Epigenetic alterations are considered to be reversible and, therefore, all these molecules are subject of study as promising therapeutic targets for cancer treatment. Three main groups of epigenetic drugs can be distinguished according to their targets. The group of compounds targeting epigenetic writers consists mainly of DNMT, HKMT and HAT inhibitors. The second group is directed against epigenetic erasers, which includes HDAC and HKDM inhibitors. Finally, inhibitors of methyl CpG binding proteins, histone methylation and acetylation proteins form the third group targeting epigenetic readers. DNMTi, methyltranferases of DNA inhibitor; HKMTi, histone lysine methyltransferase inhibitor; HATi, histone acetyltransferase inhibitor; HDACi, histone deacetylase inhibitor; HKDMi, histone lysine demethylase inhibitor. 
TABLE 1 | A representation of experimental epigenetic drugs targeting writers, readers and erasers.

Drugs Targeting Epigenetic Writers

\begin{tabular}{|c|c|c|c|c|}
\hline Category & Compound Name & Development Stage & Cancer Type & References \\
\hline \multicolumn{5}{|c|}{ DNA Methyltransferase inhibitors (DNMTi) } \\
\hline \multirow[t]{3}{*}{ Nucleoside analogue } & Decitabine & Approved & MDS & $\begin{array}{l}\text { Giagounidis et al., 2014; Lu } \\
\text { et al., } 2011\end{array}$ \\
\hline & Azacytidine & Approved & MDS & $\begin{array}{l}\text { Giagounidis et al., 2014; Lu } \\
\text { et al., } 2011\end{array}$ \\
\hline & Guadecitabine & Clinical & MDS, AML & NCT03603964 \\
\hline \multirow[t]{3}{*}{ Non-nucleoside analogue } & MG98 & Clinical & MRCC & Winquist et al., 2006 \\
\hline & SGl-1027 & Preclinical & Colorectal & Datta et al., 2009 \\
\hline & Nanaomycin A & Preclinical & Colorectal & Kuck et al., 2010 \\
\hline \multicolumn{5}{|c|}{ Histone Lysine Methyltransferase inhibitors (HKMTi) } \\
\hline \multirow[t]{3}{*}{ G9a } & A-366 & Preclinical & Neuroblastoma & Pappano et al., 2015 \\
\hline & BRD4770 & Preclinical & Breast & Vedadi et al., 2012 \\
\hline & UNC0638 & Preclinical & Leukemia & Yuan et al., 2012 \\
\hline \multirow[t]{4}{*}{$\mathrm{EZH} 2$} & UNC1999 & Preclinical & Large B-cell lymphoma & Konze et al., 2014 \\
\hline & GSK343 & Preclinical & Glioblastoma & Yu et al., 2017 \\
\hline & GSK126 & Clinical & Large B-cell lymphomas & NCT02082977 \\
\hline & EPZ6438 & Clinical & B-cell Lymphomas & NCT03010982 \\
\hline \multicolumn{5}{|c|}{ Histone Acetyltransferase inhibitors (HATi) } \\
\hline \multirow[t]{2}{*}{ p300 } & C646 & Preclinical & Gastric & Gajer et al., 2015 \\
\hline & PU141 & Preclinical & Neuroblastoma & Wang et al., 2017 \\
\hline \multicolumn{5}{|c|}{ Drugs Targeting Epigenetic Readers } \\
\hline \multicolumn{5}{|l|}{ Histone Methylation Proteins } \\
\hline PHD Finger Domain (JARID1A) & Amiodarone & Preclinical & AML & Wagner et al., 2012 \\
\hline MBT Domain & UNC926 & Preclinical & Target domain inhibition & Herold et al., 2012 \\
\hline Chromodomain (CBX7) & MS37452 & Preclinical & Target domain inhibition & Ren et al., 2015 \\
\hline \multicolumn{5}{|l|}{ Histone Acetylation Proteins } \\
\hline \multirow[t]{2}{*}{ Bet Bromodomain } & $(+)-J Q 1$ & Preclinical & Colorectal & Zhang et al., 2018b \\
\hline & OTX015 & Clinical & Advanced Solid tumors & NCT02698176 \\
\hline \multicolumn{5}{|c|}{ Drugs Targeting Epigenetic Erasers } \\
\hline \multicolumn{5}{|c|}{ Histone Lysine demethylase inhibitors (HKDMi) } \\
\hline \multirow[t]{2}{*}{ LSD1 Inhibitors } & Pargyline & Preclinical & Target domain inhibition & Yang et al., 2018b \\
\hline & $\mathrm{HCl}-2509$ & Preclinical & Neuroblastoma & Gupta et al., 2018 \\
\hline JmjC Domain inhibitors & $\mathrm{IOX} 1$ & Preclinical & Target domain inhibition & Hopkinson et al., 2013 \\
\hline \multicolumn{5}{|c|}{ Histone Deacetylase inhibitors (HDACi) } \\
\hline \multirow[t]{4}{*}{ Hydroxamic Acid Derivates } & Vorinostat & Approved & CTCL & Mann et al., 2007 \\
\hline & Panobinostat & Approved & Blood neoplasias & Eckschlager et al., 2017 \\
\hline & Reminostat & Clinical & Hodgkin's lymphoma & NCT01037478 \\
\hline & Quisinostat & Clinical & Ovarian cancer & NCT02948075 \\
\hline
\end{tabular}

MDS, Myelodysplastic syndromes; MRCC, Metastasic renal cell carcinoma; AML, Acute Myeloid Leukaemia; CTCL, Cutaneous T cell-lymphoma.

Recently, CM272 was described as a novel G9a/DNMT1 dual inhibitor with remarkable antitumor effect in BC in vitro and in vivo (José-Enériz et al., 2017; Segovia et al., 2019). On the same line, the catalytic subunits of PRC2, EZH1 and EZH2, which catalyze the methylation of H3K27, have been well described in cancer. Some inhibitors of this complex have been studied and they are classified into three groups: (i) pyridoneindazole scaffold like UNC1999 or GSK343 (Konze et al., 2014; Yu et al., 2017) which has been demonstrated to inhibit BC cell lines growth and metastasis (Chen et al., 2019), (ii) pyridone-indole scaffold such as GSK126 (NCT02082977) and (iii) pyridone-phenyl scaffold including EPZ6438 (Brach et al., 2017), known also as Tazemetostat, which has achieved phase I/ II trial (NCT03854474) for the treatment of patients with locally advanced or metastatic urothelial carcinoma in combination with pembrolizumab. The potential use of EZH2 in the BC context has been recently reviewed and discussed (MartínezFernández et al., 2015c; Segovia and Paramio, 2017).

\section{Histone Acetyltransferase Inhibitors}

HATs are typically grouped into three broad families, namely the p300/CBP, the Gcn5 related N-acetyl-transferase and the MYST family. Among them, p300/CBP seems to be frequently mutated in BC (Duex et al., 2018a) and was reported to be associated with doxorubicin resistance (Takeuchi et al., 2012), so it could be a promising molecular therapeutic target for this disease. Accordingly, C646 and PU141 have been demonstrated to be promising in gastric cancer and neuroblastoma, respectively (Gajer et al., 2015; Wang et al., 2017). However, there is very little evidence for useful histone acetyltransferase inhibitors (HATi) being developed and tested (Baell and Miao, 2016), even though the search for new small-molecule HATi has been intense in the last decades (Figure 3). Although, to our knowledge no HATi are being tested in $\mathrm{BC}$, it is important to consider that HAT gene deficiencies may confer susceptibilities to other inhibitors, opening new possible therapeutic approaches for various tumors, including BC (Ogiwara et al., 2016). 


\section{Drugs Targeting Readers Methyl CpG Binding Proteins}

Sites of DNA methylation recruit two important protein families: MBD and ZnF proteins. The MBD protein family uses its DNA binding domains and other protein-protein domains to alter the transcriptional state of the DNA (Ginder and Williams, 2018). However, the MBD family is not the only protein family that allows the recognition of methylated DNA; for example, the Kaiso protein family (Kaiso/ZBTB33, ZBTB4 and ZBTB38) uses a three-finger zinc motif to bind methylated CGCG (Hendrich and Bird, 2015). Additionally, it has been demonstrated that ZBTB38 promotes cell migration, invasive growth and EMT in BC cell lines (Jing et al., 2018), whereas high MBD2 expression was significantly associated with reduced bladder carcinoma risk (Zhu et al., 2004). Even though different experimental approaches have identified these proteins as good therapeutic targets, inhibitors have not yet been developed to slow down their action (Figure 3).

\section{Histone Methylation Proteins}

The histone methyl protein family is a large family of proteins that binds differently to methylated lysine and arginine residues and can be divided into several subfamilies: Tudor domain, PHD finger, MBT, chromodomain and BRD. The most studied family among them is the PHD family, which comprises a group of versatile readers of the epigenome that can recognize both methylation and acetylation marks and has been involved in cancer progression (Hayami et al., 2010). Recently, Wagner et al. discovered various compounds that inhibit the PHD of this protein (Wagner et al., 2012). Among them, Amiodarone is able to induce apoptosis in the T24 BC cell line (Bognar et al., 2017). Upregulated UHRF1 (E3 ubiquitin-protein ligase 1), which contains PHDs, has also been shown to promote BC cell invasion in vitro and in vivo by epigenetic silencing of KiSS1 (Zhang et al., 2014).

\section{Histone Acetylation Proteins}

In general, histone acetylation is related to transcriptional activation. Different protein domains that bind specifically to acetylated histones have been identified so far, including the BRD, double PHD finger and Yeats domains. The BRD family identifies acetylated lysine residues, such as those on the $N$-terminal tails of histones, and has been proposed as an attractive therapeutic target due to its involvement in various cancer types. The BET family has been thoroughly investigated (Biswas and Rao, 2018). The first inhibitors of the BET family, I-BET762 (GSK525762) and (+)-JQ1, were reported in 2010 (Filippakopoulos et al., 2010). The inhibitor I-BET762 has recently been studied for dose escalation clinical studies to investigate the safety, pharmacokinetics, pharmacodynamics, and clinical activity in various tumors (NCT01587703), but BC patients were not included in this study. (+)-JQ1 interferes with BRD4 function, blocking the formation of the NUT-BRD4 oncoprotein, and various studies have shown its efficacy in hematological and solid malignancies (Abedin et al., 2016; Ocaña et al., 2017; Gao et al., 2018; Sakaguchi et al., 2018; Tan et al., 2018; Zhang et al., 2018b).
Regarding BC, the (+)-JQ1 inhibitor induces autophagy through activation of the LKB1/AMPK pathway, contributing to the inhibition of proliferation of $\mathrm{BC}$ cell lines in vitro (Li et al., 2019). In combination with Mitomicyn C, (+)-JQ1 enhances cell death, which offers the possibility of a dose reduction of the chemotherapeutic agent (Simm et al., 2018). Hölscher et al. had also shown significant synergistic effects on the induction of apoptosis in urothelial cancer cells by treatment with (+)-JQ1 and Romidepsin, an HDAC inhibitor (HDACi), thus suggesting a promising new combination therapy approach for urothelial cancer (Hölscher et al., 2018).

Even though BRD3 inhibitors have not been studied as much as those of the BRD2/4, it has been observed that I-BET151, a pan-BET inhibitor that targets BRD3 (Picaud et al., 2013), halts the progression of the cell cycle and decreases cell proliferation in vitro and in vivo by targeting lncRNA HOTAIR in glioblastoma (Pastori et al., 2014). Remarkably, HOTAIR increased expression is also associated with poor clinical outcome in BC (MartínezFernández et al., 2015b), thereby indicating the possible relevance of studying I-BET151 inhibitor in this type of cancer.

\section{Drugs Targeting Erasers}

Epigenetic marks can be 'erased', depending on the requirement of the cell, by a group of enzymes that oppose to the writers. Since they also modulate gene expression affecting tumor suppressor genes or oncogenes, they can be considered potential targets.

\section{Histone Lysine Demethylase Inhibitors}

Researchers have been exploring inhibitory molecules for the HKDMs KDM1 (LSD1) and KDM2-8 for years (Højfeldt et al., 2013). Early compounds were developed based on the structural characteristics of LSD1 (Yang et al., 2018b). Treatment with LSD1 inhibitor supressed BC cell proliferation and androgeninduced transcription, supporting a novel role for the androgen receptor-KDM (lysine demethylases) complex in BC initiation and progression (Kauffman et al., 2012). Even though numerous LSD1 inhibitors have been reported in the literature, they are in the initial phase of development and there are still many problems that have to be overcome before histone lysine demethylase inhibitors (HKDMi) can reach the clinic (Figure 3).

\section{Histone Deacetylase Inhibitors}

Various reports have shown that HDACs could be involved in regulating protein function and tumorigenesis. In this line, the use of HDACi has been clinically validated in cancer treatment and, so far, four drugs have been approved by the FDA: Vorinostat, Romidepsin, Panobinostat and Belinostat (Figure 3). Vorinostat was the first pan-HDACi approved by the FDA for the treatment of advanced primary cutaneous T-cell lymphoma (Mann et al., 2007). Next, various pharmaceutical companies developed other molecules such as Panobinostat or Belinostat (Eckschlager et al., 2017), all of them intended initially for blood neoplasias.

Moreover, HDACi are being studied for BC therapy (Kaletsch et al., 2018). Romidepsin and Vorinostat have been tested in a phase II trial as monotherapy, and Vorinostat has also completed phase I trials as a combination therapy with docetaxel, but it 
was surprisingly toxic and had limited efficacy (Cheung et al., 2008). Additionally, Belinostat has obtained positive responses in $\mathrm{BC}$ cells through decreasing cell proliferation in vitro and in vivo (Buckley et al., 2007) and is being tested in clinical trials against various solid tumors including BC (NCT00413322, NCT00413075).

Apart from the hydroxamic acid derivates, which are approved for the clinic, other molecules are in different phases of study. Some of them are Reminostat (4SC-201) evaluated for Hodgkin's lymphoma (NCT01037478), Quisinostat (JNJ-26481585) for the treatment of ovarian cancer (NCT02948075), or Abexinostat (PCI-24781) which is being evaluated for sarcoma in combination with Doxorubicin (NCT01027910). Table 1 summarizes HDACi approved and some experimental HDACi in different stages of clinical development.

Epigenetic drugs, as seen previously, have been approved as monotherapy for the treatment of different types of cancer. In addition, the combination of epigenetic drugs with standard chemotherapy or immunotherapy has been explored in recent years with promising results. The basis for this approach comes from results showing that epigenetic drugs reduce the apoptotic threshold, reverse drug resistance and/or induce immune response. Regarding BC, a large proportion of patients are not candidates to chemotherapy due to comorbidities. The use of epigenetic drugs could bring the possibility of a dose reduction, which makes these compounds attractive candidates for combination therapy for these BC patients (Witjes et al., 2014b; Fardi et al., 2018).

\section{Drugs Targeting ncRNAs LncRNAs}

Even though no lncRNA-based targeted BC treatment has been developed so far, modulation of lncRNA expression as a therapy seems promising and has already been described for other cancer types (Bhan et al., 2017). Methods described for the modulation of lncRNA expression include the use of antisense oligonucleotide (ASO) or lncRNA-specific siRNAs for transcript destabilization or degradation, as well as transcript alteration by modulation of lncRNA-encoded promotor activity. Additionally, functional disruption of lncRNAs through aptamers antagonizing the interaction with their binding partners, or the production of synthetic molecules interfering with the association between lncRNAs and regulatory factors, are possible mechanisms to modulate lncRNA expression (Bhan et al., 2017). Finally, these ncRNAs might be valuable in combination therapy and augmentation of therapeutic efficacy since modulation of their expression can enhance the therapeutic sensitivity of tumors (Bhan et al., 2017).

\section{MiRNAs}

There are many approaches that have been employed to silence miRNAs in cancer. These include anti-miRNA oligonucleotides (AMOs), miRNA-masking antisense oligonucleotides, peptide nucleic acids and miRNA sponges (Garzon et al., 2010). AMOs mechanism relies on the complementary base pairing of the oligonucleotide sequence to its target miRNA. Therefore, these molecules can repress cellular mRNAs involved in tumor progression and proliferation, and they can also act as competitive inhibitors of miRNAs and impair their interaction with other molecules (Lima et al., 2018b). Joana Filipa and colleagues showed that, using AMOs, they were able to silence the expression of upregulated miR-9 in a cancer cell model of gastric cancer (Lima et al., 2018a).

For BC treatment, there are some indirect therapeutic approaches that affect miRNA expression. For instance, some EZH2 inhibitors act in BC cells modulating the expression of miR101 (Wang et al., 2014) or miR-143 (Zhang et al., 2015). However, some of these miRNAs are also induced by specific oncogenic insults in BC, indicating the potential problems of considering them as possible targets for treatment (Segovia et al., 2017).

Remarkably, a miRNA-based drug mimicking miR-34a has reached a phase I clinical trial (NCT01829971). MiRNA$34 \mathrm{a}$ significance in various human cancers, including $\mathrm{BC}$, is increasingly recognized nowadays (Bader, 2012; Misso et al., 2014), hence the expectation in this new approach.

\section{Other nCRNAs}

CircRNAs and piRNAs have been described as a promising therapeutic target in multiple cancer types, including BC (see corresponding section). Potential strategies for the modulation of circRNA expression include the use of ASOs or siRNAs in order to antagonize these ncRNAs, as well as the application of the CRISPR/Cas system to partially or completely remove oncogenic circRNAs (Zhang and Xin, 2018). Regarding the modulation of piRNA expression, possible strategies include the use of synthetic piRNAs at the transcriptional and posttranscriptional level, while antibodies against PIWI proteins might be effective as a posttranscriptional approach (Assumpção et al., 2015). Nonetheless, none of these approaches are being tested in BC therapy so far.

\section{EPIGENETIC ALTERATIONS AS BIOMARKERS IN BC: THE POTENTIAL USE OF LIQUID BIOPSY}

Regarding diagnosis and surveillance of $\mathrm{BC}$, a combination of cystoscopy and urine cytology is the most widely used methodology nowadays. Currently, cystoscopy is the gold standard method in clinical practice for detection and follow-up of this disease, with a sensitivity of $85-90 \%$ to detect exophytic tumors. However, this technique is highly invasive, showing a big inter-observer and intra-observer variation. On the other hand, BC urinary cytology shows a specificity of approximately $98 \%$ but a low sensitivity of $38 \%$. The high rates of recurrence and progression of $\mathrm{BC}$ require continuous follow-up of patients by cystoscopy (every 3-6 months during the next 5 years) and urine cytology, making $\mathrm{BC}$ one of the most costly malignancies for the National Health systems of developed countries (Lodewijk et al., 2018).

For these reasons, there is a clear need to improve the current systems of diagnosis, prognosis and surveillance of BC patients. Based on the important role of epigenetic modifications in this disease, status evaluation of the involved molecules could 
contribute to improve these available systems. In this context, liquid biopsy has emerged as a non-invasive way to determine the genomic landscape of cancer patients, as well as to monitor treatment response, quantify minimal residual disease, and assess therapy resistance (Bardelli and Pantel, 2017; Di Meo et al., 2017; Heitzer et al., 2017; Khetrapal et al., 2018). Liquid biopsy makes reference to the sampling and assessment of biological fluids. In genitourinary cancer, due to the proximity of tumors, urine has been considered a bona fide liquid biopsy sample, being one of the most interesting samples for its easy access and collection. However, in MIBC patients after cystectomy, serum and plasma could be the most appropriate liquid biopsy samples given its invasive and metastatic character (Lodewijk et al., 2018). Currently, there are several systems to detect and follow-up BC using liquid biopsy biomarkers (including sediment cells in urine samples, CTCs in blood samples as well as RNAs and proteins in both cases), which present sensitivity and specificity values within a range of $38-98 \%$ and $65-98 \%$, respectively (Lodewijk et al., 2018). The determination of epigenetic alterations in liquid biopsy samples, such as variation in expression levels of ncRNAs or changes in DNA methylation profiles, could improve the predictive values of the current systems of $\mathrm{BC}$ diagnosis, prognosis and monitoring. Next, some of the most relevant studies of epigenetic biomarkers in urine and serum/plasma samples are discussed.

\section{Non-Coding RNAs as Epigenetic Biomarkers in Liquid Biopsy of BC Patients}

Among the different ncRNAs previously described, miRNAs have been the most widely studied molecules in liquid biopsies so far. MiRNA molecules have several characteristics which make them potential candidates as good biomarkers in liquid biopsy samples: i) they show very homogeneous expression levels among individuals and specific expression profiles in different types of tissue (Liang et al., 2007); ii) they are included in a protein complex and, usually, in exosomes, which confers them high stability, preserving their integrity and preventing their degradation (Weber et al., 2010; Ge et al., 2014; MartínezFernández et al., 2016); iii) there are several systems designed to determinate ncRNA expression using RT-qPCR, which allow evaluating a large number of miRNAs from very small amounts of total RNA and at a low cost.

Given the potential of miRNAs, many studies have evaluated their predictive properties, individually or in combination, in the urine of $\mathrm{BC}$ patients. In this context, high expression levels of miR-146a-5p and miR-106b have been related with invasion and high grade and stage BC (Zhou et al., 2014; Sasaki et al., 2016). NMIBC patients present high levels of miR-214 in urine samples and, curiously, expression of this miRNA was inversely correlated with risk of recurrence of BC patients (Kim et al., 2013). Besides, some miRNAs such as miR-92a-3p and miR-140-5p have been associated with progression after recurrence (Ingelmo-Torres et al., 2017). Yun and collaborators have demonstrated that urine miR-145 expression levels decrease in BC patients with respect to healthy controls, both in non-invasive and invasive tumors $(77.8 \%$ and $84.1 \%$ sensitivity, respectively, and $61.1 \%$ specificity in both cases). They observed an association between downregulation of miR-200a and high risk of recurrence in patients with invasive tumors (Yun et al., 2012). Besides, miR-155 has proved to be a good biomarker in urine samples, distinguishing non-invasive tumors, inflammation and healthy controls with a sensitivity of $80.2 \%$ and a specificity of $84.6 \%$ (Zhang et al., 2016).

As previously mentioned, detection of miRNA deregulation in serum or plasma may have special relevance in invasive and metastatic tumors. Yang and colleagues observed miR-210 increased expression levels in serum samples of BC patients, being associated with tumor stage, grade, and useful to predict tumor progression (AUC $=0.898$ ) (Yang et al., 2015). Moreover, some studies using plasma have found a positive correlation between upregulation of miR-19a and miR-200b with tumor grade and stage respectively, whereas miR-92 and miR-33 presented inverse association with tumor stage (Adam et al., 2013; Feng et al., 2014).

In recent years, several panels of miRNAs (encompassing profiles from 6 to 25 miRNAs) have been developed in both urine and serum for $\mathrm{BC}$ diagnosis, prognosis and monitoring of recurrence. In this context, we have recently gathered some of the main miRNA profiles in BC liquid biopsies which can be consulted in Table 2 at Lodewijk et al. (2018).

Although variation in lncRNA expression levels has not been studied as widely as miRNAs in liquid biopsy samples, altered levels of expression of these molecules have been found in urine and blood samples of BC patients. Increased expression levels of UCA1 in urine samples has been associated with the presence of high-grade NMIBC, and an integrative meta-analysis including more than $500 \mathrm{BC}$ patients and healthy donors determined that its upregulation may predict BC (81\% sensitivity and $86 \%$ specificity, AUC = 0.88) (Wang et al., 2006; Cui et al., 2017). In addition, other lncRNAs such as HOTAIR, MALAT1, HOX-AS-2, OTX2-AS1, HYMAI, LINC00477 and LOC100506688, have shown upregulation in urine exosomes of MIBC patients (Berrondo et al., 2016). In addition, H19 gene expression is significantly higher in BC patients, and its presence has been detected in the urine of $90.5 \%$ of patients versus $25.9 \%$ of healthy controls (AUC $=0.933$ ) (Gielchinsky et al., 2017).

Additionally, other ncRNAs such as piRNAs and circRNA have been evaluated in biofluids. Both molecules have shown a particular resistance to degradation by exoribonuclease, making them ideal candidates for biomarker development (Pardini and Naccarati, 2017; Vo et al., 2019). Several studies have reported that piRNAs are widely detected in liquid biopsy samples, being especially abundant in urine samples and, therefore, good candidates as new biomarkers for BC. Although no deregulated piRNAs have been found in urine or blood of $\mathrm{BC}$ patients so far, expression level alterations of some of these molecules have been shown in liquid biopsy samples of other tumor types (Freedman et al., 2016; Iliev et al., 2016; Yuan et al., 2016; Pardini and Naccarati, 2017). Regarding circRNA, Vo and collaborators have recently developed MiOncoCirc, a technology based on exome capture RNA-seq, which stands as the first cancer-focused circRNA resource to facilitate the study of circRNAs as new biological markers of cancer (Vo et al., 2019). They were able to 
identify candidate circRNAs which could serve as biomarkers for prostate cancer, detecting circRNAs in urine (Vo et al., 2019). This technology could open new possibilities to find new biomarkers with predictive values in liquid biopsy samples of BC patients. Nevertheless, even though circRNAs show great potential as valuable biomarker in urine, these RNAs seem to be highly susceptible to circulating RNA endonucleases showing a half-life of only 15 seconds in human serum, which limits their use as a biomarker in this biological fluid (Jeck and Sharpless, 2014).

\section{DNA Methylation Profiles as Epigenetic Biomarkers in Liquid Biopsy of BC Patients.}

As mentioned above, changes in methylation are chemically stable and have been broadly reported in BC. Therefore, they are an interesting source of candidate biomarkers to be detected in biofluids including both blood and urine. Currently, there are multiple methods for detecting changes in methylation comprising global genome methylation and specific genes of interest assays. The majority of methods to evaluate specific genes are based on bisulfite conversion followed by PCR and sequencing, pyrosequencing or methylation-specific PCR, among others, which generally show a high sensitivity and specificity and low assay-to-assay variability (Kurdyukov and Bullock, 2016). Already in 2002, Valenzuela and collaborators found that methylation in $p 16(\mathrm{lNK} 4 a)$ promoter in serum could be useful as diagnostic biomarker with $22 \%$ of sensitivity, $95 \%$ of specificity and a positive predictive value of 0.98 (Valenzuela et al., 2002). Also in serum, both the methylation in promoters of protocadherin 17 (PCDH17) and protocadherin-10 (PCDH10) showed an association with BC poor prognosis (Lin et al., 2012; Luo et al., 2014). A slight association between hypermethylation in $p 16(l N K 4 a)$ and $D A P K$ promoter regions and NMIBC has been also described (Jabłonowski et al., 2011). Finally, the presence of hypermethylated DNA in APC, GSTP1 or TIG1 in the serum of $\mathrm{BC}$ patients was associated with a worse outcome showing $80 \%$ sensitivity and $93 \%$ specificity for BC detection (Ellinger et al., 2015).

Important for BC, alterations in DNA methylation can be also assessed both in circulating cell-free DNA and in cells shed into urine. In general, it seems that a prevalence of hypermethylated genes is found in urine from BC patients. For instance, the evaluation of methylation in TWIST1 and NID2 in urine sediment has shown 90\% sensitivity and 93\% specificity (Renard et al., 2010; Fantony et al., 2017; van der Heijden et al., 2018). Other studies showed promising results using methylation of CFTR, SALL3 and TWIST1 genes in urine cell pellets in combination with cytology (van der Heijden et al., 2018). Interestingly, SOX-1, IRAK3, and Li-MET genes methylation status has showed better recurrence predictivity than urine cytology and cystoscopy (80 vs. 35 vs. $15 \%$ ) (Su et al., 2014). Also in urine sediments, methylation in $p 14 A R F, p 16 I N K 4 A, R A S S F 1 A, D A P K$, and APC showed a correlation with $\mathrm{BC}$ grade and stage (Pietrusiński et al., 2017). Guo et al. used the methylation status for VIM, RASSF1A, GDF15, and TMEFF2 to identify BC with $82 \%$ sensitivity and $53 \%$ specificity (Li et al., 2018b). RBBP8 has been identified as almost exclusively hypermethylated in BC (Mijnes et al., 2018), while Chen et al. showed $\mathrm{CDH} 13$ methylation as a biomarker with prognostic value for $\mathrm{BC}$ screening in urine samples (Ren et al., 2016). Using quantitative methylation-specific PCR, a novel two-gene panel with high accuracy in an urine-based test has just been described (Bosschieter et al., 2019). When stratifying in low- or high-risk NMIBC patients, $97.6 \%$ sensitivity and $84.8 \%$ specificity were obtained using promoter hypermethylation of HS3ST2, SEPTIN9 and SLIT2 genes in combination with FGFR3 mutation (Roperch et al., 2016). Interestingly, Patchsung et al. obtained a sensitivity and specificity of $96 \%$ for BC screening using a combination of the urinary hypomethylated LINE-1 loci and the plasma protein carbonyl content (Patchsung et al., 2012). But methylation value has not only been studied in genes and their promoters: for example, last year Shindo et al. reported a study using the methylation of four miRNAs (miR-9-3, miR-1242, miR-124-3, and miR-137) in voided urine samples, finding an association with recurrence and radical cystectomy (Kitajima et al., 2017).

As a consequence of these new results, there are currently several clinical trials using promising urine-based tests. Among them, Bladder EpiCheck ${ }^{\text {Trm }}$ (based on the use of methylationsensitive restriction enzymes followed by RT-PCR) includes a panel of 15 DNA methylation patterns for the identification of recurrent $\mathrm{BC}$ from urine samples. First validation results with data from 357 patients showed $88 \%$ specificity and a negative predictive value (NPV) of $94.4 \%$ for the detection of any cancer, and a NPV of $99.3 \%$ for the detection of high-grade cancer (D’Andrea et al., 2019). Another test is AssureMDx, which uses methylation of OTX1, ONECUT2 and TWIST1 in addition to mutational load of FGFR3, TERT and HRAS in cell pellets from urine samples, showing a sensitivity of $93-97 \%$ and a specificity around $81.7-86 \%$ (van Kessel et al., 2017). Finally, Uromark was described 2 years ago as a targeted bisulfite nextgeneration sequencing assay based on $150 \mathrm{CpG}$ loci to diagnose BC from urine with a sensitivity of $98 \%$, specificity of $97 \%$ and NPV of $97 \%$ for the detection of primary BC (Feber et al., 2017). Following these results, DETECT I and DETECT II are two multi-centre prospective observational studies designed to conduct a robust validation of the UroMark assay. DETECT I will recruit patients having diagnostic investigations for haematuria, while DETECT II will recruit patients with new or recurrent $\mathrm{BC}$ to determine respectively the NPV and the sensitivity of UroMark.

As a conclusion, although validation studies are still ongoing, the recent and promising results prompt us to be optimistic and have confidence in a near clinical implementation of a urine methylation test for $\mathrm{BC}$ diagnosis and prognosis.

\section{FUTURE PROSPECTS}

It is clear that epigenetics has reshaped most of our concepts of biology and, undoubtedly, molecular biology understanding of human pathologies. From the point of view of those researchers interested in BC, or even in cancer in general, it is almost impossible to predict what the future will bring us in this field, 
but there are two clear emerging facets at our hands. On the one hand, the use of compounds interfering with many epigenetic processes combined with other therapies currently in the clinics and, on the other hand, the use of these therapies directed not only towards the tumor cells, but also the tumor niche. Obviously, from our current knowledge of immunotherapies, there is a faint border between these two concepts.

Epigenetic drugs, as seen in the previous sections, have been approved as monotherapy for the treatment of different types of cancer. Additionally, they have been shown to synergize with other epigenetic substances or anticancer therapies. The first preclinical investigations focused on the combination of DNMTi and HDACi (Cameron et al., 1999). After a while and due to the development of new epigenetic agents directed to other targets such as HMTs, HDMs or BRDs, new synergistic combinations with DNMTi and/or HDACi are being explored. In addition, due to the importance of immunotherapy in cancer, the combination of epigenetic drugs with standard chemotherapy or immunotherapy has also increased in recent years (Dunn and Rao, 2017). This is based on the theory of using epigenetic drugs to reduce the apoptotic threshold, reverse drug resistance or induce immune responses for further treatment such as chemotherapy or immunotherapy. The concept of partnering epigenetic therapy with reshaping stromal component strategies has generated a wave of translational research that highlights the potential for this approach in many different cancer types. Epigenetic drugs such as DMNTi and HDACi can reverse immune suppression, and modulate stromal cells and extracellular matrix via several mechanisms such as enhancing expression of tumor-associated antigens, components of the

\section{REFERENCES}

Abedin, S. M., Boddy, C. S., and Munshi, H. G. (2016). BET inhibitors in the treatment of hematologic malignancies: current insights and future prospects. Oncol. Targets Ther. 9, 5943-5953. doi: 10.2147/OTT.S100515

Adam, L., Wszolek, M. F., Liu, C.-G., Jing, W., Diao, L., Zien, A., et al. (2013). Plasma microRNA profiles for bladder cancer detection. Urol. Oncol. Semin. Orig. Investig. 31, 1701-1708. doi: 10.1016/j.urolonc.2012.06.010

Agger, K., Cloos, P. A. C., Christensen, J., Pasini, D., Rose, S., Rappsilber, J., et al. (2007). UTX and JMJD3 are histone H3K27 demethylases involved in HOX gene regulation and development. Nature 449, 731-734. doi: 10.1038/nature06145

Agundez, M., Grau, L., Palou, J., Algaba, F., Villavicencio, H., and SanchezCarbayo, M. (2011). Evaluation of the Methylation Status of Tumour Suppressor Genes for Predicting Bacillus Calmette-Guérin Response in Patients With T1G3 High-Risk Bladder Tumours. Eur. Urol. 60, 131-140. doi: 10.1016/j.eururo.2011.04.020

Albrengues, J., Bertero, T., Grasset, E., Bonan, S., Maiel, M., Bourget, I., et al. (2015). Epigenetic switch drives the conversion of fibroblasts into proinvasive cancerassociated fibroblasts. Nat. Commun. 6, 10204. doi: 10.1038/ncomms10204

Allis, C. D., Berger, S. L., Cote, J., Dent, S., Jenuwien, T., Kouzarides, T., et al. (2007). New Nomenclature for Chromatin-Modifying Enzymes. Cell 131, 633636. doi: $10.1016 /$ j.cell.2007.10.039

Amato, R. J., Stephenson, J., Hotte, S., Nemunaitis, J., Karl, B., Reid, G., et al., (2012). MG98, a Second-Generation DNMT1 Inhibitor, in the Treatment of Advanced Renal Cell Carcinoma. Cancer Invest. 2, 415-421. doi: 10.3109/07357907.2012.675381.

Anastasiadou, E., Jacob, L. S., and Slack, F. J. (2017). Non-coding RNA networks in cancer. Nat. Rev. Cancer 18, 5-18. doi: 10.1038/nrc.2017.99 antigen processing and presenting machinery pathways, immune checkpoint inhibitors, chemokines, and other immune-related genes, as well as changing the CAFs secretomes that will favor or impede the tumor growth. But deep studies of each component interaction are still in their early days. The discoveries in these areas have established a highly promising basis for studies using combined epigenetic and immunotherapeutic agents as anticancer therapies with expected long lasting antitumor responses.

Finally, new areas of research such as the use of new gene targeting strategies as therapeutic tools or the potential role of epigenetic mechanisms leading to altered glycosylation, which may clearly impact the liquid biopsy and immunotherapy fields (Dall'Olio and Trinchera, 2017), may represent new horizons in $\mathrm{BC}$ management and detection.

\section{AUTHOR CONTRIBUTIONS}

All authors contributed equally to review the current literature and write specific sections. The whole work was coordinated by JP. All the authors agreed with the final version.

\section{FUNDING}

This study was funded by the following: FEDER cofounded MINECO grant SAF2015-66015-R, grant ISCIII-RETIC RD12/0036/0009, PIE $15 / 00076$ and CB/16/00228 to JP. VM is funded by Consejería de investigación e Innovación, Comunidad de Madrid (ref 2018-T2/BMD-10342).

Ariel, I., de Groot, N., and Hochberg, A. (2000). Imprinted H19 gene expression in embryogenesisandhumancancer:theoncofetalconnection.Am.J.Med.Genet.91, 46-50. doi: 10.1002/(sici)1096-8628(20000306)91:1<46::aid-ajmg8>3.0.co;2-i

Assumpção, C. B., Calcagno, D. Q., Araújo, T. M. T., Santos, S. E. B., dos, Santos, Â. K. C. R., dos, Riggins, G. J., et al. (2015). The role of piRNA and its potential clinical implications in cancer. Epigenomics 7, 975-984. doi: 10.2217/epi.15.37

Babjuk, M., Böhle, A., Burger, M., Capoun, O., Cohen, D., Compérat, E. M., et al. (2017). EAU Guidelines on Non-Muscle-invasive Urothelial Carcinoma of the Bladder: Update 2016. Eur. Urol. 71, 447-461. doi: 10.1016/j. eururo.2016.05.041

Bader, A. G. (2012). MiR-34 - a microRNA replacement therapy is headed to the clinic. Front. Genet. 3, 1-9. doi: 10.3389/fgene.2012.00120

Baell, J. B., and Miao, W. (2016). Histone acetyltransferase inhibitors: where art thou? Futur. Med. Chem. 8, 1525-1528. doi: 10.4155/fmc-2016-0151

Balar, A. V., Galsky, M. D., Rosenberg, J. E., Powles, T., Petrylak, D. P., Bellmunt, J., et al. (2017). Atezolizumab as first-line treatment in cisplatin-ineligible patients with locally advanced and metastatic urothelial carcinoma: a single-arm, multicentre, phase 2 trial. Lancet 389, 67-76. doi: 10.1016/ S0140-6736(16)32455-2

Balbás-Martínez, C., Sagrera, A., Carrillo-de-Santa-Pau, E., Earl, J., Márquez, M., Vazquez, M., et al. (2013). Recurrent inactivation of STAG2 in bladder cancer is not associated with aneuploidy. Nat. Genet. 45, 1464-1469. doi: 10.1038/ ng.2799

Banerjee, J., Mishra, R., Li, X., Jackson, R. S., Sharma, A., and Bhowmick, N. A. (2014). A reciprocal role of prostate cancer on stromal DNA damage. Oncogene 33, 4924-4931. doi: 10.1038/onc.2013.431

Bardelli, A., and Pantel, K. (2017). Liquid Biopsies, What We Do Not Know (Yet). Cancer Cell 31, 172-179. doi: 10.1016/j.ccell.2017.01.002 
Barrett, S. P., and Salzman, J., (2016). Circular RNAs: analysis, expression and potential functions. Development. 143, 1838-1847. doi: 10.1242/dev.128074

Baylin, S. B., and Jones, P. A. (2016). Epigenetic Determinants of Cancer. Cold Spring Harb. Perspect. Biol. 8, a019505. doi: 10.1101/cshperspect.a019505

Baylln, S. B., Herman, J. G., Graff, J. R., Vertino, P. M., and Issa, J.-P. (1997). Alterations in DNA Methylation: A Fundamental Aspect of Neoplasia. Adv. Cancer Res. 72, 141-196. doi: 10.1016/S0065-230X(08)60702-2

Bechtel, W., McGoohan, S., Zeisberg, E. M., Müller, G. A., Kalbacher, H., Salant, D. J., et al. (2010). Methylation determines fibroblast activation and fibrogenesis in the kidney. Nat. Med. 16, 544-550. doi: 10.1038/nm.2135

Bellmunt, J., de Wit, R., Vaughn, D. J., Fradet, Y., Lee, J. L., Fong, L., et al. (2017). Pembrolizumab as Second-Line Therapy for Advanced Urothelial Carcinoma. N. Engl. J. Med. 376, 1015-1026. doi: 10.1056/NEJMoa1613683

Bernstein, B. E., Meissner, A., and Lander, E. S. (2007). The mammalian epigenome. Cell 128, 669-681. doi: 10.1016/j.cell.2007.01.033

Berraondo, P., Minute, L., Ajona, D., Corrales, L., Melero, I., and Pio, R. (2016). Innate immune mediators in cancer: between defense and resistance. Immunol. Rev. 274, 290-306. doi: 10.1111/imr.12464

Berrondo, C., Flax, J., Kucherov, V., Siebert, A., Osinski, T., Rosenberg, A., et al. (2016). Expression of the long non-coding RNA HOTAIR correlates with disease progression in Bladder Cancer and Is Contained in Bladder Cancer Patient Urinary Exosomes. PloS One 11, e0147236. doi: 10.1371/journal. pone. 0147236

Bertino, E. M., and Otterson, G. A. (2011). Romidepsin: a novel histone deacetylase inhibitor for cancer. Expert Opin. Investig. Drugs 20, 1151-1158. doi: 10.1517/13543784.2011.594437

Bhan, A., Soleimani, M., and Mandal, S. S. (2017). Long noncoding RNA and cancer: A new paradigm. Cancer Res. 77, 3965-3981. doi: 10.1158/0008-5472. CAN-16-2634

Bian, C., Chen, Q., and Yu, X. (2015). The zinc finger proteins ZNF644 and WIZ regulate the G9a/GLP complex for gene repression. ELife 4(e05606). doi: $10.7554 /$ elife. 05606

Bistoni, F., Vecchiarelli, A., Cenci, E., Puccetti, P., Marconi, P., and Cassone, A. (1986). Evidence for macrophage-mediated protection against lethal Candida albicans infection. Infect. Immun. 51, 668-674.

Biswas, S., and Rao, C. M. (2017). Epigenetics in cancer: Fundamentals and Beyond. Pharmacol. Ther. 173, 118-134. doi: 10.1016/j.pharmthera.2017.02.011

Biswas, S., and Rao, C. M. (2018). Epigenetic tools (The Writers, The Readers and The Erasers) and their implications in cancer therapy. Eur. J. Pharmacol. 837, 8-24. doi: 10.1016/j.ejphar.2018.08.021

Bitler, B. G., Aird, K. M., Garipov, A., Li, H., Amatangelo, M., Kossenkov, A. V., et al. (2015). Synthetic lethality by targeting EZH2 methyltransferase activity in ARID1A-mutated cancers. Nat. Med. 21, 231-238. doi: 10.1038/nm.3799

Bochner, B. H., Cote, R. J., Weidner, N., Groshen, S., Chen, S.-C., Skinner, D. G., et al. (1995). ). Angiogenesis in Bladder Cancer: Relationship Between Microvessel Density and Tumor Prognosis. JNCI J. Natl. Cancer Inst. 87, 16031612. doi: 10.1093/jnci/87.21.1603

Bock, C., Beerman, I., Lien, W.-H., Smith, Z. D., Gu, H., Boyle, P., et al. (2012). DNA methylation dynamics during in vivo differentiation of blood and skin stem cells. Mol. Cell 47, 633-647. doi: 10.1016/j.molcel.2012.06.019

Bognar, Z., Fekete, K., Antus, C., Hocsak, E., Bognar, R., Tapodi, A., et al. (2017). Desethylamiodarone-A metabolite of amiodarone-Induces apoptosis on T24 human bladder cancer cells via multiple pathways. PloS One 12, 1-18. doi: 10.1371/journal.pone.0189470

Bosschieter, J., Nieuwenhuijzen, J. A., Hentschel, A., van Splunter, A. P., Segerink, L. I., Vis, A. N., et al. (2019). A two-gene methylation signature for the diagnosis of bladder cancer in urine. Epigenomics 11, 337-347. doi: 10.2217/epi-2018-0094

Brach, D., Johnston-blackwell, D., Drew, A., Lingaraj, T., Motwani, V., Warholic, N. M., et al. (2017). EZH2 Inhibition by Tazemetostat Results in Altered Dependency on B-cell Activation Signaling in DLBCL. Mol. Cancer Ther. 16 (11). doi: 10.1158/1535-7163.MCT-16-0840

Bröske, A.-M., Vockentanz, L., Kharazi, S., Huska, M. R., Mancini, E., Scheller, M., et al. (2009). DNA methylation protects hematopoietic stem cell multipotency from myeloerythroid restriction. Nat. Genet. 41, 1207-1215. doi: 10.1038/ ng.463

Buckley, M. T., Yoon, J., Yee, H., Chiriboga, L., Liebes, L., Ara, G., et al. (2007). The histone deacetylase inhibitor belinostat (PXD101) suppresses bladder cancer cell growth in vitro and in vivo. J. Transl. Med. 5, 1-12. doi: 10.1186/1479-5876-5-49

Cameron, E. E., Bachman, K. E., Myöhänen, S., Herman, J. G., and Baylin, S. B. (1999). Synergy of demethylation and histone deacetylase inhibition in the re-expression of genes silenced in cancer. Nat. Genet. 21, 103-107. doi: $10.1038 / 5047$

Cao, R., Tsukada, Y., and Zhang, Y. (2005). Role of Bmi-1 and Ring1A in H2A Ubiquitylation and Hox Gene Silencing. Mol. Cell 20, 845-854. doi: 10.1016/J. MOLCEL.2005.12.002

Casadevall, D., Kilian, A. Y., and Bellmunt, J. (2017). The prognostic role of epigenetic dysregulation in bladder cancer: A systematic review. Cancer Treat. Rev. 61, 82-93. doi: 10.1016/j.ctrv.2017.10.004

Catto, J. W. F., Azzouzi, A.-R., Rehman, I., Feeley, K. M., Cross, S. S., Amira, N., et al. (2005). Promoter hypermethylation is associated with tumor location, stage, and subsequent progression in transitional cell carcinoma. J. Clin. Oncol. 23, 2903-2910. doi: 10.1200/JCO.2005.03.163

Chalbatani, G. M., Dana, H., Memari, F., Gharagozlou, E., Ashjaei, S., Kheirandish, P., et al. (2019). Biological function and molecular mechanism of piRNA in cancer. Pract. Lab. Med. 13, 1-6. doi: 10.1016/j.plabm.2018.e00113

Chan, B., Manley, J., Lee, J., and Singh, S. R. (2015). The emerging roles of microRNAs in cancer metabolism. Cancer Lett. 356, 301-308. doi: 10.1016/j. canlet.2014.10.011

Chen, W., Wu, W., Li, X., Zhao, L., and Chen, W. (2011). HDAC6 and SIRT2 promote bladder cancer cell migration and invasion by targeting cortactin. Oncol. Rep. 27, 819-824. doi: 10.3892/or.2011.1553

Chen, X., Chen, R.-X., Wei, W.-S., Li, Y.-H., Feng, Z.-H., Tan, L., et al. (2018). PRMT5 Circular RNA Promotes Metastasis of Urothelial Carcinoma of the Bladder through Sponging miR-30c to Induce Epithelial-Mesenchymal Transition. Clin. Cancer Res. 24, 6319-6330. doi: 10.1158/1078-0432.CCR-18-1270

Chen, X., Wurtmann, E. J., Van Batavia, J., Zybailov, B., Washburn, M. P., and Wolin, S. L. (2007). An ortholog of the Ro autoantigen functions in $23 \mathrm{~S}$ rRNA maturation in D. radiodurans. Genes Dev. 21, 1328-1339. doi: 10.1101/ gad. 1548207

Chen, Z., Du, Y., Liu, X., Chen, H., Weng, X., Guo, J., et al. (2019). EZH2 inhibition suppresses bladder cancer cell growth and metastasis via the JAK2/STAT3 signaling pathway. Oncol. Lett. 18, 907-915. doi: 10.3892/ol.2019.10359

Cheung, E. M., Quinn, D. I., Tsao-Wei, D. D., Groshen, S. G., Aparicio, A. M., Twardowski, P., et al. (2008). Phase II study of vorinostat (Suberoylanilide Hydroxamic Acid, SAHA) in patients with advanced transitional cell urothelial cancer (TCC) after platinum-based therapy-California Cancer Consortium/ University of Pittsburgh NCI/CTEP-sponsored trial. J. Clin. Oncol. 26, 1605816058. doi: 10.1200/jco.2008.26.15_suppl.16058

Cho, H.-S., Kelly, J. D., Hayami, S., Toyokawa, G., Takawa, M., Yoshimatsu, M., et al. (2015). Enhanced Expression of EHMT2 Is Involved in the Proliferation of Cancer Cells through Negative Regulation of SIAH1. Neoplasia 13, 676IN10. doi: 10.1593/neo.11512

Chou, J., Shahi, P., and Werb, Z. (2013). microRNA-mediated regulation of the tumor microenvironment. Cell Cycle 12, 3262-3271. doi: 10.4161/cc.26087

Christov, C. P., Gardiner, T. J., Szuts, D., and Krude, T. (2006). Functional Requirement of Noncoding Y RNAs for Human Chromosomal DNA Replication. Mol. Cell. Biol. 26, 6993-7004. doi: 10.1128/mcb.01060-06

Christov, C. P., Trivier, E., and Krude, T. (2008). Noncoding human Y RNAs are overexpressed in tumours and required for cell proliferation. Br. J. Cancer 98, 981-988. doi: 10.1038/sj.bjc.6604254

Chu, H., Hui, G., Yuan, L., Shi, D., Wang, Y., Du, M., et al. (2015). Identification of novel piRNAs in bladder cancer. Cancer Lett. 356, 561-567. doi: 10.1016/j. canlet.2014.10.004

Chung, W., Bondaruk, J., Jelinek, J., Lotan, Y., Liang, S., Czerniak, B., et al. (2011). Detection of bladder cancer using novel DNA methylation biomarkers in urine sediments. Cancer Epidemiol. Biomarkers Prev. 20, 1483-1491. doi: 10.1158/1055-9965.EPI-11-0067

Clark, M. B., Johnston, R. L., Inostroza-Ponta, M., Fox, A. H., Fortini, E., Moscato, P., et al. (2012). Genome-wide analysis of long noncoding RNA stability. Genome Res. 22, 885-898. doi: 10.1101/gr.131037.111

Comito, G., Iscaro, A., Bacci, M., Morandi, A., Ippolito, L., Parri, M., et al. (2019). Lactate modulates $\mathrm{CD} 4+\mathrm{T}$-cell polarization and induces an immunosuppressive environment, which sustains prostate carcinoma progression via TLR8/miR21 axis. Oncogene 38, 3681-3695. doi: 10.1038/s41388-019-0688-7 
Costa, V. L., Henrique, R., Danielsen, S. A., Duarte-Pereira, S., Eknaes, M., Skotheim, R. I., et al. (2010). Three epigenetic biomarkers, GDF15, TMEFF2, and VIM, accurately predict bladder cancer from DNA-based analyses of urine samples. Clin. Cancer Res. 16, 5842-5851. doi: 10.1158/1078-0432. CCR-10-1312

Cui, J., Sun, W., Hao, X., Wei, M., Su, X., Zhang, Y., et al. (2015). EHMT2 inhibitor BIX-01294 induces apoptosis through PMAIP1-USP9X-MCL1 axis in human bladder cancer cells. Cancer Cell Int. 15, 1-9. doi: 10.1186/ s12935-014-0149-x

Cui, X., Jing, X., Long, C., Yi, Q., Tian, J., and Zhu, J. (2017). Accuracy of the urine UCA1 for diagnosis of bladder cancer: a meta-analysis. Oncotarget 8, 3522235233. doi: 10.18632/oncotarget. 16473

D’Andrea, D., Soria, F., Zehetmayer, S., Gust, K. M., Korn, S., Witjes, J. A., et al. (2019). Diagnostic accuracy, clinical utility and influence on decision-making of a methylation urine biomarker test in the surveillance of non-muscleinvasive bladder cancer. BJU Int. 123, 959-967. doi: 10.1111/bju.14673

Dall'Olio, F., and Trinchera, M. (2017). Epigenetic Bases of Aberrant Glycosylation in Cancer. Int. J. Mol. Sci. 18(5), 998. doi: 10.3390/ijms18050998

Datta, J., Ghoshal, K., Denny, W. A., Gamage, S. A., Darby, G., Phiasivongsa, P., et al. (2009). A New Class of Quinoline-Based DNA Hypomethylating Agents Reactivates Tumor Suppressor Genes by Blocking DNA Methyltransferase 1 Activity and Inducing Its Degradation. Cancer Res. 69 (10), 4277-4285. doi: 10.1158/0008-5472.CAN-08-3669

Dawson, M. A., and Kouzarides, T. (2012). Cancer epigenetics: from mechanism to therapy. Cell 150, 12-27. doi: 10.1016/j.cell.2012.06.013

De Palma, G., Di Lorenzo, V. F., Krol, S., and Paradiso, A. V. (2019). Urinary exosomal shuttle RNA: Promising cancer diagnosis biomarkers of lower urinary tract. Int. J. Biol. Markers, 34 (2), 101-107. doi: 10.1177/1724600819827023

Deb, G., Singh, A. K., and Gupta, S. (2014). EZH2: Not EZHY (Easy) to Deal. Mol. Cancer Res. 12, 639-653. doi: 10.1158/1541-7786.MCR-13-0546

Deroanne, C. F., Bonjean, K., Servotte, S., Devy, L., Colige, A., Clausse, N., et al. (2002). Histone deacetylases inhibitors as anti-angiogenic agents altering vascular endothelial growth factor signaling. Oncogene 21, 427-436. doi: 10.1038/sj.onc. 1205108

Dhalluin, C., Carlson, J. E., Zeng, L., He, C., Aggarwal, A. K., Zhou, M.-M., et al. (1999). Structure and ligand of a histone acetyltransferase bromodomain. Nature 399, 491-496. doi: 10.1038/20974

Di Meo, A., Bartlett, J., Cheng, Y., Pasic, M. D., and Yousef, G. M. (2017). Liquid biopsy: A step forward towards precision medicine in urologic malignancies. Mol. Cancer 16, 1-14. doi: 10.1186/s12943-017-0644-5

Ding, B., Yan, L., Zhang, Y., Wang, Z., Zhang, Y., Xia, D., et al. (2019). Analysis of the role of mutations in the KMT2D histone lysine methyltransferase in bladder cancer. FEBS Open Bio 9, 693-706. doi: 10.1002/2211-5463.12600

$\mathrm{Du}, \mathrm{H}$., and Che, G. (2017). Genetic alterations and epigenetic alterations of cancer-associated fibroblasts. Oncol. Lett. 13, 3-12. doi: 10.3892/ol.2016.5451

Duex, J. E., Swain, K. E., Dancik, G. M., Paucek, R. D., Owens, C., Churchill, M. E. A., et al. (2018a). Functional Impact of Chromatin Remodeling Gene Mutations and Predictive Signature for Therapeutic Response in Bladder Cancer. Mol. Cancer Res. 16, 69-77. doi: 10.1158/1541-7786.MCR-17-0260

Duex, J. E., Swain, K. E., Dancik, G. M., Paucek, R. D., Owens, C., Churchill, M. E. A., et al. (2018b). Functional Impact of Chromatin Remodeling Gene Mutations and Predictive Signature for Therapeutic Response in Bladder Cancer. Mol. Cancer Res. 16, 69-77. doi: 10.1158/1541-7786.MCR-17-0260

Dunn, J., and Rao, S. (2017). Epigenetics and immunotherapy: The current state of play. Mol. Immunol. 87, 227-239. doi: 10.1016/j.molimm.2017.04.012

Eckert, M. A., Coscia, F., Chryplewicz, A., Chang, J. W., Hernandez, K. M., Pan, S., et al. (2019). Proteomics reveals NNMT as a master metabolic regulator of cancer-associated fibroblasts. Nature 569, 723-728. doi: 10.1038/ s41586-019-1173-8

Eckschlager, T., Plch, J., Stiborova, M., and Hrabeta, J. (2017). Histone Deacetylase Inhibitors as Anticancer Drugs. Int. J. Mol. Sci. 18(7), 1414. doi: 10.3390/ijms18071414

Ellinger, J., Müller, S. C., and Dietrich, D. (2015). Epigenetic biomarkers in the blood of patients with urological malignancies. Expert Rev. Mol. Diagn. 15, 505-516. doi: 10.1586/14737159.2015.1019477

Ellinger, J., Schneider, A.-C., Bachmann, A., Kristiansen, G., Müller, S. C., and Rogenhofer, S. (2016). Evaluation of Global Histone Acetylation Levels in Bladder Cancer Patients. Anticancer Res. 36, 3961-3964.
Enkelmann, A., Heinzelmann, J., von Eggeling, F., Walter, M., Berndt, A., Wunderlich, H., et al. (2011). Specific protein and miRNA patterns characterise tumour-associated fibroblasts in bladder cancer. J. Cancer Res. Clin. Oncol. 137, 751-759. doi: 10.1007/s00432-010-0932-6

Enokida, H., Yoshino, H., Matsushita, R., and Nakagawa, M. (2016). The role of microRNAs in bladder cancer. Investig. Clin. Urol. 57, S60. doi: 10.4111/ icu.2016.57.s1.s60

Esteller, M. (2008). Epigenetics in Cancer. N. Engl. J. Med. 358, 1148-1159. doi: 10.1056/NEJMra072067

Fabbri, M., and Calin, G. A. (2010). Epigenetics and miRNAs in Human Cancer. Adv. Genet. 70, 87-99. doi: 10.1016/B978-0-12-380866-0.60004-6

Fantony, J. J., Longo, T. A., Gopalakrishna, A., Owusu, R., Lance, R. S., Foo, W.-C., et al. (2017). Urinary NID2 and TWIST1 methylation to augment conventional urine cytology for the detection of bladder cancer. Cancer Biomark. 18, 381387. doi: 10.3233/CBM-160261

Fardi, M., Solali, S., and Farshdousti Hagh, M. (2018). Epigenetic mechanisms as a new approach in cancer treatment: An updated review. Genes Dis. 5, 304-311. doi: 10.1016/j.gendis.2018.06.003

Feber, A., Dhami, P., Dong, L., de Winter, P., Tan, W. S., Martínez-Fernández, M., et al. (2017). UroMark-a urinary biomarker assay for the detection of bladder cancer. Clin. Epigenet. 9(1), 1-10. doi: 10.1186/s13148-016-0303-5

Feinberg, A. P., and Vogelstein, B. (1983). Hypomethylation distinguishes genes of some human cancers from their normal counterparts. Nature 301, 89-92. doi: 10.1038/301089a0

Feng, Y., Liu, J., Kang, Y., He, Y., Liang, B., Yang, P., et al. (2014). miR-19a acts as an oncogenic microRNA and is up-regulated in bladder cancer. J. Exp. Clin. Cancer Res. 33, 67. doi: 10.1186/PREACCEPT-9242556491295527

Fischle, W. (2003). Molecular basis for the discrimination of repressive methyllysine marks in histone $\mathrm{H} 3$ by Polycomb and HP1 chromodomains. Genes Dev. 17, 1870-1881. doi: 10.1101/gad.1110503

Freedman, J. E., Gerstein, M., Mick, E., Rozowsky, J., Levy, D., Kitchen, R., et al. (2016). Diverse human extracellular RNAs are widely detected in human plasma. Nat. Commun. 7, 11106. doi: 10.1038/ncomms11106

Gajer, J. M., Furdas, S. D., Gründer, A., Gothwal, M., Heinicke, U., Keller, K., et al. (2015). Histone acetyltransferase inhibitors block neuroblastoma cell growth in vivo. Oncogenesis 4, e137. doi: 10.1038/oncsis.2014.51

Gao, Z., Yuan, T., Zhou, X., Ni, P., Sun, G., Li, P., et al. (2018). Targeting BRD4 proteins suppresses the growth of NSCLC through downregulation of eIF4E expression. Cancer Biol. Ther. 19, 407-415. doi: 10.1080/15384047.2018.1423923

García-Baquero, R., Puerta, P., Beltran, M., Alvarez-Mújica, M., Alvarez-Ossorio, J. L., and Sánchez-Carbayo, M. (2014). Methylation of tumor suppressor genes in a novel panel predicts clinical outcome in paraffin-embedded bladder tumors. Tumor Biol. 35, 5777-5786. doi: 10.1007/s13277-014-1767-6

Garzon, R., Marcucci, G., and Croce, C. M. (2010). Targeting microRNAs in cancer: rationale, strategies and challenges. Nat. Rev. Drug Discovery 9, 775789. doi: $10.1038 / \mathrm{nrd} 3179$

Ge, Q., Zhou, Y., Lu, J., Bai, Y., Xie, X., and Lu, Z. (2014). miRNA in Plasma Exosome is Stable under Different Storage Conditions. Molecules 19, 1568 1575. doi: 10.3390/molecules 19021568

Giagounidis, A., Schoch, R., Gattermann, N., Sanz, G., List, A., Gore, S. D., et al. (2014). Efficacy of azacitidine compared with that of conventional care regimens in the treatment of higher-risk myelodysplastic syndromes: a randomised, open-label, phase III study. Lancet Oncol. 10, 223-232. doi: 10.1016/S1470-2045(09)70003-8.Efficacy

Gielchinsky, I., Gilon, M., Abu-lail, R., Matouk, I., Hochberg, A., Gofrit, O. N., et al. (2017). H19 non-coding RNA in urine cells detects urothelial carcinoma: a pilot study. Biomarkers 22, 1-6. doi: 10.1080/1354750X.2016.1276625

Gillette, T. G., and Hill, J. A. (2015). Readers, writers, and erasers: chromatin as the whiteboard of heart disease. Circ. Res. 116, 1245-1253. doi: 10.1161/ CIRCRESAHA.116.303630

Ginder, G. D., and Williams, D. C. (2018). Readers of DNA methylation, the MBD family as potential therapeutic targets. Pharmacol. Ther. 184, 98-111. doi: 10.1016/j.pharmthera.2017.11.002

Goll, M. G., and Bestor, T. H. (2005). Eukaryotic cytosine methyltransferases. Annu. Rev. Biochem. 74, 481-514. doi: 10.1146/annurev.biochem.74.010904.153721

Gotwals, P., Cameron, S., Cipolletta, D., Cremasco, V., Crystal, A., Hewes, B., et al. (2017). Prospects for combining targeted and conventional cancer therapy with immunotherapy. Nat. Rev. Cancer 17, 286-301. doi: 10.1038/nrc.2017.17 
Goulet, C. R., Champagne, A., Bernard, G., Vandal, D., Chabaud, S., Pouliot, F., et al. (2019). Cancer-associated fibroblasts induce epithelial-mesenchymal transition of bladder cancer cells through paracrine IL-6 signalling. BMC Cancer 19, 137. doi: 10.1186/s12885-019-5353-6

Grimm, S., Jennek, S., Singh, R., Enkelmann, A., Junker, K., Rippaus, N., et al. (2015). Malignancy of bladder cancer cells is enhanced by tumor-associated fibroblasts through a multifaceted cytokine-chemokine loop. Exp. Cell Res. 335, 1-11. doi: 10.1016/j.yexcr.2015.04.001

Guan, B., Xing, Y., Xiong, G., Cao, Z., Fang, D., Li, Y., et al. (2018). Predictive value of gene methylation for second recurrence following surgical treatment of first bladder recurrence of a primary upper-tract urothelial carcinoma. Oncol. Lett. 15, 9397-9405. doi: 10.3892/ol.2018.8498

Gui, Y., Guo, G., Huang, Y., Hu, X., Tang, A., Gao, S., et al. (2011). Frequent mutations of chromatin remodeling genes in transitional cell carcinoma of the bladder. Nat. Genet. 43, 875-878. doi: 10.1038/ng.907

Gulì, C., Baldassarra, S., Signore, F., Rigon, G., Pizzuti, V., Gaffi, M., et al. (2017). Role of Non-Coding RNAs in the Etiology of Bladder Cancer. Genes (Basel) 8, 339. doi: 10.3390/genes8110339

Guo, P., Zhang, G., Meng, J., He, Q., Li, Z., and Guan, Y. (2018). Upregulation of Long Noncoding RNA TUG1 Promotes Bladder Cancer Cell Proliferation, Migration, and Invasion by Inhibiting miR-29c. Oncol. Res. Featur. Preclin. Clin. Cancer Ther. 26, 1083-1091. doi: 10.3727/096504018X15152085755247

Gupta, P. B., Fillmore, C. M., Jiang, G., Shapira, S. D., Tao, K., Kuperwasser, C., et al. (2011). Stochastic State Transitions Give Rise to Phenotypic Equilibrium in Populations of Cancer Cells. Cell 146, 633-644. doi: 10.1016/j.cell.2011.07.026

Gupta, S., Doyle, K., Mosbruger, T. L., Butterfield, A., Ast, A., Kaadige, M., et al. (2018). Reversible LSD1 inhibition with HCI-2509 induces the p53 gene expression signature and disrupts the MYCN signature in high- risk neuroblastoma cells. Oncotarget 9 (11), 9907-9924.

Gupta, R. A., Shah, N., Wang, K. C., Kim, J., Horlings, H. M., Wong, D. J., et al. (2010). Long non-coding RNA HOTAIR reprograms chromatin state to promote cancer metastasis. Nature 464, 1071-1076. doi: 10.1038/nature08975

Han, C., Seebacher, N. A., Hornicek, F. J., Kan, Q., and Duan, Z. (2017). Regulation of microRNAs function by circular RNAs in human cancer. Oncotarget 8, 64622-64637. doi: 10.18632/oncotarget.19930

Han, H., Wolff, E. M., and Liang, G. (2012). Epigenetic Alterations in Bladder Cancer and Their Potential Clinical Implications. Adv. Urol. 2012, 1-11. doi: $10.1155 / 2012 / 546917$

Hashizume, H., Baluk, P., Morikawa, S., McLean, J. W., Thurston, G., Roberge, S., et. al (2000). Openings between Defective Endothelial Cells Explain Tumor Vessel Leakiness. Am. J. Pathol. 156, 1363-1380. doi: 10.1016/ S0002-9440(10)65006-7

Havel, J. J., Chowell, D., and Chan, T. A. (2019). The evolving landscape of biomarkers for checkpoint inhibitor immunotherapy. Nat. Rev. Cancer 19, 133-150. doi: 10.1038/s41568-019-0116-x

Hayami, S., Yoshimatsu, M., Veerakumarasivam, A., Unoki, M., Iwai, Y., Tsunoda, T., et al. (2010). Overexpression of the JmjC histone demethylase KDM5B in human carcinogenesis: Involvement in the proliferation of cancer cells through the E2F/RB pathway. Mol. Cancer 9, 1-14. doi: 10.1186/1476-4598-9-59

Heitzer, E., Perakis, S., Geigl, J. B., and Speicher, M. R. (2017). The potential of liquid biopsies for the early detection of cancer. NPJ Precis. Oncol. 1 (36). doi: 10.1038/s41698-017-0039-5

Hellebrekers, D. M. E. I., Jair, K.-W., Viré, E., Eguchi, S., Hoebers, N. T. H., Fraga, M. F., et al. (2006). Angiostatic activity of DNA methyltransferase inhibitors. Mol. Cancer Ther. 5, 467-475. doi: 10.1158/1535-7163.MCT-05-0417

Helming, K. C., Wang, X., Wilson, B. G., Vazquez, F., Haswell, J. R., Manchester, H. E., et al. (2014). ARID1B is a specific vulnerability in ARID1Amutant cancers. Nat. Med. 20, 251-254. doi: 10.1038/nm.3480

Hendrich, B., and Bird, A. (2015). Identification and Characterization of a Family of Mammalian Methyl-CpG Binding Proteins. Mol. Cell. Biol. 18, 6538-6547. doi: $10.1128 / \mathrm{mcb} \cdot 18.11 .6538$

Herold, J. M., James, L. I., Korboukh, V. K., Gao, C., Coil, K. E., Bua, D. J., et al. (2012). Structure-activity relationships of methyl-lysine reader antagonists. Med. Chem. Commun. 3, 45-51. doi: 10.1039/C1MD00195G

Hicks, K. C., Fantini, M., Donahue, R. N., Schwab, A., Knudson, K. M., Tritsch, S. R., et al. (2018). Epigenetic priming of both tumor and NK cells augments antibody-dependent cellular cytotoxicity elicited by the anti-PD-L1 antibody avelumab against multiple carcinoma cell types. Oncoimmunology 7, e1466018. doi: 10.1080/2162402X.2018.1466018

Hida, K., Hida, Y., Amin, D. N., Flint, A. F., Panigrahy, D., Morton, C. C., et al. (2004). Tumor-Associated Endothelial Cells with Cytogenetic Abnormalities. Cancer Res. 64, 8249-8255. doi: 10.1158/0008-5472.CAN-04-1567

Højfeldt, J. W., Agger, K., and Helin, K. (2013). Histone lysine demethylases as targets. Nat. Publ. Gr. 12, 917-930. doi: 10.1038/nrd4154

Hölscher, A. S., Schulz, W. A., Pinkerneil, M., Niegisch, G., and Hoffmann, M. J. (2018). Combined inhibition of BET proteins and class I HDACs synergistically induces apoptosis in urothelial carcinoma cell lines. Clin. Epigenet. 10, 1-14. doi: 10.1186/s13148-017-0434-3

Homami, A., and Ghazi, F. (2016). MicroRNAs as biomarkers associated with bladder cancer. Med. J. Islam. Repub. Iran 30.

Hopkinson, R.J., Tumber, A., Yapp, C., Chowdhury, R., Aik, W.S., Che, K.H., et al. (2013). 5-Carboxy-8-hydroxyquinoline is a broad spectrum 2-oxoglutarate oxygenase inhibitor which causes iron translocation. Chem Sci. 4 (8), 3110 3117. doi: 10.1039/C3SC51122G

Hu, L., Zang, M., Wang, H.-X., Zhang, B.-G., Wang, Z.-Q., Fan, Z.-Y., et al. (2018). G9A promotes gastric cancer metastasis by upregulating ITGB3 in a SET domainindependent manner. Cell Death Dis. 9, 278. doi: 10.1038/s41419-018-0322-6

Hu, M., Yao, J., Cai, L., Bachman, K. E., van den Brûle, F., Velculescu, V., et al. (2005). Distinct epigenetic changes in the stromal cells of breast cancers. Nat. Genet. 37, 899-905. doi: 10.1038/ng1596

Huang, C., Liao, X., Jin, H., Xie, F., Zheng, F., Li, J., et al. (2019a). MEG3, as a Competing Endogenous RNA, Binds with miR-27a to Promote PHLPP2 Protein Translation and Impairs Bladder Cancer Invasion. Mol. Ther. Nucleic Acids 16, 51-62. doi: 10.1016/j.omtn.2019.01.014

Huang, M., Zhong, Z., Lv, M., Shu, J., Tian, Q., and Chen, J. (2016). Comprehensive analysis of differentially expressed profiles of lncRNAs and circRNAs with associated co-expression and ceRNA networks in bladder carcinoma. Oncotarget 7, 47186-47200. doi: 10.18632/oncotarget.9706

Huang, Z., Zhang, M., Chen, G., Wang, W., Zhang, P., Yue, Y., et al. (2019b). Bladder cancer cells interact with vascular endothelial cells triggering EGFR signals to promote tumor progression. Int. J. Oncol. 54, 1555-1566. doi: 10.3892/ijo.2019.4729

Hulshoff, M. S., Xu, X., Krenning, G., and Zeisberg, E. M. (2018). Epigenetic Regulation of Endothelial-to-Mesenchymal Transition in Chronic Heart Disease. Arterioscler. Thromb. Vasc. Biol. 38, 1986-1996. doi: 10.1161/ ATVBAHA.118.311276

Hurst, C. D., Alder, O., Platt, F. M., Droop, A., Stead, L. F., Burns, J. E., et al. (2017). Genomic Subtypes of Non-invasive Bladder Cancer with Distinct Metabolic Profile and Female Gender Bias in KDM6A Mutation Frequency. Cancer Cell 32, 701-715.e7. doi: 10.1016/j.ccell.2017.08.005

Hyun, K., Jeon, J., Park, K., and Kim, J. (2017). Writing, erasing and reading histone lysine methylations. Exp. Mol. Med. 49, e324-e324. doi: 10.1038/emm.2017.11

Iliev, R., Fedorko, M., Machackova, T., Mlcochova, H., Svoboda, M., Pacik, D., et al. (2016). Expression Levels of PIWI-interacting RNA, piR-823, Are Deregulated in Tumor Tissue, Blood Serum and Urine of Patients with Renal Cell Carcinoma. Anticancer Res. 36, 6419-6423. doi: 10.21873/anticanres.11239

Ingelmo-Torres, M., Lozano, J. J., Izquierdo, L., Carrion, A., Costa, M., Gomez, L., et al. (2017). Urinary cell microRNA-based prognostic classifier for nonmuscle invasive bladder cancer. Oncotarget 8, 18238-18247. doi: 10.18632/ oncotarget.15315

Jabłonowski, Z., Reszka, E., Gromadzińska, J., Wąsowicz, W., and Sosnowski, M. (2011). Hypermethylation of $\mathrm{p} 16$ and DAPK promoter gene regions in patients with non-invasive urinary bladder cancer. Arch. Med. Sci. 3, 512-516. doi: 10.5114/aoms.2011.23421

Janson, P. C. J., Marits, P., Thörn, M., Ohlsson, R., Winqvist, O., Gerard, J. R., et al. (2008). CpG methylation of the IFNG gene as a mechanism to induce immunosuppression [correction of immunosupression] in tumor-infiltrating lymphocytes. J. Immunol. 181, 2878-2886. doi: 10.4049/jimmunol.181.4.2878

Jeck, W. R., and Sharpless, N. E. (2014). Detecting and characterizing circular RNAs. Nat. Biotechnol. 32, 453-461. doi: 10.1038/nbt.2890

Jerónimo, C., and Henrique, R. (2014). Epigenetic biomarkers in urological tumors: A systematic review. Cancer Lett. 342, 264-274. doi: 10.1016/j. canlet.2011.12.026

Jiang, L., Gonda, T. A., Gamble, M. V., Salas, M., Seshan, V., Tu, S., et al. (2008). Global Hypomethylation of Genomic DNA in Cancer-Associated 
Myofibroblasts. Cancer Res. 68, 9900-9908. doi: 10.1158/0008-5472. CAN-08-1319

Jiao, D., Li, Z., Zhu, M., Wang, Y., Wu, G., and Han, X. (2018). LncRNA MALAT1 promotes tumor growth and metastasis by targeting miR-124/foxq1 in bladder transitional cell carcinoma (BTCC). Am. J. Cancer Res. 8, 748-760.

Jing, J., Liu, J., Wang, Y., Zhang, M., Yang, L., Shi, F., et al. (2018). The role of ZBTB38 in promoting migration and invasive growth of bladder cancer cells. Oncol. Rep. 41 (3), 1980-1990. doi: 10.3892/or.2018.6937

Jones, P. A., and Liang, G. (2009). Rethinking how DNA methylation patterns are maintained. Nat. Rev. Genet. 10, 805-811. doi: 10.1038/nrg2651

José-Enériz, E. S., Agirre, X., Rabal, O., Vilas-Zornoza, A., Sanchez-Arias, J. A., Miranda, E., et al. (2017). Discovery of first-in-class reversible dual small molecule inhibitors against G9a and DNMTs in hematological malignancies. Nat. Commun. 8, 15424. doi: 10.1038/ncomms15424

Josson, S., Gururajan, M., Sung, S. Y., Hu, P., Shao, C., Zhau, H. E., et al. (2015). Stromal fibroblast-derived miR-409 promotes epithelial-to-mesenchymal transition and prostate tumorigenesis. Oncogene 34, 2690-2699. doi: 10.1038/ onc.2014.212

Kaletsch, A., Pinkerneil, M., Hoffmann, M. J., Jaguva Vasudevan, A. A., Wang, C., Hansen, F. K., et al. (2018). Effects of novel HDAC inhibitors on urothelial carcinoma cells. Clin. Epigenet. 10, 1-18. doi: 10.1186/s13148-018-0531-y

Kalluri, R. (2016). The biology and function of fibroblasts in cancer. Nat. Rev. Cancer 16, 582-598. doi: 10.1038/nrc.2016.73

Kandimalla, R., van Tilborg, A. A. G., Kompier, L. C., Stumpel, D. J. P. M., Stam, R. W., Bangma, C. H., et al. (2012). Genome-wide analysis of CpG island methylation in bladder cancer identified TBX2, TBX3, GATA2, and ZIC4 as pTa-specific prognostic markers. Eur. Urol. 61, 1245-1256. doi: 10.1016/j. eururo.2012.01.011

Kauffman, E. C., Robinson, B. D., Downes, M., Powell, L. G., Ming, M., Scherr, D. S., et al. (2012). Role of androgen receptor and associated lysine-demethylase coregulators, LSD1 and JMJD2A, in localized and advanced human bladder cancer. Mol. Carcinog. 50, 931-944. doi: 10.1002/mc.20758.Role

Khetrapal, P., Lee, M. W. L., Tan, W. S., Dong, L., de Winter, P., Feber, A., et al. (2018). The role of circulating tumour cells and nucleic acids in blood for the detection of bladder cancer: A systematic review. Cancer Treat. Rev. 66, 56-63. doi: 10.1016/J.CTRV.2018.03.007

Kiany, S., Huang, G., and Kleinerman, E. S. (2017). Effect of entinostat on NK cell-mediated cytotoxicity against osteosarcoma cells and osteosarcoma lung metastasis. Oncoimmunology6, e1333214. doi: 10.1080/2162402X.2017.1333214

Kim, D. E., Procopio, M.-G., Ghosh, S., Jo, S.-H., Goruppi, S., Magliozzi, F., et al. (2017). Convergent roles of ATF3 and CSL in chromatin control of cancerassociated fibroblast activation. J. Exp. Med. 214, 2349-2368. doi: 10.1084/ jem. 20170724

Kim, D. J., Dunleavey, J. M., Xiao, L., Ollila, D. W., Troester, M. A., Otey, C. A., et. al (2018). Suppression of TGF $\beta$-mediated conversion of endothelial cells and fibroblasts into cancer associated (myo)fibroblasts via HDAC inhibition. Br. J. Cancer 118, 1359-1368. doi: 10.1038/s41416-018-0072-3

Kim, J., Akbani, R., Creighton, C. J., Lerner, S. P., Weinstein, J. N., Getz, G., et al. (2015a). Invasive Bladder Cancer: Genomic Insights and Therapeutic Promise. Clin. Cancer Res. 21, 4514-4524. doi: 10.1158/1078-0432.CCR-14-1215

Kim, K. H., Kim, W., Howard, T. P., Vazquez, F., Tsherniak, A., Wu, J. N., et al. (2015b). SWI/SNF-mutant cancers depend on catalytic and non-catalytic activity of EZH2. Nat. Med. 21, 1491-1496. doi: 10.1038/nm.3968

Kim, M. S., Kwon, H. J., Lee, Y. M., Baek, J. H., Jang, J.-E., Lee, S.-W., et al. (2001). Histone deacetylases induce angiogenesis by negative regulation of tumor suppressor genes. Nat. Med. 7, 437-443. doi: 10.1038/86507

Kim, S. M., Kang, H. W., Kim, W. T., Kim, Y.-J., Yun, S. J., Lee, S.-C., et al. (2013). Cell-Free microRNA-214 From Urine as a Biomarker for Non-Muscle-Invasive Bladder Cancer. Korean J. Urol. 54, 791. doi: 10.4111/kju.2013.54.11.791

Kitajima, H., Itoh, N., Shindo, T., Maruyama, R., Nojima, M., Suzuki, H., et al. (2017). Evaluation of Urinary DNA Methylation as a Marker for Recurrent Bladder Cancer: A 2-Center Prospective Study. Urology 113, 71-78. doi: 10.1016/j.urology.2017.11.025

Kitchen, M. O., Bryan, R. T., Emes, R. D., Luscombe, C. J., Cheng, K., Zeegers, M. P., et al. (2018). HumanMethylation450K Array-Identified Biomarkers Predict Tumour Recurrence/Progression at Initial Diagnosis of High-risk Nonmuscle Invasive Bladder Cancer. Biomark. Cancer 10, 1179299X1775192. doi: $10.1177 / 1179299 \times 17751920$
Kitchen, M. O., Bryan, R. T., Haworth, K. E., Emes, R. D., Luscombe, C., Gommersall, L., et al. (2015). Methylation of HOXA9 and ISL1 Predicts Patient Outcome in High-Grade Non-Invasive Bladder Cancer. PloS One 10, e0137003. doi: 10.1371/journal.pone.0137003

Knowles, M. A., and Hurst, C. D. (2015). Molecular biology of bladder cancer: New insights into pathogenesis and clinical diversity. Nat. Rev. Cancer 15, 25-41. doi: 10.1038/nrc3817

Kogo, R., Shimamura, T., Mimori, K., Kawahara, K., Imoto, S., Sudo, T., et al. (2011). Long noncoding RNA HOTAIR regulates polycombdependent chromatin modification and is associated with poor prognosis in colorectal cancers. Cancer Res. 71, 6320-6326. doi: 10.1158/0008-5472. CAN-11-1021

Kohlhapp, F. J., Mitra, A. K., Lengyel, E., and Peter, M. E. (2015). MicroRNAs as mediators and communicators between cancer cells and the tumor microenvironment. Oncogene 34, 5857-5868. doi: 10.1038/onc.2015.89

Komatsu, Y., Waku, T., Iwasaki, N., Ono, W., Yamaguchi, C., and Yanagisawa, J. (2012). Global analysis of DNA methylation in early-stage liver fibrosis. BMC Med. Genomics 5, 5. doi: 10.1186/1755-8794-5-5

Konze, K. D., Macnevin, C. J., Liu, F., Gao, C., Huang, X., Kuznetsova, E., et al. (2014). An orally bioavailable chemical probe of the lysine methyltransferase ezh2 and ezh1. ACS Chemical Biology 8 (6), 1324-1334. doi: 10.1021/ cb400133j

Korpal, M., Lee, E. S., Hu, G., and Kang, Y. (2008). The miR-200 family inhibits epithelial-mesenchymal transition and cancer cell migration by direct targeting of E-cadherin transcriptional repressors ZEB1 and ZEB2. J. Biol. Chem. 283, 14910-14914. doi: 10.1074/jbc.C800074200

Kouzarides, T. (2007). Chromatin Modifications and Their Function. Cell 128, 693-705. doi: 10.1016/j.cell.2007.02.005

Kreimer, U., Schulz, W. A., Koch, A., Niegisch, G., and Goering, W. (2013). HERV-K and LINE-1 DNA Methylation and Reexpression in Urothelial Carcinoma. Front. Oncol. 3, 255. doi: 10.3389/fonc.2013.00255

Kristensen, L. S., Hansen, T. B., Venø, M. T., and Kjems, J. (2018). Circular RNAs in cancer: Opportunities and challenges in the field. Oncogene 37, 555-565. doi: 10.1038/onc. 2017.361

Kubicek, S., Sullivan, R. J. O., August, E. M., Hickey, E. R., Zhang, Q., Teodoro, M. L., et al., (2007). Technique Reversal of H3K9me2 by a Small-Molecule Inhibitor for the G9a Histone Methyltransferase. Mol. Cell 1, 473-481. doi: 10.1016/j.molcel.2007.01.017

Kuck, D., Caulfield, T., Lyko, F., and Medina-franco, J. L., (2010). Nanaomycin A Selectively Inhibits DNMT3B and Reactivates Silenced Tumor Suppressor Genes in Human Cancer Cells. Mol. Cancer Ther. 9 (11), 3015-3024. doi: 10.1158/1535-7163.MCT-10-0609

Kulcheski, F. R., Christoff, A. P., and Margis, R. (2016). Circular RNAs are miRNA sponges and can be used as a new class of biomarker. J. Biotechnol. 238, 42-51. doi: 10.1016/j.jbiotec.2016.09.011

Kuninty, P. R., Schnittert, J., Storm, G., and Prakash, J. (2016). MicroRNA Targeting to Modulate Tumor Microenvironment. Front. Oncol. 6, 3. doi: 10.3389/fonc. 2016.00003

Kurdyukov, S., and Bullock, M. (2016). DNA methylation analysis: Choosing the right method. Biology (Basel) 5 (1), 3. doi: 10.3390/biology5010003

Lamprecht, S., Sigal-Batikoff, I., Shany, S., Abu-Freha, N., Ling, E., Delinasios, G. J., et al. (2018). Teaming up for trouble: Cancer cells, transforming growth factor- $\beta 1$ signaling and the epigenetic corruption of stromal naive fibroblasts. Cancers 10(61). doi: 10.3390/cancers 10030061

Laurent, V. M., Duperray, A., Sundar Rajan, V., and Verdier, C. (2014). Atomic Force Microscopy Reveals a Role for Endothelial Cell ICAM-1 Expression in Bladder Cancer Cell Adherence. PloS One 9, e98034. doi: 10.1371/journal. pone.0098034

Lee, J.-E., Wang, C., Xu, S., Cho, Y.-W., Wang, L., Feng, X., et al. (2013). H3K4 mono- and di-methyltransferase MLL4 is required for enhancer activation during cell differentiation. Elife 2, e01503. doi: 10.7554/eLife.01503

Lee, J.-Y., Lee, S.-H., Heo, S.-H., Kim, K.-S., Kim, C., Kim, D.-K., et al. (2015). Novel Function of Lysine Methyltransferase G9a in the Regulation of Sox2 Protein Stability. PloS One 10, e0141118. doi: 10.1371/journal. pone.0141118

Lee, K.-H., and Song, C. G. (2017). Epigenetic regulation in bladder cancer: development of new prognostic targets and therapeutic implications. Transl. Cancer Res. 6, S677-S688. doi: 10.21037/14111 
Lee, M. G., Villa, R., Trojer, P., Norman, J., Yan, K.-P., Reinberg, D., et al. (2007). Demethylation of H3K27 regulates polycomb recruitment and H2A ubiquitination. Science 318, 447-450. doi: 10.1126/science.1149042

Ler, L. D., Ghosh, S., Chai, X., Thike, A. A., Heng, H. L., Siew, E. Y., et al. (2017). Loss of tumor suppressor KDM6A amplifies PRC2-regulated transcriptional repression in bladder cancer and can be targeted through inhibition of EZH2. Sci. Transl. Med. 9, eaai8312. doi: 10.1126/scitranslmed.aai8312

Li, B., Xie, F., Zheng, F., Jiang, G., Zeng, F., and Xiao, X. (2017). Overexpression of CircRNA BCRC4 regulates cell apoptosis and MicroRNA-101/EZH2 signaling in bladder cancer. Curr. Med. Sci. 37, 886-890. doi: 10.1007/s11596-017-1822-9

Li, F., Yang, C., Zhang, H.-B., Ma, J., Jia, J., Tang, X., et al. (2019). BET inhibitor JQ1 suppresses cell proliferation via inducing autophagy and activating LKB1/ AMPK in bladder cancer cells. Cancer Med. 8 (10) 1-14. doi: 10.1002/cam4.2385

Li, H.-T., Duymich, C. E., Weisenberger, D. J., and Liang, G. (2016a). Genetic and Epigenetic Alterations in Bladder Cancer. Int. Neurourol. J. 20, S84-S94. doi: 10.5213/inj.1632752.376

Li, P., Shan, J.-X., Chen, X.-H., Zhang, D., Su, L.-P., Huang, X.-Y., et al. (2015). Epigenetic silencing of microRNA-149 in cancer-associated fibroblasts mediates prostaglandin E2/interleukin-6 signaling in the tumor microenvironment. Cell Res. 25, 588-603. doi: 10.1038/cr.2015.51

Li, P., Yang, X., Yuan, W., Yang, C., Zhang, X., Han, J., et al. (2018a). CircRNA-Cdr1as Exerts Anti-Oncogenic Functions in Bladder Cancer by Sponging MicroRNA135a. Cell. Physiol. Biochem. 46, 1606-1616. doi: 10.1159/000489208

Li, Q. Q., Hao, J. J., Zhang, Z., Hsu, I., Liu, Y., Tao, Z., et al. (2016b). Histone deacetylase inhibitor-induced cell death in bladder cancer is associated with chromatin modification and modifying protein expression: A proteomic approach. Int. J. Oncol. 48, 2591-2607. doi: 10.3892/ijo.2016.3478

Li, X.-Y., Zhang, K., Li, X.-S., Xiong, G.-Y., He, Q., Yang, K.-W., et al. (2018b). Detection of urothelial carcinoma, upper tract urothelial carcinoma, bladder carcinoma, and urothelial carcinoma with gross hematuria using selected urine-DNA methylation biomarkers: A prospective, single-center study. Urol. Oncol. Semin. Orig. Investig. 36, 342.e15-342.e23. doi: 10.1016/j. urolonc.2018.04.001

Liang, Y., Ridzon, D., Wong, L., and Chen, C. (2007). Characterization of microRNA expression profiles in normal human tissues. BMC Genomics 8, 166. doi: 10.1186/1471-2164-8-166

Liep, J., Rabien, A., and Jung, K. (2012). Feedback networks between microRNAs and epigenetic modifications in urological tumors. Epigenetics 7, 315-325. doi: 10.4161/epi.19464

Lima, J. F., Carvalho, J., Pinto-Ribeiro, I., Almeida, C., Wengel, J., Cerqueira, L., et al. (2018a). Targeting miR-9 in gastric cancer cells using locked nucleic acid oligonucleotides. BMC Mol. Biol. 19, 1-13. doi: 10.1186/s12867-018-0107-6

Lima, J. F., Cerqueira, L., Figueiredo, C., Oliveira, C., and Azevedo, N. F. (2018b). Anti-miRNA oligonucleotides: A comprehensive guide for design. RNA Biol. 15, 338-352. doi: 10.1080/15476286.2018.1445959

Lin, Y., Li, Z., He, Z., Guan, T., and Ma, J. (2012). Clinical and Prognostic Significance of Protocadherin-10 (PCDH10) Promoter Methylation in Bladder Cancer. J. Int. Med. Res. 40, 2117-2123. doi: 10.1177/030006051204000609

Liu, C., Chen, Z., Fang, J., Xu, A., Zhang, W., and Wang, Z. (2016). H19-derived miR-675 contributes to bladder cancer cell proliferation by regulating p53 activation. Tumour Biol. 37, 263-270. doi: 10.1007/s13277-015-3779-2

Liu, G., Zhao, X., Zhou, J., Cheng, X., Ye, Z., and Ji, Z. (2018a). Long non-coding RNA MEG3 suppresses the development of bladder urothelial carcinoma by regulating miR-96 and TPM1. Cancer Biol. Ther. 19, 1039-1056. doi: 10.1080/15384047.2018.1480279

Liu, H., Bi, J., Dong, W., Yang, M., Shi, J., Jiang, N., et al. (2018b). Invasion-related circular RNA circFNDC3B inhibits bladder cancer progression through the miR-1178-3p/G3BP2/SRC/FAK axis. Mol. Cancer 17, 161. doi: 10.1186/ s12943-018-0908-8

Liu, M., Zhou, J., Chen, Z., and Cheng, A. S.-L. (2017a). Understanding the epigenetic regulation of tumours and their microenvironments: opportunities and problems for epigenetic therapy. J. Pathol. 241, 10-24. doi: 10.1002/ path. 4832

Liu, Q., Liu, H., Cheng, H., Li, Y., Li, X., and Zhu, C. (2017b). Downregulation of long noncoding RNA TUG1 inhibits proliferation and induces apoptosis through the TUG1/miR-142/ZEB2 axis in bladder cancer cells. Oncol. Targets Ther. 10, 2461-2471. doi: 10.2147/OTT.S124595
Lodewijk, I., Dueñas, M., Rubio, C., Munera-Maravilla, E., Segovia, C., Bernardini, A., et al. (2018). Liquid Biopsy Biomarkers in Bladder Cancer: A Current Need for Patient Diagnosis and Monitoring. Int. J. Mol. Sci. 19, 2514. doi: 10.3390/ ijms19092514

Lu, C., Han, H. D., Mangala, L. S., Ali-Fehmi, R., Newton, C. S., Ozbun, L., et al. (2010). Regulation of Tumor Angiogenesis by EZH2. Cancer Cell 18, 185-197. doi: 10.1016/j.ccr.2010.06.016

Lu, C., Paschall, A. V., Shi, H., Savage, N., Waller, J. L., Sabbatini, M. E., et al. (2017). The MLL1-H3K4me3 axis-mediated PD-L1 expression and pancreatic cancer immune evasion. J. Natl. Cancer Inst. 109, djw283. doi: 10.1093/jnci/djw283

Lu, M., Selleslag, D., Labar, B., Germing, U., Salih, H. R., Beeldens, F., et al., (2011). Low-Dose Decitabine Versus Best Supportive Care in Elderly Patients With Intermediate- or High-Risk Myelodysplastic Syndrome (MDS) Ineligible for Intensive Chemotherapy : Final Results of the Randomized Phase III Study of the European Organisation for R. J. Clin. Oncol. 29, 1987-1996. doi: 10.1200/ JCO.2010.30.9245

Luo, J., Chen, J., Li, H., Yang, Y., Yun, H., Yang, S., et al. (2017). LncRNA UCA1 promotes the invasion and EMT of bladder cancer cells by regulating the miR-143/HMGB1 pathway. Oncol. Lett. 14, 5556-5562. doi: 10.3892/ ol.2017.6886

Luo, Z.-G., Li, Z.-G., Gui, S.-L., Chi, B.-J., and Ma, J.-G. (2014). Protocadherin-17 promoter methylation in serum-derived DNA is associated with poor prognosis of bladder cancer. J. Int. Med. Res. 42, 35-41. doi: 10.1177/0300060513504705

Luperchio, T. R., Wong, X., and Reddy, K. L. (2014). Genome regulation at the peripheral zone: lamina associated domains in development and disease. Curr. Opin. Genet. Dev. 25, 50-61. doi: 10.1016/J.GDE.2013.11.021

Maier, V. K., Feeney, C. M., Taylor, J. E., Creech, A. L., Qiao, J. W., Szanto, A., et al. (2015). Functional Proteomic Analysis of Repressive Histone Methyltransferase Complexes Reveals ZNF518B as a G9A Regulator. Mol. Cell. Proteomics 14, 1435-1446. doi: 10.1074/mcp.M114.044586

Majewski, T., Yao, H., Bondaruk, J., Chung, W., Lee, S., Lee, J. G., et al. (2019). Whole-Organ Genomic Characterization of Mucosal Field Effects Initiating Bladder Carcinogenesis. Cell Rep. 26, 2241-2256.e4. doi: 10.1016/j. celrep.2019.01.095

Mann, B. S., Johnson, J. R., Cohen, M. H., Justice, R., and Pazdur, R. (2007), FDA Approval Summary: Vorinostat for Treatment of Advanced Primary Cutaneous T-Cell Lymphoma. Oncologist 12 (10), 1247-1252. doi: 10.1634/ theoncologist.12-10-1247

Marks, D. L., Olson, R. L., and Fernandez-Zapico, M. E. (2016). Epigenetic control of the tumor microenvironment. Epigenomics 8, 1671-1687. doi: 10.2217/ epi-2016-0110

Marques-Magalhaes, A., Graca, I., Henrique, R., and Jeronimo, C. (2018). Targeting DNA Methyltranferases in Urological Tumors. Front. Pharmacol. 9, 366. doi: 10.3389/fphar.2018.00366

Martens-Uzunova, E. S., Böttcher, R., Croce, C. M., Jenster, G., Visakorpi, T., and Calin, G. A. (2014). Long noncoding RNA in prostate, bladder, and kidney cancer. Eur. Urol. 65, 1140-1151. doi: 10.1016/j.eururo.2013.12.003

Martínez-Fernández, M., Dueñas, M., Feber, A., Segovia, C., García-Escudero, R., Rubio, C., et al. (2015a). A Polycomb-mir200 loop regulates clinical outcome in bladder cancer. Oncotarget 6, 42258-42275. doi: 10.18632/oncotarget.5546

Martínez-Fernández, M., Feber, A., Dueñas, M., Segovia, C., Rubio, C., Fernandez, M., et al. (2015b). Analysis of the Polycomb-related lncRNAs HOTAIR and ANRIL in bladder cancer. Clin. Epigenet. 7, 109. doi: 10.1186/ s13148-015-0141-x

Martínez-Fernández, M., Paramio, J. M., and Dueñas, M. (2016). RNA Detection in Urine. J. Mol. Diagnostics 18, 15-22. doi: 10.1016/j.jmoldx.2015.07.008

Martínez-Fernández, M., Rubio, C., Segovia, C., López-Calderón, F. F., Dueñas, M., and Paramio, J. M. (2015c). EZH2 in bladder cancer, a promising therapeutic target. Int. J. Mol. Sci. 16, 27107-27132. doi: 10.3390/ijms161126000

Martinez, V. D., Vucic, E. A., Thu, K. L., Hubaux, R., Enfield, K. S. S., Pikor, L. A., et al. (2015). Unique somatic and malignant expression patterns implicate PIWIinteracting RNAs in cancer-type specific biology. Sci. Rep. 5, 10423. doi: 10.1038/ srep10423

Mijnes, J., Veeck, J., Gaisa, N. T., Burghardt, E., de Ruijter, T. C., Gostek, S., et al. (2018). Promoter methylation of DNA damage repair (DDR) genes in human tumor entities: RBBP8/CtIP is almost exclusively methylated in bladder cancer. Clin. Epigenet. 10, 1-20. doi: 10.1186/s13148-018-0447-6 
Mio, C., Bulotta, S., Russo, D., and Damante, G. (2019). Reading Cancer: Chromatin Readers as Druggable Targets for Cancer Treatment. Cancers (Basel) 11, 61. doi: 10.3390/cancers11010061

Mishra, R., Haldar, S., Placencio, V., Madhav, A., Rohena-Rivera, K., Agarwal, P., et al. (2018). Stromal epigenetic alterations drive metabolic and neuroendocrine prostate cancer reprogramming. J. Clin. Invest. 128, 4472-4484. doi: 10.1172/ JCI99397

Misso, G., Di Martino, M. T., De Rosa, G., Farooqi, A. A., Lombardi, A., Campani, V., et al. (2014). Mir-34: A new weapon against cancer? Mol. Ther. Nucleic Acids 3, e195. doi: 10.1038/mtna.2014.47

Moore, L. E., Pfeiffer, R. M., Poscablo, C., Real, F. X., Kogevinas, M., Silverman, D., et al. (2008). Genomic DNA hypomethylation as a biomarker for bladder cancer susceptibility in the Spanish Bladder Cancer Study: a case-control study. Lancet Oncol. 9, 359-366. doi: 10.1016/S1470-2045(08)70038-X

Morini, M. F., Giampietro, C., Corada, M., Pisati, F., Lavarone, E., Cunha, S. I., et al (2018). VE-Cadherin-Mediated Epigenetic Regulation of Endothelial Gene Expression. Circ. Res. 122, 231-245. doi: 10.1161/CIRCRESAHA.117.312392

Mozzetta, C., Pontis, J., and Ait-Si-Ali, S. (2015). Functional Crosstalk Between Lysine Methyltransferases on Histone Substrates: The Case of G9A/GLP and Polycomb Repressive Complex 2. Antioxid. Redox Signal. 22, 1365-1381. doi: 10.1089/ars.2014.6116

Mozzetta, C., Pontis, J., Fritsch, L., Robin, P., Portoso, M., Proux, C., et al. (2014). The histone H3 lysine 9 methyltransferases G9a and GLP regulate polycomb repressive complex 2-mediated gene silencing. Mol. Cell 53, 277-289. doi: 10.1016/j.molcel.2013.12.005

Nagai, N., Ohguchi, H., Nakaki, R., Matsumura, Y., Kanki, Y., Sakai, J., et al. (2018). Downregulation of ERG and FLI1 expression in endothelial cells triggers endothelial-to-mesenchymal transition. PloS Genet. 14, e1007826. doi: 10.1371/journal.pgen.1007826

Nagano, T., Mitchell, J. A., Sanz, L. A., Pauler, F. M., Ferguson-Smith, A. C., Feil, R., et al. (2008). The Air noncoding RNA epigenetically silences transcription by targeting G9a to chromatin. Science 322, 1717-1720. doi: 10.1126/ science. 1163802

Nickerson, M. L., Dancik, G. M., Im, K. M., Edwards, M. G., Turan, S., Brown, J., et al. (2014). Concurrent alterations in TERT, KDM6A, and the BRCA pathway in bladder cancer. Clin. Cancer Res. 20, 4935-4948. doi: 10.1158/1078-0432. CCR-14-0330

Nicorescu, I., Dallinga, G. M., de Winther, M. P. J., Stroes, E. S. G., and Bahjat, M. (2019). Potential epigenetic therapeutics for atherosclerosis treatment. Atherosclerosis 281, 189-197. doi: 10.1016/j.atherosclerosis.2018.10.006

Niegisch, G., Knievel, J., Koch, A., Hader, C., Fischer, U., Albers, P., et al. (2013). Changes in histone deacetylase (HDAC) expression patterns and activity of HDAC inhibitors in urothelial cancers. Urol. Oncol. Semin. Orig. Investig. 31, 1770-1779. doi: 10.1016/j.urolonc.2012.06.015

Ocaña, A., Nieto-Jiménez, C., and Pandiella, A. (2017). BET inhibitors as novel therapeutic agents in breast cancer. Oncotarget 8, 71285-71291. doi: 10.18632/ oncotarget.19744

Ogiwara, H., Sasaki, M., Mitachi, T., Oike, T., Higuchi, S., Tominaga, Y., et al. (2016). Targeting p300 addiction in cbp-deficient cancers causes synthetic lethality by apoptotic cell death due to abrogation of MYC expression. Cancer Discovery 6, 430-445. doi: 10.1158/2159-8290.CD-15-0754

Okano, M., Bell, D. W., Haber, D. A., and Li, E. (1999). DNA methyltransferases Dnmt3a and Dnmt3b are essential for de novo methylation and mammalian development. Cell 99, 247-257. doi: 10.1016/S0092-8674(00)81656-6

Olivieri, M., Ferro, M., Terreri, S., Durso, M., Romanelli, A., Avitabile, C., et al. (2016). Long non-coding RNA containing ultraconserved genomic region 8 promotes bladder cancer tumorigenesis. Oncotarget 7(15), 20636-20654. doi: 10.18632/oncotarget.7833

Olkhov-Mitsel, E., Savio, A. J., Kron, K. J., Pethe, V. V., Hermanns, T., Fleshner, N. E., et al. (2017). Epigenome-wide DNA methylation profiling identifies differential methylation biomarkers in high-grade bladder cancer. Transl. Oncol. 10, 168-177. doi: 10.1016/j.tranon.2017.01.001

Pal, S. K., Milowsky, M. I., and Plimack, E. R. (2013). Optimizing systemic therapy for bladder cancer. JNCCN J. Natl. Compr. Cancer Netw. 11, 793-804. doi: 10.6004/jnccn.2013.0101

Palazzo, A. F., and Lee, E. S. (2015). Non-coding RNA: what is functional and what is junk? Front. Genet. 6, 2. doi: 10.3389/fgene.2015.00002
Pang, W., Su, J., Wang, Y., Feng, H., Dai, X., Yuan, Y., et al. (2015). Pancreatic cancer-secreted miR-155 implicates in the conversion from normal fibroblasts to cancer-associated fibroblasts. Cancer Sci. 106, 1362-1369. doi: 10.1111/ cas. 12747

Pappano, W. N., Guo, J., He, Y., Ferguson, D., Jagadeeswaran, S., Osterling, D. J., et al. (2015). The histone methyltransferase inhibitor A-366 uncovers a role for G9a/GLP in the epigenetics of leukemia. PloS One 10, 1-13. doi: 10.1371/ journal.pone.0131716

Pardini, B., and Naccarati, A. (2017). Altered piRNA Profiles in bladder cancer: a new challenge in the next- generation sequencing era? J. Genet. Genomes 1 (2), 1000110.

Pardoll, D. M. (2012). The blockade of immune checkpoints in cancer immunotherapy. Nat. Rev. Cancer 12, 252-264. doi: 10.1038/nrc3239

Park, S. M., Gaur, A. B., Lengyel, E., and Peter, M. E. (2008). The miR-200 family determines the epithelial phenotype of cancer cells by targeting the E-cadherin repressors ZEB1 and ZEB2. Genes Dev. 22, 894-907. doi: 10.1101/gad.1640608

Pastori, C., Daniel, M., Penas, C., Volmar, C.-H., Johnstone, A. L., Brothers, S. P., et al. (2014). BET bromodomain proteins are required for glioblastoma cell proliferation. Epigenetics 9, 611-620. doi: 10.4161/epi.27906

Patchsung, M., Boonla, C., Amnattrakul, P., Dissayabutra, T., Mutirangura, A., and Tosukhowong, P. (2012). Long interspersed nuclear element-1 hypomethylation and oxidative stress: correlation and bladder cancer diagnostic potential. PloS One 7, e37009. doi: 10.1371/journal.pone.0037009

Peng, D., Ge, G., Xu, Z., Ma, Q., Shi, Y., Zhou, Y., et al. (2018). Diagnostic and prognostic biomarkers of common urological cancers based on aberrant DNA methylation. Epigenomics 10, 1189-1199. doi: 10.2217/epi-2018-0017

Petrylak, D. P., Tagawa, S. T., Kohli, M., Eisen, A., Canil, C., Sridhar, S. S., et al. (2016). Docetaxel as monotherapy or combined with ramucirumab or icrucumab in second-line treatment for locally advanced or metastatic urothelial carcinoma: an open-label, three-arm, randomized controlled phase II Trial. J. Clin. Oncol. 34, 1500-1509. doi: 10.1200/JCO.2015.65.0218

Picaud, S., Wells, C., Felletar, I., Brotherton, D., Martin, S., Savitsky, P., et al. (2013). RVX-208, an inhibitor of BET transcriptional regulators with selectivity for the second bromodomain. Proc. Natl. Acad. Sci. U. S. A. 110, 19754-19759. doi: 10.1073/pnas.1310658110

Pietrusiński, M., Kẹpczyński, Ł, Jẹdrzejczyk, A., Borkowska, E., TraczykBorszyńska, M., Constantinou, M., et al. (2017). Detection of bladder cancer in urine sediments by a hypermethylation panel of selected tumor suppressor genes. Cancer Biomark. 18, 47-59. doi: 10.3233/CBM-160673

Plimack, E. R., Bellmunt, J., Gupta, S., Berger, R., Chow, L. Q., Juco, J., et al. (2017). Safety and activity of pembrolizumab in patients with locally advanced or metastatic urothelial cancer (KEYNOTE-012): a non-randomised, open-label, phase 1b study. Lancet Oncol. 18, 212-220. doi: 10.1016/S1470-2045(17)30007-4

Plummer, R., Vidal, L., Griffin, M., Lesley, M., De Bono, J., Coulthard, S., et al. (2009). Phase I study of MG98, an oligonucleotide antisense inhibitor of human DNA methyltransferase 1, given as a 7-day infusion in patients with advanced solid tumors. Clin. Cancer Res. 15, 3177-3183. doi: 10.1158/10780432.CCR-08-2859

Pop-Bica, C., Gulei, D., Cojocneanu-Petric, R., Braicu, C., Petrut, B., and Berindan-Neagoe, I. (2017). Understanding the role of non-coding rnas in bladder cancer: from dark matter to valuable therapeutic targets. Int. J. Mol. Sci. 18(7), 1514. doi: 10.3390/ijms18071514

Porten, S. P. (2018). Epigenetic alterations in bladder cancer. Curr. Urol. Rep. 19. doi: 10.1007/s11934-018-0861-5

Powles, T., Eder, J. P., Fine, G. D., Braiteh, F. S., Loriot, Y., Cruz, C., et al. (2014). MPDL3280A (anti-PD-L1) treatment leads to clinical activity in metastatic bladder cancer. Nature 515, 558-562. doi: 10.1038/nature13904

Poyet, C., Jentsch, B., Hermanns, T., Schweckendiek, D., Seifert, H.-H., Schmidtpeter, M., et al. (2014). Expression of histone deacetylases 1, 2 and 3 in urothelialbladder cancer. BMCClin. Pathol. 14, 10. doi: 10.1186/1472-6890-14-10

Rampias, T., Karagiannis, D., Avgeris, M., Polyzos, A., Kokkalis, A., Kanaki, Z., et al. (2019). The lysine-specific methyltransferase KMT2C/MLL3 regulates DNA repair components in cancer. EMBO Rep. 20, e46821. doi: 10.15252/ embr.201846821

Raulet, D. H., Marcus, A., and Coscoy, L. (2017). Dysregulated cellular functions and cell stress pathways provide critical cues for activating and targeting natural killer cells to transformed and infected cells. Immunol. Rev. 280, 93-101. doi: $10.1111 /$ imr.12600 
Reinert, T. (2012). Methylation markers for urine-based detection of bladder cancer: the next generation of urinary markers for diagnosis and surveillance of bladder cancer. Adv. Urol. 2012, 503271. doi: 10.1155/2012/503271

Reinert, T., Modin, C., Castano, F. M., Lamy, P., Wojdacz, T. K., Hansen, L. L., et al. (2011). Comprehensive genome methylation analysis in bladder cancer: identification and validation of novel methylated genes and application of these as urinary tumor markers. Clin. Cancer Res. 17, 5582-5592. doi: 10.1158/10780432.CCR-10-2659

Ren, C., Morohashi, K., Plotnikov, A. N., Jakoncic, J., Smith, S. G., Li, J., et al. (2015). Small-molecule modulators of methyl-lysine binding for the CBX7 chromodomain. Chem. Biol. 22 (2), 161-168. doi: 10.1016/j.chembiol.2014.11.021

Ren, Y., Huang, T., Lou, Z., Weng, G., Chen, F., Fan, X., et al. (2016). Clinical significance of $\mathrm{CDH} 13$ promoter methylation as a biomarker for bladder cancer: a meta-analysis. BMC Urol. 16, 1-9. doi: 10.1186/s12894-016-0171-5

Renard, I., Joniau, S., van Cleynenbreugel, B., Collette, C., Naômé, C., Vlassenbroeck, I., et al. (2010). Identification and validation of the methylated TWIST1 and NID2 genes through real-time methylation-specific polymerase chain reaction assays for the noninvasive detection of primary bladder cancer in urine samples. Eur. Urol. 58, 96-104. doi: 10.1016/j.eururo.2009.07.041

Ringuette Goulet, C., Bernard, G., Tremblay, S., Chabaud, S., Bolduc, S., and Pouliot, F. (2018). Exosomes induce fibroblast differentiation into cancerassociated fibroblasts through TGF $\beta$ signaling. Mol. Cancer Res. 16, 11961204. doi: 10.1158/1541-7786.mcr-17-0784

Robertson, A. G., Kim, J., Al-Ahmadie, H., Bellmunt, J., Guo, G., Cherniack, A. D., et al. (2018). Comprehensive molecular characterization of muscle-invasive bladder cancer. Cell 174, 1033. doi: 10.1016/j.cell.2018.07.036

Roger, T., Lugrin, J., Le Roy, D., Goy, G., Mombelli, M., Koessler, T., et al. (2011). Histone deacetylase inhibitors impair innate immune responses to Tolllike receptor agonists and to infection. Blood 117, 1205-1217. doi: 10.1182/ blood-2010-05-284711

Romero-Cordoba, S. L., Salido-Guadarrama, I., Rodriguez-Dorantes, M., and Hidalgo-Miranda, A. (2014). miRNA biogenesis: biological impact in the development of cancer. Cancer Biol. Ther. 15, 1444-1455. doi: 10.4161/15384047.2014.955442

Roperch, J. P., Grandchamp, B., Desgrandchamps, F., Mongiat-Artus, P., Ravery, V., Ouzaid, I., et al. (2016). Promoter hypermethylation of HS3ST2, SEPTIN9 and SLIT2 combined with FGFR3 mutations as a sensitive/specific urinary assay for diagnosis and surveillance in patients with low or high-risk non-muscleinvasive bladder cancer. BMC Cancer 16, 1-9. doi: 10.1186/s12885-016-2748-5

Rosenberg, J. E., Hoffman-Censits, J., Powles, T., van der Heijden, M. S., Balar, A. V., Necchi, A., et al. (2016). Atezolizumab in patients with locally advanced and metastatic urothelial carcinoma who have progressed following treatment with platinum-based chemotherapy: a single-arm, multicentre, phase 2 trial. Lancet 387, 1909-1920. doi: 10.1016/S0140-6736(16)00561-4

Ross, J. S., Wang, K., Al-Rohil, R. N., Nazeer, T., Sheehan, C. E., Otto, G. A., et al (2014). Advanced urothelial carcinoma: next-generation sequencing reveals diverse genomic alterations and targets of therapy. Mod. Pathol. 27, 271-280. doi: 10.1038/modpathol.2013.135

Rothbart, S. B., and Strahl, B. D. (2014). Interpreting the language of histone and DNA modifications. Biochim. Biophys. Acta - Gene Regul. Mech. 1839, 627-643. doi: 10.1016/j.bbagrm.2014.03.001

Roudnicky, F., Dieterich, L. C., Poyet, C., Buser, L., Wild, P., Tang, D., et al. (2017). High expression of insulin receptor on tumour-associated blood vessels in invasive bladder cancer predicts poor overall and progression-free survival. $J$. Pathol. 242, 193-205. doi: 10.1002/path.4892

Roudnicky, F., Poyet, C., Wild, P., Krampitz, S., Negrini, F., Huggenberger, R., et al. (2013). Endocan Is Upregulated on Tumor Vessels in Invasive Bladder Cancer Where It Mediates VEGF-A-Induced Angiogenesis. Cancer Res. 73, 1097-1106. doi: 10.1158/0008-5472.CAN-12-1855

Roudnicky, F., Yoon, S. Y., Poghosyan, S., Schwager, S., Poyet, C., Vella, G., et al. (2018). Alternative transcription of a shorter, non-anti-angiogenic thrombospondin-2 variant in cancer-associated blood vessels. Oncogene 37, 2573-2585. doi: 10.1038/s41388-018-0129-z

Ruthenburg, A. J., Li, H., Patel, D. J., and David Allis, C. (2007). Multivalent engagement of chromatin modifications by linked binding modules. Nat. Rev. Mol. Cell Biol. 8, 983-994. doi: 10.1038/nrm2298

Sakaguchi, T., Yoshino, H., Sugita, S., Miyamoto, K., Yonemori, M., Osako, Y., et al. (2018). Bromodomain protein BRD4 inhibitor JQ1 regulates potential prognostic molecules in advanced renal cell carcinoma. Oncotarget 9, 23003. doi: 10.18632/ONCOTARGET.25190

Sánchez-Carbayo, M. (2012). Hypermethylation in bladder cancer: biological pathways and translational applications. Tumor Biol. 33, 347-361. doi: 10.1007/ s13277-011-0310-2

Santos, M., Martínez-Fernández, M., Dueñas, M., García-Escudero, R., Alfaya, B., Villacampa, F., et al. (2014). In vivo disruption of an Rb-E2F-Ezh2 signaling loop causes bladder cancer. Cancer Res. 74, 6565-6577. doi: 10.1158/00085472.CAN-14-1218

Sasaki, H., Yoshiike, M., Nozawa, S., Usuba, W., Katsuoka, Y., Aida, K., et al. (2016). Expression Level of Urinary MicroRNA-146a-5p Is Increased in Patients With Bladder Cancer and Decreased in Those After Transurethral Resection. Clin. Genitourin. Cancer 14, e493-e499. doi: 10.1016/j.clgc.2016.04.002

Schenk, A., Bloch, W., and Zimmer, P. (2016). Natural Killer Cells-An Epigenetic Perspective of Development and Regulation. Int. J. Mol. Sci. 17, 326. doi: 10.3390/ijms17030326

Schlereth, K., Weichenhan, D., Bauer, T., Heumann, T., Giannakouri, E., Lipka, D., et al. (2018). The transcriptomic and epigenetic map of vascular quiescence in the continuous lung endothelium. Elife 7(e34423). doi: 10.7554/elife.34423

Schoepp, M., Ströse, A. J., and Haier, J. (2017). Dysregulation of miRNA Expression in Cancer Associated Fibroblasts (CAFs) and Its Consequences on the Tumor Microenvironment. Cancers (Basel) 9, 54. doi: 10.3390/cancers9060054

Schulte, J., Weidig, M., Balzer, P., Richter, P., Franz, M., Junker, K., et al. (2012). Expression of the E-cadherin repressors Snail, Slug and Zeb1 in urothelial carcinoma of the urinary bladder: relation to stromal fibroblast activation and invasive behaviour of carcinoma cells. Histochem. Cell Biol. 138, 847-860. doi: 10.1007/s00418-012-0998-0

Schulz, W. A. (2006). L1 retrotransposons in human cancers. J. Biomed. Biotechnol. 2006, 83672. doi: 10.1155/JBB/2006/83672

Schuyler, R. P., Merkel, A., Raineri, E., Altucci, L., Vellenga, E., Martens, J. H. A., et al. (2016). Distinct Trends of DNA Methylation Patterning in the Innate and Adaptive Immune Systems Europe PMC Funders Group. Cell Rep. 17, 21012111. doi: 10.1016/j.celrep.2016.10.054

Segovia, C., Martínez-Fernández, M., Dueñas, M., Rubio, C., López-Calderón, F. F., Costa, C., et al. (2017). Opposing roles of $<\mathrm{i}<\mathrm{PIK} 3 \mathrm{CA}</ \mathrm{i}<$ gene alterations to EZH2 signaling in non-muscle invasive bladder cancer. Oncotarget 8, 1053110542. doi: 10.18632/oncotarget.14453

Segovia, C., and Paramio, J. M. (2017). Ezh2-dependent therapies in bladder cancer: Synthetic lethality. Ann. Transl. Med. 5, 3-6. doi: 10.21037/atm.2017.10.08

Segovia, C., San José-Enériz, E., Munera-Maravilla, E., Martínez-Fernández, M., Garate, L., Miranda, E., et al. (2019). Inhibition of a G9a/DNMT network triggers immune-mediated bladder cancer regression. Nat. Med. 25, 10731081. doi: 10.1038/s41591-019-0499-y

Serizawa, R. R., Ralfkiaer, U., Steven, K., Lam, G. W., Schmiedel, S., Schüz, J., et al. (2011). Integrated genetic and epigenetic analysis of bladder cancer reveals an additive diagnostic value of FGFR3 mutations and hypermethylation events. Int. J. Cancer 129, 78-87. doi: 10.1002/ijc.25651

Shah, M. Y., and Calin, G. A. (2014). MicroRNAs as therapeutic targets in human cancers. Wiley Interdiscip. Rev. RNA 5, 537-548. doi: 10.1002/wrna.1229

Shah, S. H., Miller, P., Garcia-Contreras, M., Ao, Z., Machlin, L., Issa, E., et al (2015). Hierarchical paracrine interaction of breast cancer associated fibroblasts with cancercells via hMAPK-microRNAsto driveER-negativebreast cancerphenotype. Cancer Biol. Ther. 16, 1671-1681. doi: 10.1080/15384047.2015.1071742

Shang, D., Liu, Y., Matsui, Y., Ito, N., Nishiyama, H., Kamoto, T., et al. (2008). Demethylating Agent 5-Aza-2'-Deoxycytidine Enhances Susceptibility of Bladder Transitional Cell Carcinoma to Cisplatin. Urology 71, 1220-1225. doi: 10.1016/J.UROLOGY.2007.11.029

Shankar, S. R., Bahirvani, A. G., Rao, V. K., Bharathy, N., Ow, J. R., and Taneja, R. (2013). G9a, a multipotent regulator of gene expression. Epigenetics 8, 16-22. doi: 10.4161/epi.23331

Sharma, A., Jamil, M. A., Nuesgen, N., Dauksa, A., Gulbinas, A., Schulz, W. A., et al. (2019). Detailed methylation map of LINE-1 5' -promoter region reveals hypomethylated $\mathrm{CpG}$ hotspots associated with tumor tissue specificity. Mol. Genet. Genomic Med. 7, e601. doi: 10.1002/mgg3.601

Shi, H., Jiang, H., Wang, L., Cao, Y., Liu, P., Xu, X., et al. (2015). Overexpression of monocarboxylate anion transporter 1 and 4 in T24-induced cancer-associated fibroblasts regulates the progression of bladder cancer cells in a $3 \mathrm{D}$ microfluidic device. Cell Cycle 14, 3058-3065. doi: 10.1080/15384101.2015.1053666 
Simm, C., Caridis, A., Di Maio, A., Knowles, P., Gorman, B., Jones, R., et al. (2018). Targeting of BRD4 with JQ1, combined with mitomycin C as a novel combination therapy for non-muscle invasive bladder cancer. Eur. Urol. Suppl. 17, e663. doi: 10.1016/S1569-9056(18)31300-9

Simon, J. M., Parker, J. S., Liu, F., Rothbart, S. B., Ait-Si-ali, S., Strahl, B. D., et al (2015). A role for widely interspaced zinc finger (WIZ) in retention of the G9a methyltransferase on chromatin. J. Biol. Chem. 290, 26088-26102. doi: 10.1074/jbc.M115.654459

Siomi, M. C., Sato, K., Pezic, D., and Aravin, A. A. (2011). PIWI-interacting small RNAs: the vanguard of genome defence. Nat. Rev. Mol. Cell Biol. 12, 246-258. doi: $10.1038 / \mathrm{nrm} 3089$

Smith, Z. D., and Meissner, A. (2013). DNA methylation: roles in mammalian development. Nat. Rev. Genet. 14, 204-220. doi: 10.1038/nrg3354

Sohel, M. H. (2016). Extracellular/Circulating MicroRNAs: Release Mechanisms, Functions and Challenges. Achiev. Life Sci. 10, 175-186. doi: 10.1016/j. als.2016.11.007

Sonpavde, G., and Bellmunt, J. (2016). Angiogenesis as a therapeutic target in urothelial carcinoma. Nat. Rev. Urol. 13, 306-307. doi: 10.1038/nrurol.2016.69

Stenzl, A., Cowan, N. C., De Santis, M., Kuczyk, M. A., Merseburger, A. S., Ribal, M. J., et al. (2011). Treatment of Muscle-invasive and Metastatic Bladder Cancer: Update of the EAU Guidelines. Eur. Urol. 59, 1009-1018. doi: 10.1016/j.eururo.2011.03.023

Stone, O. A., El-Brolosy, M., Wilhelm, K., Liu, X., Romão, A. M., Grillo, E., et al (2018). Loss of pyruvate kinase M2 limits growth and triggers innate immune signaling in endothelial cells. Nat. Commun. 9, 4077. doi: 10.1038/ s41467-018-06406-8

Stubendorff, B., Wilhelm, K., Posselt, K., Catto, J., Hartmann, A., Bertz, S., et al. (2019). A three-gene methylation marker panel for the nodal metastatic risk assessment of muscle-invasive bladder cancer Keywords Muscle-invasive bladder cancer - Methylation - Biomarker - Metastasis. J. Cancer Res. Clin. Oncol. 145, 811-820. doi: 10.1007/s00432-018-02829-4

Su, H., Tao, T., Yang, Z., Kang, X., Zhang, X., Kang, D., et al. (2019). Circular RNA cTFRC acts as the sponge of MicroRNA-107 to promote bladder carcinoma progression. Mol. Cancer 18, 27. doi: 10.1186/s12943-019-0951-0

Su, S.-F., de Castro Abreu, A. L., Chihara, Y., Tsai, Y., Andreu-Vieyra, C., Daneshmand, S., et al. (2014). A panel of three markers hyper- and hypomethylated in urine sediments accurately predicts bladder cancer recurrence. Clin. Cancer Res. 20, 1978-1989. doi: 10.1158/1078-0432.CCR-13-2637

Sukari, A., Nagasaka, M., Al-Hadidi, A., and Lum, L. G. (2016). Cancer immunology and immunotherapy. Anticancer Res. 36, 5593-5606. doi: 10.21873/anticanres.11144

Sun, H., Tian, J., Xian, W., Xie, T., and Yang, X. (2015). miR-34a inhibits proliferation and invasion of bladder cancer cells by targeting orphan nuclear receptor HNF4G. Dis. Markers 2015, 1-8. doi: 10.1155/2015/879254

Sundar Rajan, V., Laurent, V. M., Verdier, C., and Duperray, A. (2017). Unraveling the receptor-ligand interactions between bladder cancer cells and the endothelium using AFM. Biophys. J. 112, 1246-1257. doi: 10.1016/j. bpj.2017.01.033

Tada, Y., Wada, M., Kuroiwa, K., Kinugawa, N., Harada, T., Nagayama, J., et al. (2000). MRD1 gene overexpression and altered degree of methylation at the promoter region in bladder cancer during chemotherapeutic treatment. Clin. Cancer Res. 6, 4618-4627.

Taheri, M., Omrani, M. D., and Ghafouri-Fard, S. (2018). Long non-coding RNA expression in bladder cancer. Biophys. Rev. 10, 1205-1213. doi: 10.1007/ s12551-017-0379-y

Takeuchi, A., Shiota, M., Tatsugami, K., Yokomizo, A., Tanaka, S., Kuroiwa, K., et al. (2012). P300 Mediates cellular resistance to doxorubicin in bladder cancer. Mol. Med. Rep. 5, 173-176. doi: 10.3892/mmr.2011.593

Tan, Y., Wang, L., Du, Y., Liu, X., Chen, Z., Weng, X., et al. (2018). Inhibition of BRD4 suppresses tumor growth in prostate cancer via the enhancement of FOXO1 expression. Int. J. Oncol. 53, 2503-2517. doi: 10.3892/ijo.2018.4577

Tao, L., Huang, G., Song, H., Chen, Y., and Chen, L. (2017). Cancer associated fibroblasts: an essential role in the tumor microenvironment. Oncol. Lett. 14, 2611-2620. doi: 10.3892/ol.2017.6497

Taubert, H., Wach, S., Jung, R., Pugia, M., and Keck, B. (2015). Piwil 2 expression is correlated with disease-specific and progression-free survival of chemotherapy-treated bladder cancer patients. Mol. Med. 21, 371-380. doi: $10.2119 /$ molmed.2014.00250
Taverna, S. D., Li, H., Ruthenburg, A. J., Allis, C. D., and Patel, D. J. (2007). How chromatin-binding modules interpret histone modifications: lessons from professional pocket pickers. Nat. Struct. Mol. Biol. 14, 1025-1040. doi: 10.1038/ nsmb1338

Tian, Z., Cao, S., Li, C., Xu, M., Wei, H., Yang, H., et al. (2019). LncRNA PVT1 regulates growth, migration, and invasion of bladder cancer by miR-31/CDK1. J. Cell. Physiol. 234, 4799-4811. doi: 10.1002/jcp.27279

Tolkach, Y., Stahl, A. F., Niehoff, E. M., Zhao, C., Kristiansen, G., Müller, S. C., et al. (2017). YRNA expression predicts survival in bladder cancer patients. BMC Cancer 17, 1-7. doi: 10.1186/s12885-017-3746-y

Tsai, H.-C., and Baylin, S. B. (2011). Cancer epigenetics: linking basic biology to clinical medicine. Cell Res. 21, 502-517. doi: 10.1038/cr.2011.24

Vafaee, F., Colvin, E. K., Mok, S. C., Howell, V. M., and Samimi, G. (2017). Functional prediction of long non-coding RNAs in ovarian cancer-Associated fibroblasts indicate a potential role in metastasis. Sci. Rep. 7, 10374. doi: 10.1038/s41598-017-10869-y

Valenzuela, M. T., Galisteo, R., Zuluaga, A., Villalobos, M., Núñez, M. I., Oliver, F. J., et al. (2002). Assessing the use of p16(INK4a) promoter gene methylation in serum for detection of bladder cancer. Eur. Urol. 42, 622-628. discussion 628-30.

van der Heijden, A. G., Mengual, L., Ingelmo-Torres, M., Lozano, J. J., van Rijtvan de Westerlo, C. C. M., Baixauli, M., et al. (2018). Urine cell-based DNA methylation classifier for monitoring bladder cancer. Clin. Epigenet. 10, 1-10. doi: 10.1186/s13148-018-0496-x

van Kessel, K. E. M., Beukers, W., Lurkin, I., Ziel-van der Made, A., van der Keur, K. A., Boormans, J. L., et al. (2017). Validation of a DNA Methylation-Mutation Urine Assay to Select Patients with Hematuria for Cystoscopy. J. Urol. 197, 590595. doi: 10.1016/j.juro.2016.09.118

van Rhijn, B. W. G., Burger, M., Lotan, Y., Solsona, E., Stief, C. G., Sylvester, R. J., et al. (2009). Recurrence and progression of disease in non-muscle-invasive bladder cancer: from epidemiology to treatment strategy. Eur. Urol. 56, 430 442. doi: 10.1016/j.eururo.2009.06.028

Van Rhijn, B. W. G., Van Der Kwast, T. H., Liu, L., Fleshner, N. E., Bostrom, P. J., Vis, A. N., et al. (2012). The FGFR3 mutation is related to favorable pT1 bladder cancer. J. Urol. 187, 310-314. doi: 10.1016/j.juro.2011.09.008

Vedadi, M., Barsyte-lovejoy, D., Liu, F., Rival-gervier, S., Allali-hassani, A., Labrie, V., et al. (2012). A chemical probe selectively inhibits G9a and GLP methyltransferase and genanylgeranyltransferase I with antitumor activity against brest cancer in vivo. Nat. Chem. Biol. 7, 566-574. doi: 10.1038/ nchembio.599.A

Villar-garea, A., Fraga, M. F., Espada, J., and Esteller, M. (2003). Procaine Is a DNA-demethylating Agent with Growth-inhibitory Effects in Human. Cancer Res. 63, 4984-4989.

Viré, E., Brenner, C., Deplus, R., Blanchon, L., Fraga, M., Didelot, C., et al. (2006). The Polycomb group protein EZH2 directly controls DNA methylation. Nature 439, 871-874. doi: 10.1038/nature04431

Vivier, E., Tomasello, E., Baratin, M., Walzer, T., and Ugolini, S. (2008). Functions of natural killer cells. Nat. Immunol. 9, 503-510. doi: 10.1038/ni1582

Vo, J. N., Cieslik, M., Zhang, Y., Shukla, S., Xiao, L., Zhang, Y., et al. (2019). The landscape of circular RNA in cancer. Cell 176, 869-881.e13. doi: 10.1016/j. cell.2018.12.021

Wagner, E. K., Nath, N., Flemming, R., Feltenberger, J. B., and Denu, J. M. (2012). Identification and characterization of small molecule inhibitors of a plant homeodomain finger. Biochemistry 51, 8293-8306. doi: 10.1021/bi3009278

Wang, D., Quiros, J., Mahuron, K., Pai, C.-C., Ranzani, V., Young, A., et al. (2018a). Targeting EZH2 reprograms intratumoral regulatory T cells to enhance cancer immunity. Cell Rep. 23, 3262-3274. doi: 10.1016/j.celrep.2018.05.050

Wang, K. C., and Chang, H. Y. (2011). Molecular mechanisms of long noncoding RNAs. Mol. Cell 43, 904-914. doi: 10.1016/j.molcel.2011.08.018

Wang, M., Guo, C., Wang, L., Luo, G., Huang, C., Li, Y., et al. (2018b). Long noncoding RNA GAS5 promotes bladder cancer cells apoptosis through inhibiting EZH2 transcription. Cell Death Dis. 9, 238. doi: 10.1038/ s41419-018-0264-Z

Wang, P., Nishitani, M.-A., Tanimoto, S., Kishimoto, T., Fukumori, T., Takahashi, M., et al. (2007). Bladder cancer cell invasion is enhanced by cross-talk with fibroblasts through hepatocyte growth factor. Urology 69, 780-784. doi: 10.1016/j.urology.2007.01.063 
Wang, S., Chen, J., Garcia, S. P., Liang, X., Zhang, F., Yan, P., et al. (2019). A dynamic and integrated epigenetic program at distal regions orchestrates transcriptional responses to VEGFA. Genome Res. 29, 193-207. doi: 10.1101/gr.239053.118

Wang, X.-S., Zhang, Z., Wang, H.-C., Cai, J.-L., Xu, Q.-W., Li, M.-Q., et al. (2006). Rapid Identification of UCA1 as a very sensitive and specific unique marker for human bladder carcinoma. Clin. Cancer Res. 12, 4851-4858. doi: 10.1158/10780432.CCR-06-0134

Wang, Y. M., Gu, M. L., Meng, F. S., Jiao, W. R., Zhou, X. X., Yao, H. P., et al. (2017). Histone acetyltransferase p300/CBP inhibitor C646 blocks the survival and invasion pathways of gastric cancer cell lines. Int. J. Oncol. 51 (6), 1860-1868. doi: $10.3892 /$ ijo. 2017.4176

Wang, Y., Xiang, W., Wang, M., Huang, T., Xiao, X., Wang, L., et al. (2014). Methyl jasmonate sensitizes human bladder cancer cells to gambogic acid-induced apoptosis through down-regulation of EZH2 expression by miR-101. Br. J. Pharmacol. 171, 618-635. doi: 10.1111/bph.12501

Weber, J. A., Baxter, D. H., Zhang, S., Huang, D. Y., How Huang, K., Jen Lee, M., et al. (2010). The MicroRNA Spectrum in 12 Body Fluids. Clin. Chem. 56, 1733-1741. doi: 10.1373/clinchem.2010.147405

Weinstein, J. N., Akbani, R., Broom, B. M., Wang, W., Verhaak, R. G. W., McConkey, D., et al. (2014). Comprehensive molecular characterization of urothelial bladder carcinoma. Nature 507, 315-322. doi: 10.1038/nature12965

Wiklund, E. D., Bramsen, J. B., Hulf, T., Dyrskjøt, L., Ramanathan, R., Hansen, T. B., et al. (2011). Coordinated epigenetic repression of the miR-200 family and miR-205 in invasive bladder cancer. Int. J. Cancer 128, 1327-1334. doi: $10.1002 / \mathrm{ijc} .25461$

Winquist, E., Knox, J., Wood, L., Wainman, N., Reid, G. K., Pearce, L., et al., (2006). "Phase II trial of DNA methyltransferase 1 inhibition with the antisense oligonucleotide MG98 in patients with metastatic renal carcinoma," in $A$ National Cancer Institute of Canada Clinical Trials Group investigational new drug study. Invest. New Drugs 24, 159-160. doi: 10.1007/s10637-006-5938-1

Witjes, J. A., Compérat, E., Cowan, N. C., De Santis, M., Gakis, G., Lebret, T., et al. (2014a). EAU guidelines on muscle-invasive and metastatic bladder cancer: summary of the 2013 guidelines. Eur. Urol. 65, 778-792. doi: 10.1016/j. eururo.2013.11.046

Witjes, J. A., Compérat, E., Cowan, N. C., De Santis, M., Gakis, G., Lebret, T., et al. (2014b). EAU guidelines on muscle-invasive and metastatic bladder cancer: summary of the 2013 guidelines. Eur. Urol. 65, 778-792. doi: 10.1016/j. eururo.2013.11.046

Wolff, E. M., Chihara, Y., Pan, F., Weisenberger, D. J., Siegmund, K. D., Sugano, K., et al. (2010). Unique DNA methylation patterns distinguish noninvasive and invasive urothelial cancers and establish an epigenetic field defect in premalignant tissue. Cancer Res. 70, 8169-8178. doi: 10.1158/0008-5472. CAN-10-1335

Wu, J., Li, W., Ning, J., Yu, W., Rao, T., and Cheng, F. (2019a). Long noncoding RNA UCA1 targets miR-582-5p and contributes to the progression and drug resistance of bladder cancer cells through ATG7-mediated autophagy inhibition. Oncol. Targets Ther. 12, 495-508. doi: 10.2147/OTT.S183940

Wu, J., Yu, C., Cai, L., Lu, Y., Jiang, L., Liu, C., et al. (2017). Effects of increased Kindlin-2 expression in bladder cancer stromal fibroblasts. Oncotarget 8, 50692-50703. doi: 10.18632/oncotarget. 17021

Wu, M., Sheng, L., Cheng, M., Zhang, H., Jiang, Y., Lin, S., et al. (2019b). Low doses of decitabine improve the chemotherapy efficacy against basal-like bladder cancer by targeting cancer stem cells. Oncogene 38, 5425-5439. doi: 10.1038/ s41388-019-0799-1

Wu, S., Yang, Z., Ye, R., An, D., Li, C., Wang, Y., et al. (2016a). Novel variants in MLL confer to bladder cancer recurrence identified by whole-exome sequencing. Oncotarget 7, 2629-2645. doi: 10.18632/oncotarget.6380

Wu, X., Liu, D., Tao, D., Xiang, W., Xiao, X., Wang, M., et al. (2016b). BRD4 Regulates EZH2 transcription through upregulation of C-MYC and represents a novel therapeutic target in bladder cancer. Mol. Cancer Ther. 15, 1029-1042. doi: 10.1158/1535-7163.MCT-15-0750

Wu, Z., Huang, W., Wang, X., Wang, T., Chen, Y., Chen, B., et al. (2018). Circular RNA CEP128 acts as a sponge of miR-145-5p in promoting the bladder cancer progression via regulating SOX11. Mol. Med. 24, 40. doi: 10.1186/ s10020-018-0039-0

Xie, F., Li, Y., Wang, M., Huang, C., Tao, D., Zheng, F., et al. (2018). Circular RNA BCRC-3 suppresses bladder cancer proliferation through miR-182-5p/p27 axis. Mol. Cancer 17, 144. doi: 10.1186/s12943-018-0892-z
Xie, H., Liao, X., Chen, Z., Fang, Y., He, A., Zhong, Y., et al. (2017a). LncRNA MALAT1 inhibits apoptosis and promotes invasion by antagonizing miR-125b in bladder cancer cells. J. Cancer 8, 3803-3811. doi: 10.7150/jca.21228

Xie, Y., Ma, X., Chen, L., Li, H., Gu, L., Gao, Y., et al. (2017b). MicroRNAs with prognostic significance in bladder cancer: A systematic review and metaanalysis. Sci. Rep. 7, 5619. doi: 10.1038/s41598-017-05801-3

Xue, M., Pang, H., Li, X., Li, H., Pan, J., and Chen, W. (2016). Long non-coding RNA urothelial cancer-associated 1 promotes bladder cancer cell migration and invasion by way of the hsa-miR-145-ZEB1/2-FSCN1 pathway. Cancer Sci. 107, 18-27. doi: $10.1111 /$ cas. 12844

Xylinas, E., Hassler, M. R., Zhuang, D., Krzywinski, M., Erdem, Z., Robinson, B. D., et al. (2016). An epigenomic approach to improving response to neoadjuvant cisplatin chemotherapy in bladder cancer. Biomolecules 6, 37. doi: 10.3390/ biom6030037

Yamaguchi, H., and Hung, M.-C. (2014). Regulation and Role of EZH2 in Cancer. Cancer Res. Treat. 46, 209-222. doi: 10.4143/crt.2014.46.3.209

Yamamoto, K., Tateishi, K., Kudo, Y., Hoshikawa, M., Tanaka, M., Nakatsuka, T., et al. (2016). Stromal remodeling by the BET bromodomain inhibitor JQ1 suppresses the progression of human pancreatic cancer. Oncotarget 7, 6146961484. doi: 10.18632/oncotarget.11129

Yang, C., Yuan, W., Yang, X., Li, P., Wang, J., Han, J., et al. (2018a). Circular RNA circ-ITCH inhibits bladder cancer progression by sponging miR-17/miR224 and regulating p21, PTEN expression. Mol. Cancer 17, 19. doi: 10.1186/ s12943-018-0771-7

Yang, G.-J., Lei, P.-M., Wong, S., Ma, D.-L., and Leung, C.-H. (2018b). Pharmacological inhibition of LSD1 for cancer treatment. Molecules 23 (12), 3194. doi: 10.3390/molecules23123194

Yang, X., Han, H., De Carvalho, D. D., Lay, F. D., Jones, P. A., and Liang, G. (2014). Gene body methylation can alter gene expression and is a therapeutic target in cancer. Cancer Cell 26, 577-590. doi: 10.1016/j.ccr.2014.07.028

Yang, X., Yuan, W., Tao, J., Li, P., Yang, C., Deng, X., et al. (2017). Identification of circular RNA signature in bladder cancer. J. Cancer 8, 3456-3463. doi: 10.7150/ jca.19345

Yang, Y., Qu, A., Liu, J., Wang, R., Liu, Y., Li, G., et al. (2015). Serum miR-210 contributes to tumor detection, stage prediction and dynamic surveillance in patients with bladder cancer. PloS One 10, e0135168. doi: 10.1371/journal.pone.0135168

Yang, Z., Liu, A., Xiong, Q., Xue, Y., Liu, F., Zeng, S., et al. (2019). Prognostic value of differentially methylated gene profiles in bladder cancer. J. Cell. Physiol., 28515. doi: $10.1002 /$ jcp. 28515

Yates, D. R., Rehman, I., Abbod, M. F., Meuth, M., Cross, S. S., Linkens, D. A., et al. (2007). Promoter hypermethylation identifies progression risk in bladder cancer. Clin. Cancer Res. 13, 2046-2053. doi: 10.1158/1078-0432.CCR-06-2476

Yeh, C. R., Hsu, I., Song, W., Chang, H., Miyamoto, H., Xiao, G. Q., et al. (2015). Fibroblast ERalpha promotes bladder cancer invasion via increasing the CCL1 and IL-6 signals in the tumor microenvironment. Am. J. Cancer Res. 5, 1146-1157.

Yoon, C. Y., Park, M. J., Lee, J. S., Lee, S. C., Oh, J. J., Park, H., et al. (2011). The histone deacetylase inhibitor trichostatin a synergistically resensitizes a cisplatin resistant human bladder cancer cell line. J. Urol. 185, 1102-1111. doi: 10.1016/j.juro.2010.10.034

Yu, C., Longfei, L., Long, W., Feng, Z., Chen, J., Chao, L., et al. (2019). LncRNA PVT1 regulates VEGFC through inhibiting miR-128 in bladder cancer cells. J. Cell. Physiol. 234, 1346-1353. doi: 10.1002/jcp.26929

Yu, G., Yao, W., Xiao, W., Li, H., Xu, H., and Lang, B. (2014). MicroRNA-34a functions as an anti-metastatic microRNA and suppresses angiogenesis in bladder cancer by directly targeting CD44. J. Exp. Clin. Cancer Res. 33, 779. doi: 10.1186/s13046-014-0115-4

Yu, J., Walter, K., Omura, N., Hong, S.-M., Young, A., Li, A., et al. (2012). Unlike pancreatic cancer cells pancreatic cancer associated fibroblasts display minimal gene induction after 5-Aza-2'-Deoxycytidine. PloS One 7, e43456. doi: 10.1371/ journal.pone.0043456

Yu, T., Wang, Y., Hu, Q., Wu, W., Wu, Y., and Wei, W., (2017). The EZH2 inhibitor GSK343 suppresses cancer stem-like phenotypes and reverses mesenchymal transition in glioma cells. Oncotarget 8 (58), 98348-98359. doi: 10.18632/ oncotarget.21311

Yuan, T., Huang, X., Woodcock, M., Du, M., Dittmar, R., Wang, Y., et al. (2016). Plasma extracellular RNA profiles in healthy and cancer patients. Sci. Rep. 6, 19413. doi: $10.1038 /$ srep 19413 
Yuan, Y., Wang, Q., Paulk, J., Kubicek, S., Kemp, M. M., Adams, D. J., et al. (2012). A small-molecule probe of the histone methyltransferase G9a induces cellular senescence in pancreatic adenocarcinoma. ACS Chem. Biol. 7, 1152-1157. doi: $10.1021 / \mathrm{cb} 300139 y$

Yun, S. J., Jeong, P., Kim, W.-T., Kim, T. H., Lee, Y.-S., Song, P. H., et al. (2012). Cellfree microRNAs in urine as diagnostic and prognostic biomarkers of bladder cancer. Int. J. Oncol. 41, 1871-1878. doi: 10.3892/ijo.2012.1622

Zeisberg, E. M., Potenta, S., Xie, L., Zeisberg, M., and Kalluri, R. (2007). discovery of endothelial to mesenchymal transition as a source for carcinoma-associated fibroblasts. Cancer Res. 67, 10123-10128. doi: 10.1158/0008-5472.CAN-07-3127

Zeisberg, E. M., and Zeisberg, M. (2013). The role of promoter hypermethylation in fibroblast activation and fibrogenesis. J. Pathol. 229, 264-273. doi: 10.1002/ path. 4120

Zeng, Z., Zhou, W., Duan, L., Zhang, J., Lu, X., Jin, L., et al. (2019). Circular RNA circ-VANGL1 as a competing endogenous RNA contributes to bladder cancer progression by regulating miR-605-3p/VANGL1 pathway. J. Cell. Physiol. 234, 3887-3896. doi: 10.1002/jcp.27162

Zhang, C., Yao, Z., Zhu, M., Ma, X., Shi, T., Li, H., et al. (2012). Inhibitory effects of MicroRNA-34a on cell migration and invasion of invasive urothelial bladder carcinoma by targeting Notch1. J. Huazhong Univ. Sci. Technol. Med. Sci. 32, 375-382. doi: 10.1007/s11596-012-0065-Z

Zhang, M., and Xin, Y. (2018). Circular RNAs: a new frontier for cancer diagnosis and therapy. J. Hematol. Oncol. 11, 21. doi: 10.1186/s13045-018-0569-5

Zhang, Q., Miao, S., Han, X., Li, C., Zhang, M., Cui, K., et al. (2018a). MicroRNA3619-5p suppresses bladder carcinoma progression by directly targeting $\beta$-catenin and CDK2 and activating p21. Cell Death Dis. 9, 960. doi: 10.1038/ s41419-018-0986-y

Zhang, Q., Zhao, W., Ye, C., Zhuang, J., Chang, C., Li, Y., et al. (2015). Honokiol inhibits bladder tumor growth by suppressing EZH2/miR-143 axis. Oncotarget 6, 37335-37348. doi: 10.18632/oncotarget.6135

Zhang, X., Zhang, Y., Liu, X., Fang, A., Wang, J., Yang, Y., et al. (2016). Direct quantitative detection for cell-free miR-155 in urine: a potential role in diagnosis and prognosis for non-muscle invasive bladder cancer. Oncotarget 7, 3255-3266. doi: 10.18632/oncotarget.6487

Zhang, Y., Huang, Z., Zhu, Z., Zheng, X., Liu, J., Han, Z., et al. (2014). Upregulated UHRF1 promotes bladder cancer cell invasion by epigenetic silencing of KiSS1. PloS One 9(10), e104252. doi: 10.1371/journal.pone.0104252

Zhang, Y., Liang, W., Zhang, P., Chen, J., Qian, H., Zhang, X., et al. (2017). Circular RNAs: emerging cancer biomarkers and targets. J. Exp. Clin. Cancer Res. 36, 152. doi: 10.1186/s13046-017-0624-Z

Zhang, Y., Tian, S., Xiong, J., Zhou, Y., Song, H., and Liu, C. (2018b). JQ-1 Inhibits colon cancer proliferation via suppressing Wnt/ $\beta$-catenin signaling and $\mathrm{miR}$ 21. Chem. Res. Toxicol. 31, 302-307. doi: 10.1021/acs.chemrestox.7b00346

Zhao, L., Duan, Y.-T., Lu, P., Zhang, Z.-J., Zheng, X.-K., Wang, J.-L., et al. (2019). Epigenetic targets and their inhibitors in cancer therapy. Curr. Top. Med. Chem. 18, 2395-2419. doi: 10.2174/1568026619666181224095449

Zhao, L., Ji, G., Le, X., Wang, C., Xu, L., Feng, M., et al. (2017). Long noncoding rna linc00092 acts in cancer-associated fibroblasts to drive glycolysis and progression of ovarian cancer. Cancer Res. 77, 1369-1382. doi: 10.1158/00085472.CAN-16-1615

Zhong, Z., Huang, M., Lv, M., He, Y., Duan, C., Zhang, L., et al. (2017). Circular RNA MYLK as a competing endogenous RNA promotes bladder cancer progression through modulating VEGFA/VEGFR2 signaling pathway. Cancer Lett. 403, 305-317. doi: 10.1016/j.canlet.2017.06.027

Zhong, Z., Lv, M., and Chen, J. (2016). Screening differential circular RNA expression profiles reveals the regulatory role of circTCF25-miR-103a-3p/ miR-107-CDK6 pathway in bladder carcinoma. Sci. Rep. 6, 30919. doi: 10.1038/ srep30919

Zhou, X., Zhang, X., Yang, Y., Li, Z., Du, L., Dong, Z., et al. (2014). Urinary cell-free microRNA-106b as a novel biomarker for detection of bladder cancer. Med. Oncol. 31, 1-7. doi: 10.1007/s12032-014-0197-Z

Zhu, J., Jiang, Z., Gao, F., Hu, X., Zhou, L., Chen, J., et al. (2011). A systematic analysis on DNA methylation and the expression of both mRNA and microRNA in bladder cancer. PloS One 6, e28223. doi: 10.1371/journal. pone.0028223

Zhu, S., Denman, C. J., Cobanoglu, Z. S., Kiany, S., Lau, C. C., Gottschalk, S. M., et al. (2015). The narrow-spectrum HDAC inhibitor entinostat enhances NKG2D expression without NK cell toxicity, leading to enhanced recognition of cancer cells. Pharm. Res. 32, 779-792. doi: 10.1007/s11095-013-1231-0

Zhu, Y., Spitz, M. R., Zhang, H., Grossman, H. B., Frazier, M. L., and Wu, X. (2004). Methyl-CpG-binding domain 2: a protective role in Bladder Carcinoma. Cancer 100, 1853-1858. doi: 10.1002/cncr.20199

Zhuang, J., Lu, Q., Shen, B., Huang, X., Shen, L., Zheng, X., et al. (2015). TGF $\beta 1$ secreted by cancer-associated fibroblasts induces epithelial-mesenchymal transition of bladder cancer cells through IncRNA-ZEB2NAT. Sci. Rep. 5, 11924. doi: 10.1038/srep11924

Ziani, L., Chouaib, S., and Thiery, J. (2018). alteration of the antitumor immune response by cancer-associated fibroblasts. Front. Immunol. 9, 414. doi: 10.3389/ FIMMU.2018.00414

Zong, Y., Huang, J., Sankarasharma, D., Morikawa, T., Fukayama, M., Epstein, J. I., et al. (2012). Stromal epigenetic dysregulation is sufficient to initiate mouse prostate cancer via paracrine Wnt signaling. Proc. Natl. Acad. Sci. 109, E3395E3404. doi: 10.1073/pnas.1217982109

Conflict of Interest: The authors declare that the research was conducted in the absence of any commercial or financial relationships that could be construed as a potential conflict of interest.

Copyright (C) 2019 Martinez, Munera-Maravilla, Bernardini, Rubio, Suarez-Cabrera, Segovia, Lodewijk, Dueñas, Martínez-Fernández and Paramio. This is an openaccess article distributed under the terms of the Creative Commons Attribution License (CC BY). The use, distribution or reproduction in other forums is permitted, provided the original author(s) and the copyright owner(s) are credited and that the original publication in this journal is cited, in accordance with accepted academic practice. No use, distribution or reproduction is permitted which does not comply with these terms. 